${ }_{8 \times 1}^{N K} 8$

P4P63 







- Sonruni J'une chamnante Sovié Jous \& Charme de Miss Jean Hailey Tacyur Chatel Lyon Jeptunhe 1955

CAMILLE PERNON

FABRICANT DE SOIERIES A LYON

$1753-1808$ 

P1. I.

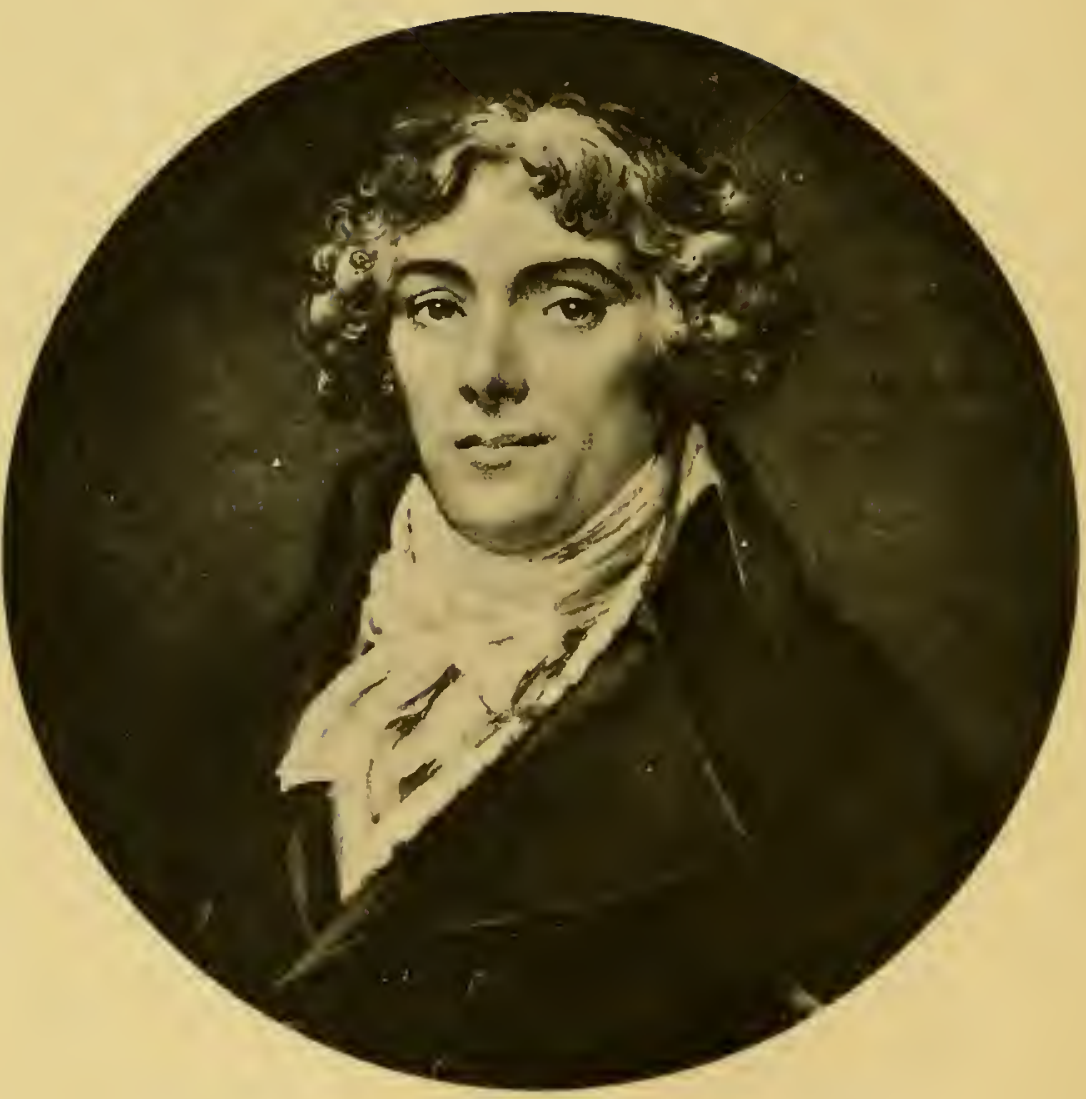

\section{CAMILLE PERNON}

Reproduction d'une miniature du temaps, 
Alexandre POIDEBARD \& Jacques CHATEL

\section{CAmille PERNON}

FABRICANT DE SOIERIES A LYON

SOUS LOUIS XVI ET NAPOLÉON f $^{\mathrm{er}}$

$1753-1808$

OUVRAGE ACCOMFAGNÉ DE TRENTE TLANCHES EN THOTOTYPIE

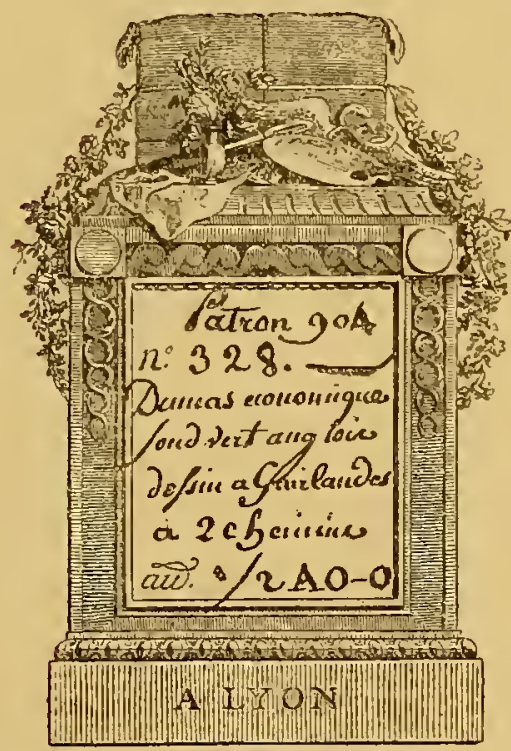

Etiquette des échantillons de la Maison Pernon

LYOD

LIBRAIRIE ANCIENNE DE LOUIS BRUN

13, RUE DU PLAT

1912 


$$
\begin{aligned}
& \text { UKK } \\
& 8898 \\
& \text { P4P63z } \\
& \text { CHM }
\end{aligned}
$$

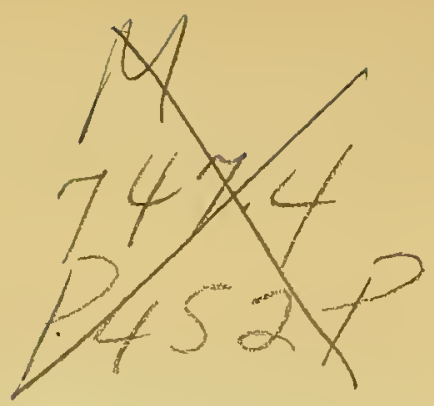

MAR 3 iSE Cooper Union Librarta

$$
\text { GMpt }
$$




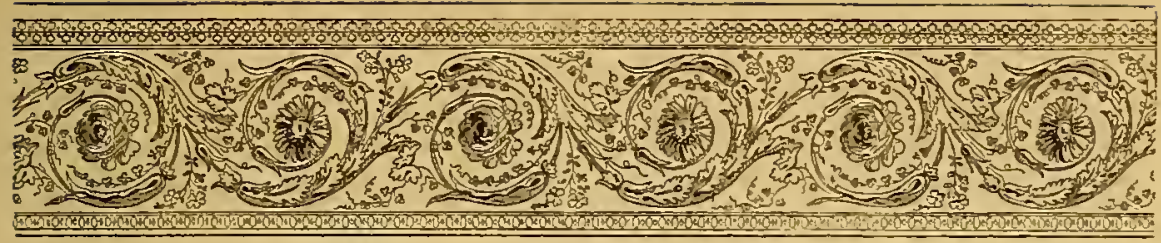

\section{CAMILLE PERNON}

\section{$1753-1808$}

\section{I \\ $S A \quad V I E$}

A u cours de l'hiver 1910-1911, les salles du Musée des Arts A Décoratifs offraient à l'admiration des visiteurs une très belle collection d'étoffes d'ameublement d'un haut intérêt pour l'histoire de la Fabrique Lyonnaise, exposée par les soins de l'Administration du Mobilier National. Ces richesses restées ignorées pendant un siècle dans les magasins du garde-meuble, et conservées, pour la plupart, dans un parfait état de fraîcheur, furent découvertes par M. Dumonthier, administrateur du Mobilier National, qui publia à cette occasion, sous le patronage du Ministère des Beaux-Arts, un ouvrage luxueusement édité par la maison Smidt : Etoffes d'ameublement de l'époque napoléonienne, in $-4^{\circ}$, avec 70 planches, dont 22 en couleur, et une préface de M. Frédéric Masson, de l'Académie Française. 
De patientes recherches dans les archives des Ministères ont permis à l'auteur d'identifier avec certitude ces étoffes, de connaître leur provenance, les dates de commande et de livraison, leur prix, enfin leur destination. Elles provenaient de commandes faites par Napoléon I ${ }^{\text {er }}$ aux fabriques de soieries de Lyon pour la décoration des palais impériaux : les Tuileries, Saint-Cloud, Fontainebleau, Versailles, Trianon, Meudon, Compiègne, la Malmaison. Quelques-unes, commandées sous l'Empire et portant les attributs propres à ce régime, ne furent pas utilisées sous la Restauration et viennent d'être retrouvées, après un siècle d'oubli, non pas à l'état d'échantillons, mais en pièces et intactes, telles qu'elles sont sorties de chez le fabricant.

Parmi les noms des fabricants lyonnais inserits au catalogue de cette exposition, il en est un qui revient plus souvent que les autres, celui de Camille Pernon ${ }^{1}$, mort en 1808, continuateur d'une maison fondée vers $1680^{2}$ et qui n'a pas cessé, sous les successeurs : MM. Grand frères, puis Paul Grand, aujourd'hui Tassinari et Chatel, d'être ce qu'il l'avait faite, la fabrique de soieries d'où sont sortis, pendant un siècle, les plus merveilleux produits de la grande industrie lyonnaise.

A plus d'un titre, Camille Pernon mérite que son nom soit rappelé; et, si l'hommage que nous rendons aujourd'hui à sa mémoire est tardif, la faute en est à ses contemporains qui, lui vivant, le comblèrent d'honneurs et de dignités, mais, après sa mort, ont négligé de conserver dans une biographie digne de lui le souvenir de ses services publics et de sa haute valeur professionnelle.

1 Le brevet de « maitrise de fabricant d'étoffes d'or, d'argent et soye 》 accordé à Camille Pernon est daté du 11 novembre 1779 . I1 est probable que cette date est celle de son association avec son père ou de sa succession à ce dernier comme chef de la maison. Camille avait vingt-six ans.

2 Lettre autographe de Camille Pernon adressée le Il août 1789 à l'Intendant du Trésor royal Dufrêne. 


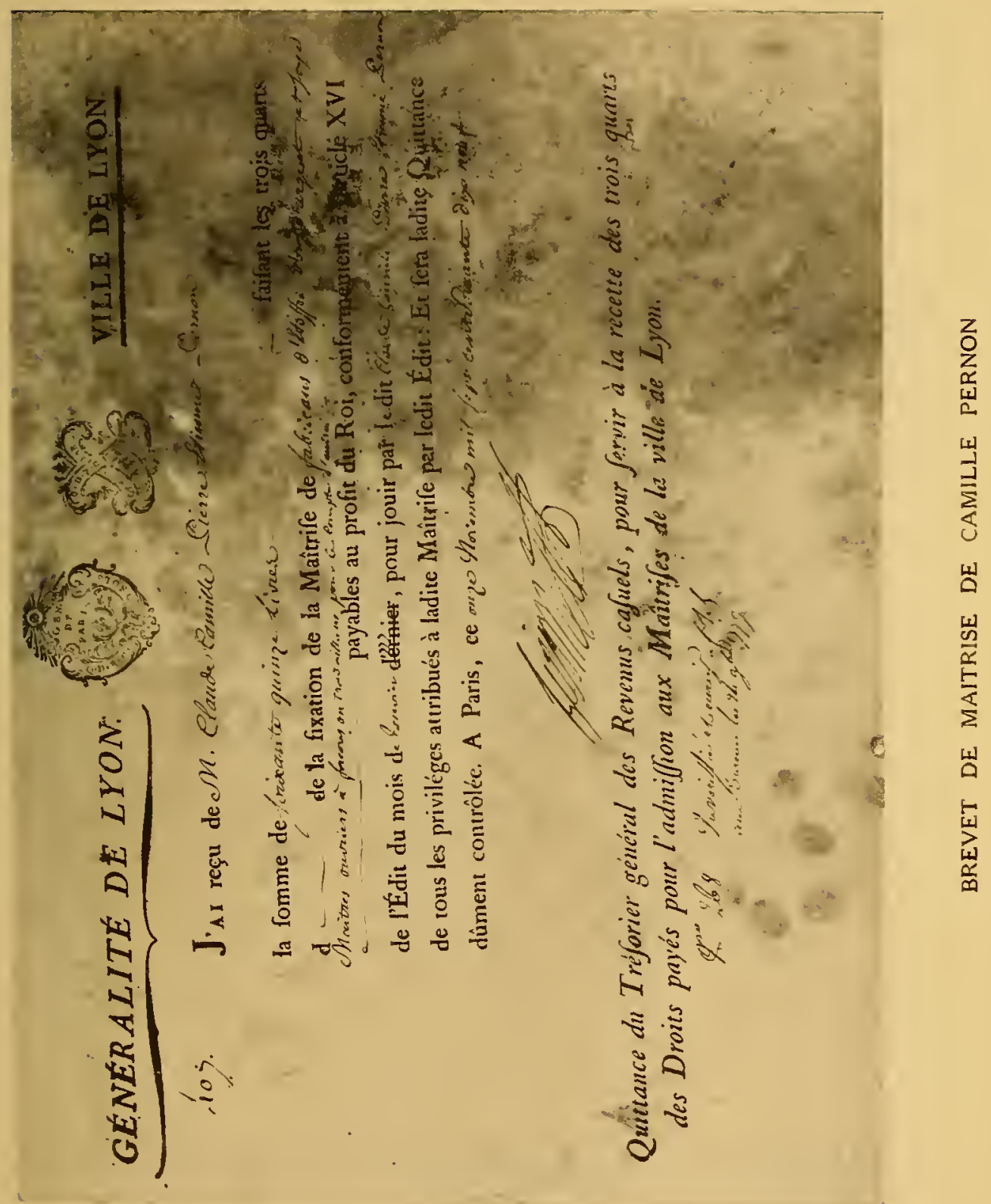



Claude-Camille-Pierre-Etienne Pernon, écuyer, né à Lyon, dans une maison du quai de Retz, le 3 novembre 1753 , mort dans sa propriété de Sainte-Foy-lès-Lyon, le 24 octobre 1808 , est noté, dans le livre d'Henri de Jouvencel, comme comparant à l'Assemblée de la noblesse de la sénéchaussée de Lyon en 1789 . Son grandpère, Claude Pernon, fut recteur de la Charité en 1735 et acquit, le 14 janvier 1740 , au prix de 29.000 livres, une charge de conseiller secrétaire du roi près la Cour des Monnaies de Lyon. Son père, Etienne Pernon, auquel il succéda à la tête de la fabrique de soieries, fut syndic de la Confrérie des Pénitents de la Miséricorde, établie à Lyon, en 1636 , pour aider les prisonniers pour dettes à se libérer, accompagner les criminels au supplice, leur donner la sépulture, secourir leur famille. L'oncle paternel de Camille Pernon, Jacques-Etienne de Pernon, écuyer, capitaine au régiment de Saint-Simon-Cavalerie, major, puis lieutenant-colonel au régiment de Roi-Cavalerie, chevalier de Saint-Louis, marié en 1753 à Benoîte de Nervo, mort à Lyon en 1792, après avoir institué, par testament fait à Paris le $1^{\text {er }}$ avril 1786 , son neveu, Camille Pernon, pour son légataire universel, comparaît, lui aussi, à l'Assemblée de la noblesse en $1789^{1}$. Un autre oncle de Camille Pernon, Louis de Pernon, trésorier général des troupes de la maison du Roi et de l'extraordinaire des Guerres, fut nommé par le Consulat le 13 mars 1751 , sur la désignation du contrôleur général des finances, député du commerce de Lyon en résidence à Paris. Le roi Louis XVI, ayant désiré qu'en suite du décès de son prédécesseur le deuil fût de huit mois, sur les représentations des députés du commerce et surtout du sieur Pernon, député de la ville de Lyon, à laquelle cette prolongation faisait le plus de tort, le roi décida que le deuil ne serait que de sept mois et finirait le 15 dé-

1 Testament de Jacques de Pernon. Archives Chatel. 
cembre 1774 , et cela afin de ne pas faire perdre au commerce le bénéfice de la saison d'hiver ${ }^{1}$.

L'Armorial du Lyonnais de Steyert donne comme armes des Pernon, un blason qui se voit sur l'imposte en fer d'une maison, rue Tramassac, 34: d'azur à une ancre d'argent au chef cousu de gueules chargé d'un soleil d'or. - Jacques de Pernon, colonel dans l'armée royale, chevalier de Saint-Louis, portait : d'argent au phénix..., sur son bûcher de gueules, au chef d'azur, chargé de deux colombes affrontées d'argent ${ }^{2}$.

Les courtes notices, consacrées à Camille Pernon par les auteurs de biographies lyonnaises, disent qu'il fut le chef d'une importante fabrique d'étoffes pour meubles et brocarts; qu'après la Révolution il eut un rôle important comme restaurateur des manufactures de soieries; qu'il voyagea à l'étranger, notamment en Russie et en Espagne, pour propager la vente de leurs produits; qu'il fut membre du Tribunat, de l'Académie de Lyon, de la Société d'Agriculture, du Bureau Consultatif du Commerce, de la Société des Amis du Commerce et des Arts, administrateur des Hospices, conseiller général du Rhône, adjoint au maire de Lyon, chevalier de la Légion d'honneur ${ }^{3}$ (il n'y avait que dix-sept légionnaires dans le département du Rhône); que ses mérites lui valurent l'estime de plusieurs souverains: de l'impératrice Catherine 11 , des rois d'Espagne Charles IIl et Charles IV, de l'empereur Napoléon $1^{\mathrm{er}}$.

Des trois portraits que nous connaissons de Camille Pernon, l'un d'eux, publié longtemps après sa mort, ne nous donne qu'une idée lointaine de sa réelle physionomie. C'est une lithographie imprimée en $1848^{4}$ pour illustrer une série de notables lyonnais.

1 Mémoires secrets, t. XXV11, p. 236. Péricaud, Tablettes chronologiques, 17 mars 1774 .

2 William Poidebard, Notes béraldiques et généalogiques coneernant les pays de Lyonnais, Forez et Beaujolais.

3 Almaracb bist. de la ville de Lyon pour 1806.

4 Lithographie de Naegelin, d'après un dessin de G. Reynaud, publiée par Perenon, auteur d'ouvrages lyonnais. 
PI. III.

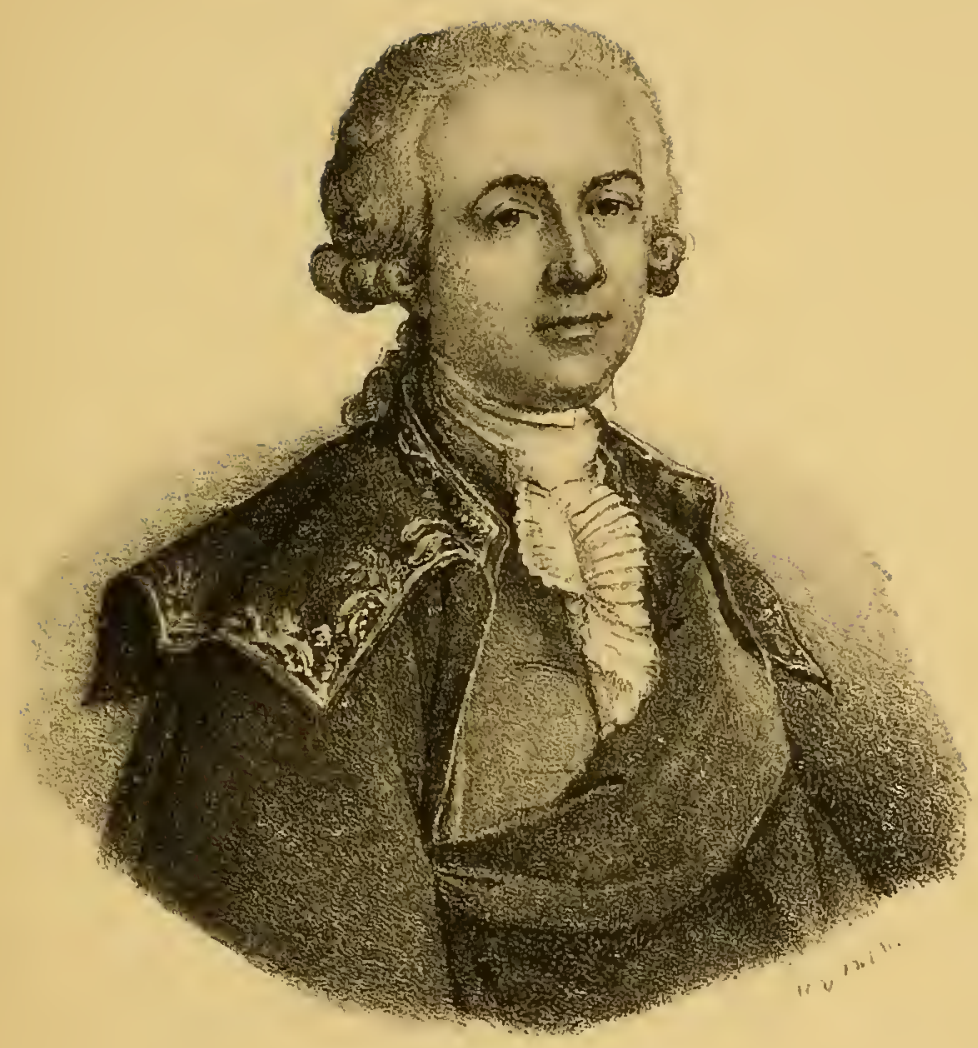

\section{CAMILLE PERNON}

D'aprés un dessin de G. Reynaud, lithograpbié par Naegelin et publié par Perenon en 1848. Ce dessin aurait èté fait d'après un médaillon du temps de Pernon resté inconnu. 

P1. IV.

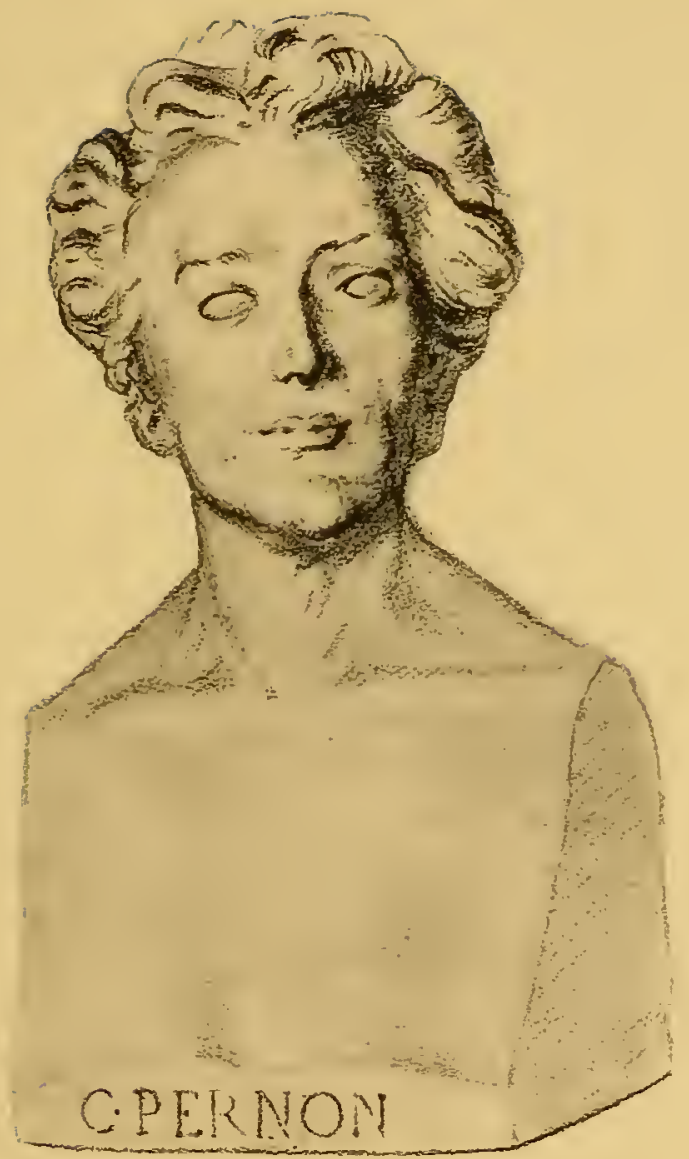

\section{CAMILLE PERNON}

Sculpture de Legendre-Hèral, Galerie des Lyonnais cèlèbres, au Palais des Beaux-Arts. Dessin de J. Cbalel 

Il y est représenté vêtu du costume officiel de tribun et coiffé de la perruque poudrée. Peut-être cette médiocre image reproduit-elle une peinture ancienne restée inconnue, mais c'est une œuvre de vulgarisation sans caractère artistique. Les deux autres sont plus intéressants: l'un est le buste que Legendre-Héral sculpta pour la galerie des Lyonnais dignes de mémoire, au Musée du Palais des Arts; l'autre est une miniature signée Dubois, appartenant encore à d'anciens amis de la famille Pernon. Le buste est un morceau de sculpture honorable, sans grand caractère. On y retrouve à peu près la même forme de visage que dans la miniature, le même arc des sourcils, le même nez régulier, le même pli de la bouche au demi-sourire un peu amer, les mêmes cheveux abondants, le même port de tête un peu hautain. Mais, dans le buste, les yeux, sculptés sans détails, à la manière antique, enlèvent à cette face humaine toute l'exprèssion qu'on retrouve si vivante dans la miniature. Tout en faisant la part de ce qu'une peinture de ce genre et de cette dimension a d'un peu précieux, celle-ci n'a pu amoindrir l'énergie de ce menton si caractéristique surmontant la haute cravate à la mode du Directoire et de l'Empire. Les yeux perçants et fins mêlent à cette énergie beaucoup de douceur et de bonté. La bouche, d'un dessin très pur, esquisse le demi-sourire habituel à tous ceux qui avaient connu la «douceur de vivre » du siècle précédent; mass une ombre de mélancolie voile ce sourire que n'a cependant pas réussi à effacer la tourmente révolutionnaire. Les cheveux, dans un désordre hâtif et voulu, gardent encore la trace des boucles régulières de la coiffure à marteau. La pose elle-même est d'une aimable aisance, et ce très bon petit portrait nous donne une charmante idée de l'allure supérieure et de la distinction élégante de ce commerçant gentilhomme.

On lit dans certaines notices publiées longtemps après sa mort, notamment dans la légende qui accompagne le portrait de 1848 , 
qu'avant d'être fabricant de soieries, Camille Pernon aurait servi dans l'armée royale et qu'il fut chevalier de Saint-Louis. Mais il n'est rien dit de cela dans l'éloge de Pernon écrit au lendemain de sa mort par un contemporain, son ami, mieux renseigné que ses biographes qui ne l'ont pas connu et lui ont sans doute attribué, par confusion, des services militaires et une dignité ayant appartenu à son oncle paternel Jacques-Simon de Pernon, colonel de cavalerie, chevalier de Saint-Louis. Du reste, s'il y a dans la vie de Camille Pernon beaucoup de choses à louer, ce ne sont pas ses services militaires. Lorsque les Lyonnais se soulevèrent contre la Convention en 1793, Camille Pernon, âgé de trente-neuf ans, paraît avoir été du nombre des prudents qui ne s'enrôlèrent pas dans l'armée de Précy. On perd alors sa trace et on le retrouve deux ans après, en 1795, à Gênes, occupé à fonder un établisse ment de commerce '.

C'est également à tort qu'on a attribué à Camille Pernon les fonctions d'administrateur général des Loteries de France qui ont appartenu à son cousin, Louis-Aimon Pernon; la charge de conseiller secrétaire du Roi près la Cour des Monnaies qui a appartenu à son grand-père, Claude Pernon; les fonctions d'échevin, qui n'ont été remplies ni par lui ni par aucun autre membre de sa famille.

La vie commerciale de Camille Pernon se divise en deux périodes, séparées par les événements de la Révolution. Dans la première, ses relations avec l'étranger furent étendues. Il reçut de belles commandes de l'Impératrice de Russie, Catherine II. En Espagne, l'Escurial et d'autres palais royaux ont conservé de riches tentures dont il les décora. Sous le Consulat et l'Empire, il profita de l'essor donné par Napoléon au relèvement de l'industrie; et ce qui reste en France de palais nationaux possède encore de belles étoffes d'ameublement sorties de ses ateliers.

1 Lettre de Grognard du 10 avril 1795. 
PI. V.

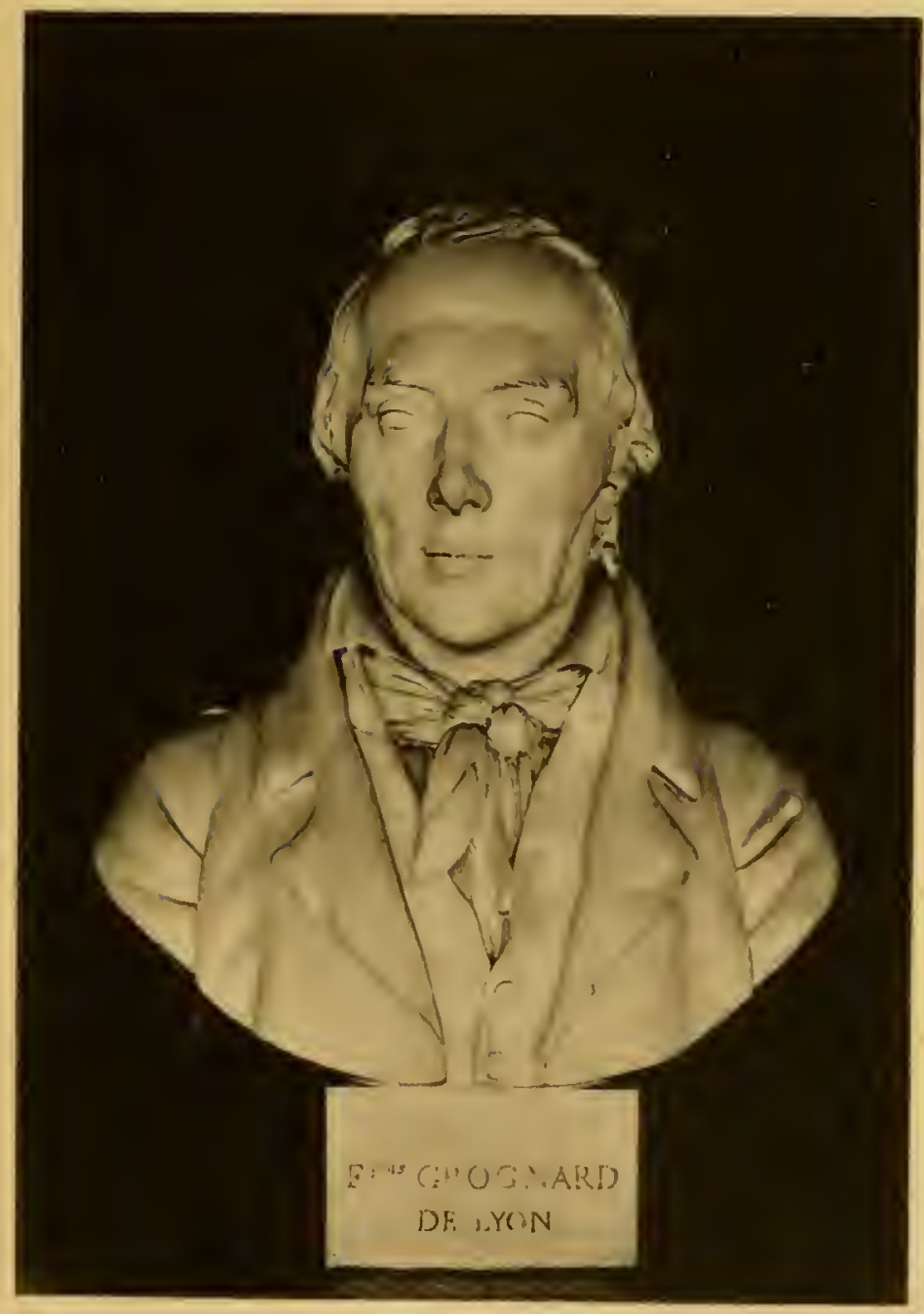

\section{F. GROGNARD}

Sculpture de Legendre-Héral, Galerie des Lyonnais cèlćbres, au Palais des Beaux-Arts. 
4

$-$ 
En 1784 , les affaires de la maison Camille Pernon et $C^{\mathrm{ie}}$, fournisseur du mobilier de la Couronne de France et de plusieurs Cours étrangères, étaient en pleine prospérité. Pourtant, Pernon ne s'enrichit jamais. Ses bénéfices commerciaux furent plus ou moins absorbés par les affaires. Ayant eu besoin de capitaux, il signa, le $\mathrm{I}^{\mathrm{er}}$ janvier 1785 , avec son cousin Louis-Aimon Pernon, administrateur de la Loterie Royale de France, résidant à Paris, un acte de Société en commandite, pour six années, sous la même raison sociale, Camille Pernon et $\mathrm{C}^{\mathrm{ie}}$, au capital de 100.000 livres, dont chacun des associés apportait la moitié, Camille, comme gérant, ayant seul la signature sociale, avec un compte de levée de 7.500 livres et trois cinquièmes des bénéfices, son cousin, comme commanditaire, avec 2.500 livres de levée annuelle et deux cinquièmes des bénéfices.

Détail intéressant : les deux associés convenaient, par une clause de l'acte de Société, de donner aux pauvres, chaque année, une somme de 150 livres pour attirer les bénédictions du ciel sur leur commerce.

Un autre article du contrat prévoyait le cas où Camille Pernon croirait utile de donner un intérêt au sieur Salomon Palû, alors à Saint-Pétersbourg, où il continuait à entretenir les bonnes relations que son patron y avait créées.

Le $1^{\mathrm{er}}$ avril de la même année 1785 , la maison Camille Pernon et $C^{i e}$ prenait comme associé en participation, pour trois années, Jean-Elzéar Peyron, successeur de la maison de commissions de la Sône et $\mathrm{C}^{\mathrm{ie}}$, gendre du chef de cette maison, avec une levée de 1.500 livres et 11 quart des bénéfices sur les affaires amenées par lui.

Jean-Elzéar Peyron fut, dans la suite, chevalier de la Légion d'honneur, juge au Tribunal de commerce de Lyon en 1813 et 1814 , président de ce Tribunal en 1818 et 1819 .

Le $1^{\text {er }}$ février 1787 , MM. Camille Pernon et $C^{\text {ie }}$ s'associaient 
définitivement en nom, pour quatre années, Jean-Elzéar Peyron, dont ils avaient apprécié l'intelligence et les services, sous la raison sociale Camille Pernon, Peyron et $C^{\text {ie }}$. Le nouvel associé faisait un apport de 20.000 livres. Sa levée annuelle était de 4.000 livres et sa part dans les bénéfices de 3 sols pour 20 , nous dirions aujourd'hui 15 pour 100.

Ces trois contrats, retrouvés récemment par le plus grand des hasards, jettent un jour intéressant sur la marche des affaires de Pernon au xvill ${ }^{\mathrm{e}}$ siècle. Ceux qu'il dut signer avec son père, avec François Grognard, le traité passé par ses héritiers avec les frères Grand, ses successeurs, malheureusement ne sont pas parvenus jusqu'à nous. Mais le peu que nous révèlent ces vieux scriptes confirme l'impression que donne, dans son ensemble, l'existence laborieuse de Pernon. Ses affaires si intéressantes par leur côté artistique, et prospères en apparence, ne lui ont pas donné la fortune. Les bénéfices qu'il réalisa durent être absorbés par son zèle à faire prévaloir la supériorité de la grande industrie lyonnaise. A côté de sa brillante vie publique, sa vie privée fut sacrifiée à sa famille. Il ne laissa, en mourant, à ses sœurs, ses héritières, qu'une fortune modeste.

Il existe à la Bibliothèque de la Ville de Lyon, un dossier de soixante-quinze lettres autographes écrites, du 14 juillet ${ }_{1} 787$ au 16 mars 1793 , à Camille Pernon, Peyron et $\mathrm{C}^{\text {ic }}$ par François Grognard, leur associé, voyageant en Espagne, toutes relatives aux affaires de commerce.

Camille Pernon, Peyron et $\mathrm{C}^{\text {ia }}$ et Grognard avaient fait, entre eux, une Société en participation pour la vente en Espagne des riches étoffes pour ameublement et vêtements d'hommes et de femmes. François Grognard, né à Lyon en I 748, mort à Fontenaysous-Bois le 5 novembre 1823 , fut, lui aussi, un Lyonnais digne de mémoire. Professeur à l'École municipale de dessin en 1818 , il légua à la Ville de Lyon une rente annuelle de 4.500 francs, pour 
pourvoir à l'éducation de l'enfant d'un négociant peu fortuné, pour des prix en faveur des élèves de l'École de dessin, et pour un prix à décerner à l'artiste, peintre ou sculpteur, auteur d'un buste ou portrait d'un Lyonnais célèbre ${ }^{1}$. Parmi les élèves de l'École des Beaux-Arts, lauréats du prix Grognard, en 1826 , on remarque Comte-Calixe, Lacuria, Flachéron, Bonirote. Une des premières œuvres récompensées sur les fonds du legs Grognard fut le buste en marbre du fondateur lui-même, exécuté par Legendre-Héral en 1825 , conservé au Musée du palais des Arts. Les dernières acquisitions de la Ville, payées sur les arrérages de la même fondation, sont le buste de Philippe de Lasalle, né à Seyssel, le 23 septembre I 723, mort à Lyon le 24 février 1804 , qui fut à la fois dessinateur, peintre, mécanicien, contemporain de Pernon, son collaborateur dans beaucoup de ses œuvres; le buste de Laurent Mourguet, le créateur du Guignol lyonnais; le buste de Louis Guy. Chaque année, une somme de 2.700 francs, produit des revenus de la fondation Grognard, est consacrée à l'exécution du buste d'un Lyonnais célèbre que désigne la Municipalité.

La clientèle visitée à Madrid par Grognard, pour le placement des étoffes sorties des ateliers de Pernon, n'était pas une clientèle quelconque. Si on parcourt la correspondance commerciale échangée de 1787 à 1793 entre les associés, on voit qu'elle se composait exclusivement du roi, de la reine, des infants et infantes, des grands personnages de la Cour, des ambassadeurs étrangers près la Cour d'Espagne. Voici de courts extraits de cette correspondance où l'on trouve quelques traits de mœurs intéressants.

Le 3 septembre 1787 , Grognard écrit à Pernon : « J'ai obtenu la fourniture des habits du roi. Les rubans pour ceinture que désire la princesse sont de chez M. Riboud, ami de M. Bouvard. Les

1 Arch. du Rhòne, t. 111 et XIII. 
rayés gaufrés de chez $M$. Chanal, rue Pizay. "Ces noms, trouvés dans une correspondance vieille de cent vingt ans, nous sont familiers, comme s'il n'y avait rien de changé dans le quartier des Terreaux. «Ci-joint une petite commission pour $\mathrm{M}^{\mathrm{me}}$ la Duchesse de la Vauguyon et pour $M^{\text {lle }}$ sa Fille. » La Duchesse de la Vauguyon était la femme de l'ambassadeur du roi de France. « M. le Duc m'a promis la fourniture de sa maison. M. le Prince m'a donné l'ordre de me rendre à l'Escurial, lorsque la Cour y sera, pour déterminer les aunages des étoffes qu'il a choisies. Je vous expédie les patrons des habits du roi, de $M$. de Valdecarsane et de M. Parisien. " Le nom de M. Parisien, qui n'est peut-être qu'un surnom, revient souvent dans la correspondance. C'était celui du valet de chambre, chef de la garde-robe de Sa Majesté. Les fournitures destinées au roi étaient facturées sous le nom de cet intermédiaire qui, en donnant la commande d'un habit de velours brodé de 420 livres, recommandait de tirer sur lui pour le montant des commissions et de ne jamais indiquer sur les lettres de change que c'est pour le compte du roi, parce que Sa Majesté ne veut pas que l'on sache qu'il fait venir ses fournitures de France, par égard pour les marchands de Madrid, fournisseurs habituels de la Cour.

«Voici, écrit Grognard quelques jours après, des commissions pour la garde-robe de Sa Majesté Catholique. Les prix des six habits sont fixés à 50 pour 100 de bénéfice. Si je peux augmenter le prix des plus riches, je le ferai. On doit me présenter à Leurs Altesses les Infantes. "La même lettre contient la commande d'un habit brodé en pierre opale du prix de 840 livres et d'un autre habit brodé en soie du prix de 500 livres pour le marquis de Valdecarsane.

Dans une lettre du 5 octobre 1787 , il est question de deux gilets excentriques dont Grognard avait passé la commande pour le prince des Asturies. Pernon, en refusant la commission, avait 
reproché ì son associé de la lui avoir transmise. Mais celui-ci, en bon négociant, insiste. Il ne croit pas que le prince les porte jamais. Mais « il suffit, dit-il, que cela l'amuse un instant. Plus ils seront ridicules, plus ils lui plairont.»

Les deux associés n'étaient pas toujours d'accord. Grognard se plaint souvent, parfois en termes très vifs, de ce que la fabrique n'exécute pas les ordres tels qu'il les transmet, ou apporte de longs retards à les exécuter et à faire les expéditions; les employés chargés de la correspondance, peu au courant des qualifications des personnages de la Cour, confondent les titres et les qualités et prennent les uns pour les autres. Il transmet, à ce sujet, les plaintes de sa royale clientèle. Nous n'avons pas les lettres de Pernon; mais il est probable qu'il n'avait pas tous les torts. Les rapports des deux associés se terminèrent par un procès, et il résulte d'une lettre de Grognard du 22 prairial an IIl, qu'après une demande en règlement de $33.52 \mathrm{I} 1.73 \mathrm{~s}$. adressée à Pernon, il consentit à transiger pour $3.1771 .19 \mathrm{~s}$.

Grognard écrivait en octobre $1787:$ : Il est essentiel que les étoffes du roi soient souples et n'accrochent pas. M. le Marquis de Valdecarsane m'a répété nombre de fois que, si vous avez le bonheur de bien contenter le roi, vous pouvez compter sur la suite des commissions de la garde-robe. Quant aux échantillons de robes pour la princesse et pour les infantes, il ne faut pas s'écarter du goût de Paris pour les nuances et le genre des broderies; on doit même observer qu'il faut plutôt de la légèreté et de la fraîcheur dans les dessins que des sujets massifs et compliqués. N'oubliez pas les échantillons brodés en camaïeu bleu, c'est la couleur favorite de la princesse. Pour l'infante Gabriel, elle aime beaucoup les broderies sur gaze, linon et généralement sur les étoffes légères, parce que, étant très puissante, elles la grossissent beaucoup moins."

Du I $^{\text {er }}$ novembre 1787 : « J'ai été présenté à Son Altesse Sérénis- 
sime l'infant don Gabriel qui m'a commis deux habits brodés en soie sur gros de Naples et un habit de gala brodé en opale sur fond or. L'infante, son épouse, m'a commis une robe à bordure en rose, sur votre échantillon riche brodé sur gros de Naples blanc. Vous achèterez une blonde à Paris conforme à la richesse de la robe. Informez-vous bien de tout ce qu'il y a de nouveau à Paris, tant pour les hommes que pour les femmes. Faites-en venir une petite note que je montrerai à la princesse et à l'infante. Je vais tourner mes batteries du côté de la tapisserie du roi et du côté des grands seigneurs."

Suivent des commandes pour l'ambassadeur de Portugal, qui ne porte jamais un habit deux ans de suite et ne veut y mettre que 12 à 1.300 réaux; pour l'ambassadeur de Venise; pour les infants don Gabriel et don Fernando ; pour le grand-duc de Russie, qui demande des délais pour se libérer, sa cassette étant épuisée par les nombreuses pensions qu'il doit payer.

Le 27 octobre 1788, Grognard annonce à Pernon de riches commissions pour lesquelles il attend d'être fixé sur des paiements à époque fixe, " parce que, dit-il, avec les grands d'Espagne, il faut bien faire son compte $»$.

Quelques clients sont de meilleur crédit. En ${ }_{17} 788$, le comte de Miranda paie une traite de 46.487 livres; le duc de Berwick acquitte une facture de 80.000 livres. A l'occasion d'un double mariage entre les enfants de la duchesse de Lira et ceux du duc de Kiffar, Pernon est payé d'une fourniture de broderie d'une valeur de 60.000 livres.

Les brillantes affaires des deux associés en Espagne sont subitement arrêtées, en décembre 1788 , par des deuils princiers : ce fut d'abord la mort, suite de couches, de l'infante de Portugal, puis la mort du roi d'Espagne, Charles III, qui régnait depuis 1759 .

Pernon reçoit l'ordre de suspendre tous les envois.

Le fils et successeur du feu roi, Charles IV, qui fut détrôné par 
Napoléon en 1808, était amateur, comme son père, de belles étoffes et de riches habits. Le 22 décembre 1788, Grognard écrit: « J'ai été présenté ce matin en cérémonie au roi et à la reine et j'ai eu l'honneur de leur baiser la main, de sorte que me voilà introduit à la nouvelle Cour, sans avoir besoin de protection. J'ai fait à Leurs Majestés mes offres de service et je leur ai demandé la continuation de leurs bontés et de leurs ordres. Elles me les ont accordés. Par le prochain courrier, je vous ferai passer une commission."

Un an après, le 9 novembre 1789 , l'associé de Pernon lui fait savoir que le roi est parfaitement content de la tapisserie brodée dont l'exécution, de l'avis de la reine, passe l'idée qu'elle s'en était formée; qu'on en a reçu les compliments les plus flatteurs. Le roi s'intéresse à ce point aux fournitures de la maison Pernon, qu' « il supporte impatiemment le moindre retard dans la réception des caisses qui les contiennent, et, quand elles arrivent, il ne laisse à personne le soin de les ouvrir ».

Jusqu'en 1793, les affaires de Pernon en Espagne ne cessent pas de prospérer. Mais, à cette date, les Français à l'étranger sont traités en ennemis et expulsés. Le 2 juillet, Grognard écrit de Bayonne : "J'arrive de Madrid, chassé tout comme un autre. J'ai sauvé tous mes effets et mes papiers. J'ai fait 7 lieues à pied pour gagner la frontière. »

Lorsque cette lettre parvint à son adresse, les Lyonnais étaient en révolte contre la Convention. Leur ville allait traverser la plus terrible crise de son histoire, qui devait l'inonder de sang, détruire ses monuments, ruiner ses manufactures.

Dans la nuit du 28 au 29 septembre 1793 , la trahison d'un caporal, dont le nom est resté tristement célèbre, chef du poste avancé de la redoute de Sainte-Foy, livra aux assiégeants le mot de passe qui était, ce soir-là : Ronde Lyonnaise. Une colonne ennemie s'empara, par surprise, de la redoute et du village. On 
lit dans les Mémoires de Guillon de Montléon ${ }^{4}$ que, dans la journée qui suivit, les représentants du peuple en mission près de l'armée du siège, Châteauneuf-Randon et Maignet, établirent leur quartier général à Sainte-Foy dans la maison de plaisance d'un honorable négociant lyonnais, M. Pernon, « dont le fils, ajoute l'auteur des Mémoires, combattait parmi les défenseurs de la ville ». Il s'agit bien de Camille Pernon, propriétaire à Sainte-Foy d'une habitation d'été dont il avait acquis l'usufruit en 1792. Mais on ne lui connaît pas de fils, et il reste douteux qu'un membre de sa famille ait combattu dans l'armée lyonnaise.

Quant à Camille Pernon, il avait probablement quitté Lyon, où on ne le retrouve plus au cours des événements dont la cité fut le théâtre. On lit dans la Biographie des Lyonnais dignes de mémoire, de Dériard, que «ses bienfaits le sauvèrent de la Terreur de 1793 ». S'il n'avait eu que cette sauvegarde, elle ne l'aurait peut-être pas préservé du sort qui fut celui de tant de négociants lyonnais après le siège. Le 10 avril 1795, son ancien associé écrit au banquier Rigal, à Madrid, que "Camille Pernon est à Gênes, où il se propose de fonder un établissement ». Il avait donc émigré, et il faut convenir que c'était le plus sûr moyen pour lui de se sauver de la Terreur, à laquelle le signalaient sa naissance, sa qualité de grand négociant fournisseur habituel d'une clientèle princière.

Le père de Camille, Etienne Pernon, ancien chef de la fabrique de soieries, âgé de soixante-quatorze ans, faillit être moins heureux. Resté à Lyon après le siège, il fut arrêté. Delandine rapporte ainsi le fait dans le Tableau des prisons de Lyon. Amené à l'Hôtel de Ville, dans le salon de la Chambre de commerce transformé en prison, il fit à ses compagnons de captivité ce récit de son arrestation : «Au Chemin-Neuf est une fontaine dont l'eau est limpide et bonne. Vieux, harassé d'une marche pénible, je me

1 Guillon de Montléon, Mémoires pour servir à l'bistoire de Lyon, t. II, p. 147. 
suis approché pour en boire dans le creux de ma main. Une femme m'apporte un verre en me disant: Dieu vous conserve, Monsieur Pernon. Par le même chemin, descendait alors un des juges. A mon nom, il s'arrêta, et, me mettant la main au collet, il s'écria : C'est donc toi qui es Pernon, toi qui, avant la Révolution, conduisais dans tes ateliers les princes et les grands qui passaient dans cette ville. Scélérat, tu paieras leur curiosité. Joseph Il, l'archiduc Ferdinand, le comte du Nord, le prince Henri de Prusse ne peuvent te sauver par leur protection. Je serai ton juge... Alors cet homme, furieux, m'a trainé au corps de garde, dont les soldats ensuite m'ont conduit ici... " Est-ce à Etienne Pernon que se rapporte ce que Dériard dit de Camille? Le père avait commencé l'œuvre commerciale continuée par le fils. Il avait propagé à l'étranger la réputation des manufactures lyonnaises. Quel qu'en ait été le motif, Etienne Pernon fut acquitté, le 20 mars 1794, par la Commission révolutionnaire qui siégea dans la salle du Consulat à l'Hôtel de Ville, du 4 décembre 1793 au I 3 avril 1794, présidée par Pierre-Marie Parrein, et prononça, en ces quatre mois, 1.684 condamnations capitales.

Camille Pernon avait donc la vie sauve, mais il était ruiné par la Révolution. Dès le mois d'août 1789 , créancier pour de grosses sommes du mobilier de la Couronne, il avait beaucoup de difficulté à se faire payer par le Trésor Royal. On sait dans quels embarras financiers se débattaient déjà les ministres du malheureux Louis XVI. La lettre autographe de C. Pernon, écrite à ce sujet à M. Dufrène, intendant du Trésor Royal, et conservée à la Bibliothèque de la Ville, mérite d'être citée en entier. Elle est datée de "Paris, le 11 aoust 1789 ".

Voici la lettre :

« Monsieur,

« Je suis chargé par notre maison de Lyon d'avoir l'honneur de 
" solliciter avec instance le payement de ce qui nous est dû par « le garde-meuble de la Courone (sic); M. Thierri ${ }^{1}$, ordon« nateur de ce département, vous a mandé avec quel désintéres« sement nous avions traité avec lui ; il a dû vous dire encore, «Monsieur, qu'il y a longtemps que l'objet qui nous est dû, « devrait être acquitté ; mais, dans un moment où tout Français « s'efforce d'être patriote, nous ne parlerons pas des sacrifices que « nous faisons; nous réclamons un payement qui nous devient « indispensable, pour acquitter des engagements sacrés que nous « avons pris vis-à-vis de M. Jaume, banquier : depuis six mois il « a bien voulu renouveler nos traites, mais pressé par les cir« constances il nous a déclaré qu'il voulait ou des espèces ou des « valeurs; vous devez sentir, Monsieur, combien cette significa« tion est impérative pour nous, et combien il serait cruel qu'une «maison qui, depuis plus d'un siècle, enrichit avec honneur les « manufactures de la ville de Lyon par son industrie et ses efforts, « vint à succomber, et pour avoir traité encore avec le roy comme « avec un particulier qu'on veut obliger. Nous serions même « encore assez bons citoyens pour temporiser, si les avances que « nous sommes obligés de faire pour les commissions d'Espagne « ne nous enlevoient heureusement cette possibilité ; je dis, heu« reusement, Monsieur, puisque sans cette ressource, les ouvriers « les plus précieux s'expatrieraient par le manque d'occupation. « Nous ne craignons pas, Monsieur, de prononcer qu'il n'y a « point de demande qui mérite plus de considération que la nôtre, « et c'est dans cette intime confiance que nous attendons avec " impatience que vous nous délivriés de la terrible anxiété où « nous sommes; notre reconnaissance égalera, Monsieur, le ser« vice que vous nous rendrés.

I Thierry de Ville-d'Avray. 
« J'ai l'honneur d'être avec un respectueux attachement, Mon« sieur, votre très humble et très obéissant serviteur.

« Pernon de la Rue Royale, « pour la maison Clle PERnoN de Lyon ».

Une brève annotation de l'intendant du Trésor, fait connaitre la réponse à la requête si juste de Pernon: «Je ne le peux dans ce moment-ci. J'ai écrit en conséquence à M. Pernon. »

Rentré à Lyon en 1795 , Pernon se remit au travail et, dès cette époque, seul et sans associé connu. Cette seconde période de sa vie fut marquée par le succès croissant de ses affaires, les hautes distinctions dues à ses mérites, et des services qui lui ont valu, de la part de ses contemporains, le titre de restaurateur de l'industrie lyonnaise.

Le Bulletin de Lyon, du i 8 ventôse an XI, publication périodique, rendant compte de l'exposition des produits de l'industrie française de l'an X, mentionne que Camille Pernon, fabricant à Lyon, ayant un dépôt à Paris, rue de Cléry, $n^{\circ} 98$, a exposé des étoffes de la plus grande magnificence et dignes de la haute réputation de la ville de Lyon; que le jury lui a décerné une médaille d'or, et qu'il fut du nombre des convives qui, ayant obtenu une semblable distinction, ont été invités à diner par le Premier Consul.

Napoléon a fait beaucoup pour relever de leurs ruines Lyon et ses manufactures. En 1803 et I804, Camille Pernon reçut pour plus de 700.000 francs de commandes de tentures d'ameublement pour le compte de l'Etat, dont une partie seulement fut utilisée pour la décoration des palais impériaux. Le reste fut mis en réserve dans les magasins du garde-meuble. On en trouve l'inventaire détaillé dans l'ouvrage publié par M. Dumonthier, en 1911: Etoffes d'ameublement de l'époque napoléonienne. Les commandes avaient donc dépassé de beaucoup les besoins, et cela afin de 
fournir du travail à une industrie considérée comme une richesse et une gloire nationales à restaurer.

Napoléon qui se connaissait en hommes avait distingué Pernon et, dès l'époque du Consulat, lui témoigna, en plusieurs occasions, l'estime qu'il avait pour lui et ne fut certainement pas sans influence sur sa nomination au Tribunat. Le Tribunat, assemblée délibérante sous le régime de la Constitution du il frimaire an VIII, partageait le pouvoir de faire les lois avec le Conseil d'Etat et le Corps législatif. Dans le travail de confection des lois, son rôle consistait à émettre un vœu d'adoption ou de rejet, après discussion en assemblée générale, sur les projets de loi préparés par le Conseil d'État. En cas d'adoption, le projet était ensuite porté devant le Corps législatif par des membres du Conseil d'Etat et du Tribunat, délégués à cette fonction par leurs collègues.

Le Tribunat était composé de cent membres désignés par le Sénat et renouvelables par cinquième tous les ans. Pernon ne fut pas compris dans les choix du Sénat lors de la première organisation de ce corps, après le 18 brumaire. Ces choix, sous l'influence de Sieyès, avaient porté presque tous sur d'anciens membres des Assemblées révolutionnaires pour les attacher au nouveau régime. Il régnait, parmi les hommes qui en bénéficiaient, un certain esprit d'opposition à la politique d'apaisement du Premier Consul. Lors de la discussion des premiers titres du projet de Code Civil, le Tribunat ayant, à deux reprises, rejeté les textes qui lui étaient soumis, Bonaparte, irrité de ces échecs, songea à modifier la composition de ce corps. L'article 38 de la Constitution avait décidé que le premier renouvellement partiel du Tribunat aurait lieu en l'an X. Lorsque ce fut le moment d'y procéder, le Sénat, dontles membres en majorité nommés par les Consuls leur étaient dévoués, profita de ce que l'article 38 de la Constitution ne fixait pas le mode de désignation des tribuns à renouveler, s'en réserva le choix et l'exerça de façon à remplacer les opposants les plus 
notables par des hommes sur qui le Premier Consul pouvait compter ${ }^{1}$. C'est ainsi que Camille Pernon fut nommé tribun en 1801 . En cette qualité, il écrivit le 30 ventôse an IX (21 mars 1801), au citoyen Chaptal, Ministre de l'Intérieur, pour défendre énergiquement la Régie de l'Octroy de Lyon, accusée de fraude, et qui, dit-il, « ne croyant avoir que des éloges à mériter, est obligée de se défendre ${ }^{2} »$.

Doué d'un certain talent de parole, il eut plusieurs fois à remplir le rôle d'orateur du Tribunat, devant le Corps législatif, notamment le 26 février 1805 , pour présenter le projet de loi relatif à la reconstruction des façades de la place Bonaparte (ci-devant Bellecour), démolies après le siège par ordre de la Convention, qui avait décrété, pour punir les Lyonnais de leur révolte, la destruction de leur cité.

Cette opération fut subventionnée par 800.000 francs à prélever, dans le délai de dix années, sur le produit des octrois de la ville et une exemption d'impôts pendant quinze ans. L'État cédait à la ville, qui engageait les revenus de l'octroi, l'ancien arsenal situé entre la rue du Plat et la Saône. Le Bulletin de Lyon, du 22 ventôse an XIII, contient le rapport du tribun Pernon au Corps législatif. En voici un extrait: « La perte de la plus grande partie du numéraire en circulation sur la place de Lyon, l'anéantissement de plus d'un tiers de la population, ne permettaient pas à des propriétaires ruinés de trouver des capitaux pour reconstruire leurs immeubles. Heureusement, le commerce anéanti par l'anarchie a retrouvé la protection de lois tutélaires dans cette cité, dont il assura longtemps la prospérité. Avec lui a reparu l'aisance. Une plus grande consommation a augmenté les revenus de la commune et lui permet d'assurer ce double avantage: donner à la place Bellecour, qui porte aujour-

\footnotetext{
1 Histoire des Assemblées politiques en France, par Eugène Pierre, t. I, p. 306.

2 Cabinet Chatel.
} 
d'hui le nom du héros qui gouverne la France, la majesté que lui impose son nouveau titre; et faire disparaitre des ruines que l'œil ne saurait voir sans porter à la pensée d'affreux souvenirs. L'impôt, qui ne doit et ne peut être créé que pour défendre, protéger et secourir tous les membres de la grande famille du peuple français, atteint ici le but que le législateur s'est proposé. L'Empereur, dans l'exécution de ces travaux, voit s'accomplir une partie de son vœu le plus cher, celui de réparer des maux qu'un temps de vertige a semés sur le sol de la patrie.»

Dans une autre circonstance plus mémorable, Camille Pernon fut encore l'orateur du Tribunat devant le Corps législatif pour présenter et défendre un projet de loi, qui n'intéressait d'abord que l'industrie lyonnaise, mais dont le bienfait ne tarda pas à s'étendre à toutes les villes industrielles de France, la loi du 18 mars 1806 , portant établissement d'un Conseil de.prud'bommes à Lyon. A près l'abolition des anciennes Corporations d'Arts et Métiers par la loi du 2 mars 1791, la liberté illimitée de l'industrie ne tarda pas à engendrer de graves abus et le désordre dans les rapports entre fabricants et ouvriers. Une loi de l'an Xl tenta d'y remédier, mais échoua, parce qu'elle confiait à des magistrats étrangers aux travaux des justiciables le soin de régler ces rapports. Les fabricants de soieries et leurs chefs d'ateliers profitèrent du séjour que Napoléon fit à Lyon en 1805 , pour lui exposer leurs griefs et demander la création d'une juridiction semblable à celle qui, sous le régime des anciennes Corporations, composée d'hommes du métier, faisait régner la paix dans le monde du travail. L'Empereur écouta leurs doléances et fit préparer, par le Conseil d'Etat, un projet qui devint la loi du 8 mars 1806 , portant établissement d'un Conseil de prud'hommes à Lyon. L'article 34 donnait au Gouvernement le droit d'en étendre l'application, par un règlement d'administration publique, à toutes les autres villes possédant des manufactures. Un demi-siècle après, quatre-vingts villes avaient leurs Conseils de 
prud'hommes. Aujourd'hui, on compte celles qui n'en ont pas.

Camille Pernon prit une part très active à cette réforme, lorsque, délégué par ses collègues du Tribunat, il prononça à la séance du Corps législatif du 18 mars 1806 le discours dont le texte est rapporté dans le Répertoire de législation de Dalloz, et dont voici le début: «Messieurs, la ville de Lyon, pendant le siècle qui vient de s'écouler, renferma dans son sein une population nombreuse composée d'hommes industrieux, dont beaucoup ont péri en défendant avec courage des coutumes et des lois protectrices des mœurs et de la prospérité publique. Leur industrieuse activité, leur probité sincère, avaient donné au commerce dont ils s'occupaient une telle étendue, les produits de leurs manufactures jouissaient à l'étranger d'une telle confiance, qu'on vit, pendant cette période de temps, les travaux de cette ville florissante ajouter chaque année à la richesse nationale 60 millions de numéraire. C'est ainsi qu'une cité, aussi célèbre par ses malheurs que par.la loyauté de ses habitants, augmentait les ressources et la force de l'Etat, et se reconnaissait de la protection accordée à son industrie. Lorsque les lois et les coutumes qui avaient fait sa splendeur furent abolies, des hommes pervers ont voulu introduire jusque dans la fabrication des étoffes la licencieuse liberté du temps, et leur donner des qualités trompeuses qui devaient éloigner la confiance de l'acheteur. Le Souverain qui nous gouverne sait que, si l'ordre ne règne pas dans les ateliers, aucune entreprise de l'industrie ne saurait avoir de succès permanent. Il s'est hâté d'y rétablir des institutions tutélaires. Déjà, par ses arrêtés du 22 floréal dernier, il a ordonné que les tissus principaux des fabriques de Lyon fussent revêtus de marques qui en assurent, dans les unes leurs qualités intrinsèques, dans les autres la valeur des métaux précieux qui y sont mélangés, de manière que le consommateur ne peut plus aujourd'hui être trompé dans les achats d'étoffes faits sous cette garantie. 
" La loi que j'ai l'honneur de vous présenter en ce moment, Messieurs, est une suite de ces dispositions qui tendent à régénérer les manufactures françaises. Les premier et second titres établissent et organisent un Conseil de prud'hommes dans la ville de Lyon et règlent ses attributions. Ce Conseil doit remplacer l'ancien Corps des maitres-gardes, débarrassé dans ses formes de tout ce que l'expérience a montré être nuisible au progrès de l'industrie et à la liberté du commerce. Ce Tribunal, par sa composition, a un avantage sur ceux qu'il remplace. II doit être composé d'hommes qui, par leurs habitudes, auront acquis toutes les connaissances qui doivent faire présumer l'équité de leurs décisions. Appelés à terminer les différends entre leurs égaux, il leur sera facile de gagner leur confiance et de remplir utilement les fonctions de juges conciliateurs dans les conflits d'intérêts entre fabricants et ouvriers. »

L'orateur du Tribunat continuait en exposant le rôle du Conseil de prud'hommes comme conservateur de la propriété des marques et dessins de fabrique.

Sur le rapport de Pernon présenté au nom du Tribunat, précédé de celui de Regnault de Saint-Jean-d'Angely au nom du Conseil d'Etat, le Corps législatif vota séance tenante la loi du 18 mars 1806, qui subsista sans changement jusqu'en 1848 et régla pendant près d'un demi-siècle, sans soulever de critiques, le fonctionnement des Conseils de prud'hommes. Depuis la loi du 17 mai 1848 , leur législation fut instable. En 1853, 1880, 1884, leur régime fut modifié sous l'influence de causes étrangères aux vrais intérêts de l'industrie. Il est aujourd'hui gouverné par la loi du 17 mars 1907 .

Tel fut le rôle officiel de Pernon dans la création d'une institution aujourd'hui séculaire, passée dans les mœurs et qui fut une partie de l'œuvre législative de Napoléon. Même avant d'attacher son nom, comme tribun, à cette réforme, il en avait été, avec ses collègues de la Chambre de commerce, l'un des promoteurs, 
lorsque le souverain en reçut, à Lyon, d'un groupe de fabricants, la première idée. Au dire de l'historien Grognier, auteur d'une notice sur le Conseil des prud'hommes, insérée, en 1816 , dans le quatrième volume des Archives bistoriques du Rhône, ce serait même à Lyon qu'une première rédaction du projet aurait été soumise à Napoléon, sur sa demande, par la Chambre de commerce.

Camille Pernon fut l'un des organisateurs des fêtes offertes à l'Empereur et à l'Impératrice, en avril 1805 , pendant leur séjour à Lyon, au cours de leur voyage de Fontainebleau à Milan, où Napoléon se rendait pour être couronné roi d'ltalie ${ }^{1}$. Partis de Fontainebleau le 5 avril, avec une suite de cent cinquante personnes comprenant des maréchaux et des ministres, Napoléon et Joséphine arrivent à Bourg le 9 , et le 10 à Lyon ${ }^{2}$, où ils sont reçus au palais de l'Archevêché. lls visitent, au palais Saint-Pierre, l'exposition des produits de l'industrie lyonnaise. Leur attention est attirée sur les belles étoffes sorties des fabriques de Pernon, les échantillons des œuvres de Philippe de Lasalle, mort un an auparavant, le métier de Jacquard, alors une nouveauté, présenté et mis en mouvement par l'inventeur, le tissage d'une étoffe de velours chiné en double largeur, sur un métier que Pernon avait fait transporter de l'un de ses ateliers.

A cette occasion, Napoléon gratifia Jacquard d'une prime de 50 francs pour chaque métier livré par lui pendant six années, accorda des pensions à la veuve de Philippe de Lasalle, à un teinturier inventeur d'un procédé de teinture en noir, à un ouvrier tisseur d'étoffes brochées. Quant à Pernon, il reçut du maréchal Duroc, qui était de la suite de l'Empereur, avec l'objet qu'elle annonçait, la lettre que voici, dont l'autographe original est

1 Bulletirt de Lyon, 28 germinal an XIll.

- Almanach bistorique de la ville de Lyon pour 1806. 
conservé dans la collection de documents lyonnais de M. Léon Galle: «A Lyon, le 25 germinal an XIIl ${ }^{1}$. Le Grand Maréchal du Palais à $M$. Camille Pernon, membre de la Chambre de commerce de Lyon. Sa Majesté, voulant vous donner, Monsieur, un témoignage d'estime et de satisfaction, m'a donné l'ordre de vous remettre une des grandes médailles en or qui ont été frappées à l'occasion de son couronnement. Recevez, Monsieur, l'assurance de ma parfaite considération. Signé : Duroc. »

D'autres mesures d'intérêt plus général, en vue de favoriser l'industrie lyonnaise, furent prises par Napoléon pendant son séjour à Lyon ou peu après. Le 13 avril, il signa deux décrets : l'un instituant la Condition générale des soies, l'autre portant défense d'exporter les soies propres à faire de la tapisserie; le 25 avril, le décret protégeant la fabrication des étoffes de soie, or et argent, contre les imitations en dorure fausse ou or mi-fin.

La liste est longue des distinctions que valurent à Pernon ses mérites et ses services. Avant la Révolution, ses voyages en Russie l'avaient fait connaitre de l'impératrice Catherine II, qui, n'ayant pas jusqu'alors d'agent consulaire à Lyon, le fit agent de Sa Majesté l'Impératrice de toutes les Russies ${ }^{2}$.

En 1802, il fut un des sept négociants de la ville désignés, à.la demande du Gouvernement, par le Tribunal et par le Conseil du commerce, pour présenter leurs observations sur le projet de Code de commerce, et qui proposèrent d'y faire plusieurs changements dans la matière des sociétés, de la faillite et de la lettre de change. Leurs propositions furent communiquées aux Tribunaux, appelés eux-mêmes à présenter les leurs au Pouvoir législatif ${ }^{3}$.

La même année, il fut nommé par le préfet du Rhône, commissaire à l'effet d'estimer la valeur des modèles de métiers à tisser

115 avril 1805 , lundi de Pâques.

${ }^{2}$ Almanach bistorique de la ville de Lyon, 1783.

${ }^{3}$ Bulletin de Lyon, de l'an XIIl. 
fabriqués par Philippe de Lasalle et que le Gouvernement voulait acquérir pour en faire profiter les ateliers de soieries.

Vers le même temps, il est membre de la Chambre de commerce lors de sa création; de la Commission des hospices; du Conseil chargé de l'organisation et de l'administration du musée et des différents services installés dans le bâtiment de l'ancien couvent des dames de Saint-Pierre ${ }^{1}$.

Le $1^{\text {er }}$ mars 1805 , avec Vittet, Camille Jordan, Dechazelle, Terret, Gensoul, Degérendo, de Boissieu et Regny, il entra au Conseil de la Société des amis du Commerce et des Arts, fondée pour encourager les Arts et l'Industrie par des récompenses offertes aux artistes et aux auteurs des inventions nouvelles. Sous sa présidence, la Société offrait un prix de 600 francs à l'auteur du meilleur mémoire sur l'Etat actuel de l'industrie dans le département du Rbône; un prix de 600 francs pour l'objet qui, dans une exposition publique, paraitrait réunir le plus d'industrie dans son exécution et d'utilité dans son application; enfin, un prix de 500 francs à l'inventeur qui, par le perfectionnement de la navette volante ou par tout autre mécanisme, mettrait l'ouvrier en état de tisser, sur un métier ou sur plusieurs marchant ensemble d'un même mouvement, plusieurs pièces d'étoffes, dans le même temps qu'il emploie à en fabriquer une seule et sans nuire à la bonne fabrication du tissu. Dès cette époque était donc posé le problème que devait résoudre bien des années plus tard l'invention du métier mécanique.

Un décret impérial, daté du camp de Boulogne du 4 août 1805 , nomme Camille Pernon, adjoint au maire de Lyon, sous l'administration de Fay de Sathonay.

Au mois de mars 1806 , les façades de Bellecour, démolies par

1 Péricaud, Tablettes, 4 mars 1803 . Faisaient partie de ce Conseil avec Pernon: de Boissieu, Dechazelle, Regny père. 
ordre de la Convention pour punir les Lyonnais de leur révolte, et dont Napoléon, alors Premier Consul, avait inauguré la reconstruction le 29 juin 1800 , étaient achevées. L'emplacement de la statue de Louis XIV, érigée en 1713 , abattue en 1793 , restait vide. Les Lyonnais décidèrent d'y élever une statue équestre au vainqueur d'Austerlitz, sur un piédestal décoré de bas-reliefs qui rappelleraient sa glorieuse campagne de trois mois suivie de la paix de Presbourg; une députation composée de Terrasson, Rieussec, Degérando et Vincent Margnolas, avec Camille Pernon à leur tête, présenta à l'Empereur, au nom de la ville de Lyon, une adresse pour obtenir son agrément. Elle fut suivie, le 9 mai, d'une loi relative à la réfection de la place Bonaparte'. Le projet de statue resta sans exécution.

Lors de la réorganisation de l'Académie de Lyon, le 13 juillet 1800 , elle se reconstitua avec quarante-cinq membres titulaires, les uns, anciens membres dispersés en 1793 , les autres, choisis parmi les Lyonnais désignés par «leur réputation et leurs talents». Ce sont les termes mêmes de la lettre que le Président leur adressa en leur envoyant le diplôme. Camille Pernon fut un de ceux-là ${ }^{2}$.

Dumas, dans son Histoire de l'Académie, consacre ces quelques mots au nouvel académicien: «Camille Pernon, manufacturier, membre du Tribunat, officier de la Légion d'honneur ${ }^{3}$, adjoint au maire de Lyon, membre de la Chambre du commerce. Sa fabrique

1 Moniteur, 4 mars 1806 . - Péricaud, Tablettes, mars et mai 1806.

- Lettre adressée le 4 vendéminire an IX à Camille Pernon par M. Verninac, préfet du Rhône, président de l'Athénée, nom sous lequel l'Académie fut reconstituée. Autographe original communiqué par $M$. Léon Galle.

${ }^{3}$ Est-il vrai que Pernon fut officier de la Légion d'honneur? Dans 1'Almanacb bislorique de la ville de Lyon de 1806 , il figure comme simple légionnaire. 11 y est fait mention, pour le département, d'un grand-ufficier, le général commandant la XIXe division militaire; un commandeur, le Premier Président de la Cour d'appel ; trois officiers, appartenant tous à l'armée, et douze légionnaires, parmi lesquels Camille Pernon. C'est donc par erreur que Dumas lui donne la qualité d'officier. Toutefois, Terret, dans l'éloge de Pernon, au lendemain de sa mort, le qualifie d'officier. 
venait au premier rang parmi celles qui s'occupent des meubles et des brocarts. Envoyé pal sa maison de commerce en Russie, il sut s'y faire distinguer par Catherine II, qui apprécia ses talents et ses connaissances. Mort le 14 décembre 1808. Son éloge par M. Terret a été inséré dans le Bulletin de Lyon du 2 I décembre I 808 . "

Le souvenir s'est conservé de deux communications de Pernon à l'Académie. Dans la séance solennelle du 24 décembre 1801, à laquelle assistait la Consulta Cisalpine composée d'hommes politiques et de savants italiens, venus en France pour décerner à Bonaparte le titre de Président de la République italienne ${ }^{1}$, Pernon expose des vues générales sur le conmerce, sujet d'actualité dans une ville en travail de relèvement après de si grands désastres. Il fut, à cette occasion, le premier à proposer la création à Lyon d'un musée industriel propre à former le goût et à perfectionner la fabrication des soieries. Le projet attendit longtemps sa réalisation, mais celui qui en avait eu le premier l'idée, devait encore lui apporter sa participation posthume, avec les échantillons sortis de ses fabriques, exposés au Musée historique des tissus du palais du Commerce.

Dans une séance de l'année 1807 , Pernon lut à l'Académie ses observations sur le projet de traité de commerce à conclure entre la France et l'Espagne. La copie de son mémoire fut envoyée au Gouvernement par le Bureau consultatif du commerce de Lyon.

Les deux manuscrits de Pernon sont indiqués par Dumas, comme conservés dans les archives de l'Académie. Des recherches faites pour les retrouver sont restées sans résultat.

1 Voir Journal de Lyon et du Midi, fondé par Delandine et Dumas, le 22 décembre 1801 , et qui exista trois mois, répertoire curieux des opérations de la Consulta. - Collombet, Etudes sur les Historiens du Lyonnais, $2^{\circ}$ série, p. 277. 
Camille Pernon habitait une maison du quai de $\operatorname{Retz}^{1}$, où il était né en 1753 , et possédait, à Sainte-Foy-lès-Lyon, une importante propriété dont il avait acquis de son cousin Louis-Aimon Pernon l'usufruit et la jouissance pour lui et ses sœurs, leur vie durant, le 15 septembre 1792 , moyennant le prix de 30.000 livres. Il y récoltait de ce vin de Sainte-Foy alors réputé. Il y passait la belle saison, vivant avec ses trois sœurs, comme lui non mariées, qui furent ses héritières et, après sa mort, firent don de 300 livres à l'hospice de l'Antiquaille ${ }^{2}$. La dernière survivante mourut à SainteFoy en 1844. L'habitation, située dans le quartier de Narcelle, avec son entrée sur la rue du Nérard, attenant à un vaste parc sur lequel a été pris le cimetière actuel, fut alors vendue à $M$. Maurice Jarrosson, puis à $M$. Louchon, agent de change, passa plus tard par héritage à $M^{\text {me }}$ Desjardins, et appartient aujourd'hui à M. Cornet, essayeur de soies. C'est là que Camille Pernon est mort le 14 décembre 1808 , âgé de cinquante-cinq ans.

Son éloge, écrit par $M$. Terret, son ami et son collègue au Conseil de la Société du Commerce et des Arts, et publié après sa mort, dans le Bulletin de Lyon du 2 I décembre 1808, est le seul document qui conserve quelques traits de sa physionomie. II joignait, y est-il dit, à une excellente éducation, une figure heureuse, une aimable simplicité dans les relations, un esprit éclairé, une disposition naturelle à rendre service, de la droiture en tout.

Cet homme, qui fut la loyauté même et avait l'amour-propre de son état, eut à subir, à la fin de sa carrière, une dure épreuve, qui, au dire de ses contemporains, aurait abrégé sa vie. Le fait est ainsi raconté, sous la signature de Grognier, dans le tome Ill des Arcbives bistoriques et statistiques du département du. Rbône,

\footnotetext{
1 Maison dite de Baco (contrat d'association du ier janvier 1785 , Cabinet Chatel). Elle porte actuellement le numéro 6 . C. Pernon habitait au premier étage six pièces, magasin et habitation (Registre de recensement, $A r c b$. mun.).

2 Note de d'Assac, administrateur de l'Antiquaille (Cabinet Chatel).
} 

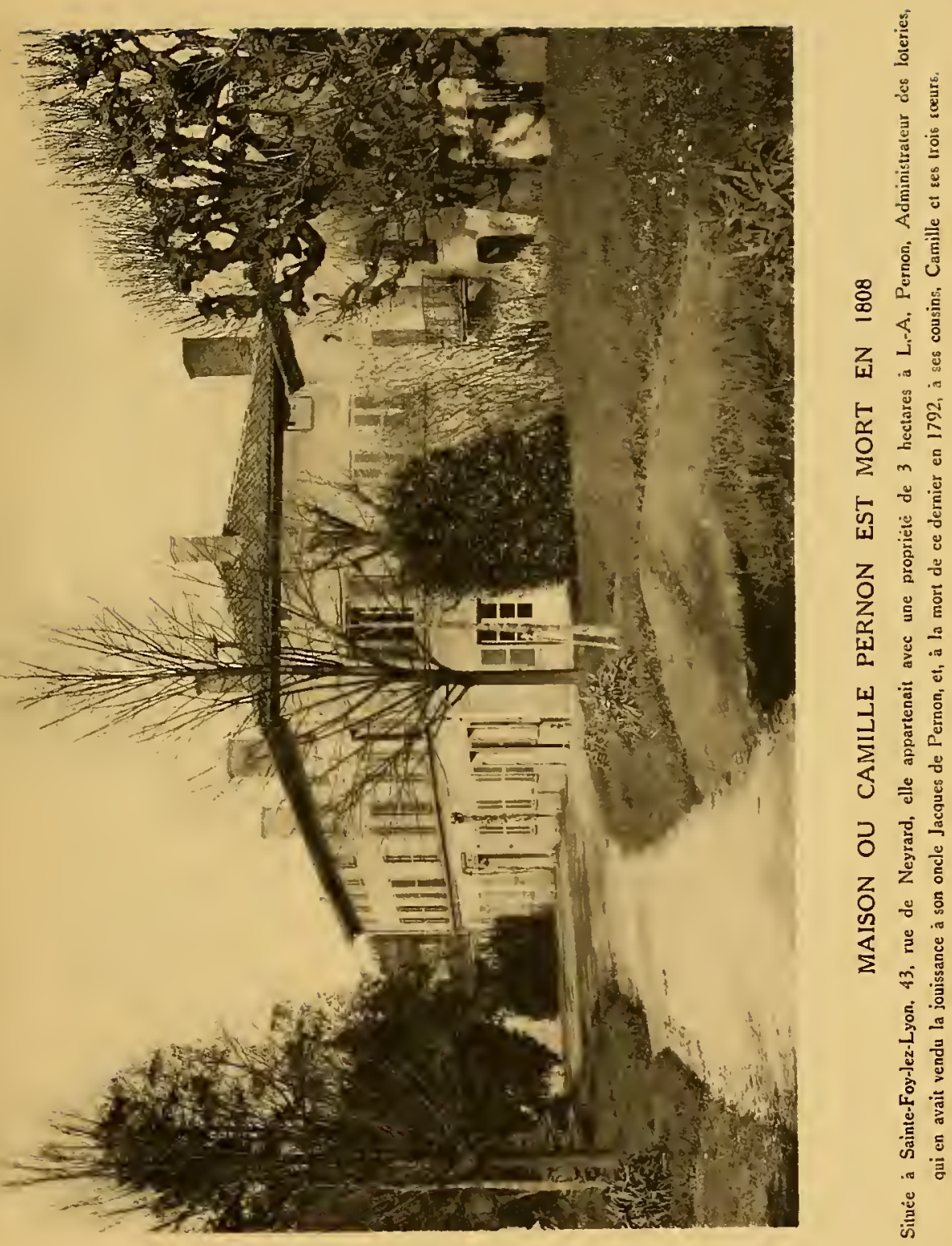

publié en 1825: «M. Camille Pernon, célèbre fabricant de notre ville, avait été chargé de tout l'ameublement du château de Saint-Cloud. Il tenait à honneur d'étaler dans cette belle résidence tout ce que l'industrie pouvait offrir de plus riche, de plus élégant, de plus somptueux, et il donna tous ses soins pour fabriquer les plus belles étoffes qui fussent sorties des ateliers de Lyon. Mais quel fut son chagrin, lorsqu'il vit par lui-même que presque toutes les couleurs avaient été flétries et fanées dans un an! Cet habile fabricant s'en trouva si profondément affligé qu'il succomba bientôt à une maladie dont la seule cause fut « l'infidélité d'un teinturier en qui il avait eu trop de confiance ${ }^{1} »$.

Napoléon qui avait l'œil à tout et s'occupait de l'administration dans ses détails, lorsqu'il connut le fait, donna l'ordre à l'administrateur du Mobilier National de faire estimer par expert le dommage causé par la mauvaise teinture aux étoffes employées à la décoration du château de Saint-Cloud. Le fait a été recueilli par les historiens de Napoléon ${ }^{2}$ qui le citent comme exemple de son esprit d'ordre et d'économie dans l'administration des affaires publiques.

L'administrateur du Mobilier National était alors un ami personnel de l'Empereur, Alexandre des Mazis ${ }^{3}$, son camarade à l'École militaire, lieutenant au régiment de la Fère en garnison à Valence, où tous deux étaient arrivés ensemble en octobre 1785 .

Des Mazis s'acquitta en conscience de sa mission dont le résultat fut consigné dans deux documents que la Bibliothèque de la Ville de Lyon se trouve de posséder dans le fonds Coste, $n^{\circ} 10614$ du catalogue de ce fonds dressé par Aimé Vingtrinier.

1 Les autres fabricants lyonnais, qui, jusqu'à cette date, n'avaient pu concurrencer Pernon pour les fournitures du Mobilier National, profitèrent de cette circonstance pour faire une pétition en leur faveur et entrer en ligne pour les commandes de l'Etat.

2 Arthur Lévy, Napoléon intine, p. 417.

3 lbid., p. 36 . 
Le premier de ces documents est le Relevé des fournitures faites par la manufacture de Lyon pour le Mobilier impérial, avec le certificat de réception et d'emploi. Paris, 9 septembre 1807 ; signé : Le Fuel. Manuscrit grand in-folio de 4 pages. Ce relevé, où aucun nom de fabricant n'est cité, comprend douze fournitures qui s'échelonnent, pendant dix mois, depuis frimaire an XII (novembre 1803), jusqu'à vendémiaire an XIII (septembre 1804), faisant ensemble 7.689 mètres de riches étoffes d'ameublement d'une valeur totale de $713.415 \mathrm{fr} .27$, dont 3.549 mètres, d'une valeur de 304.219 francs, étaient destinés aux appartements du château de Saint-Cloud. Ce sont celles-là qui furent avariées par la teinture et donnèrent lieu à une expertise et à un rabais. Les autres fournitures étaient destinées aux palais des Tuileries et de Fontainebleau.

Les tentures de Saint-Cloud étaient ainsi composées: 503 mètres de brocart or, fond tabac d'Espagne, pour la chambre à coucher de l'Empereur, valeur 43.330 francs, soit 86 francs le mètre ; 626 mètres de velours uni, fond prune, chiné vert, dessin branche de laurier, pour la salle des Ambassadeurs, valeur 69.382 francs, soit 110 francs le mètre; - 538 mètres damas terre d'Egypte, satin fond rouge étrusque, valeur 15.680 francs, soit 29 francs le mètre; -865 mètres brocart or, fond satin, damas trois coulleurs, dessin feuille de chêne, pour la salle du Conseil d'État, valeur 93.409 francs, soit 108 francs le mètre; -1.017 mètres brocart or, fond ponceau, damas fond vert à couronnes, valeur 82.428 francs, soit 80 francs le mètre; - 488 mètres brocart argent, fond bleu, dessin à couronnes, pour le grand salon de l'Impératrice, valeur 78.423 francs, soit 160 francs le mètre; la bordure 200 francs le mètre.

Toutes ces belles étoffes, dépréciées par la faute d'un teinturier inhabile ou indélicat, sont l'objet du second document joint au premier dans le cartable que possède la Bibliothèque de la Ville de 
Lyon. C'est le Rapport du Sieur Bardel, commissaire du Gouvernement, sur le rabais que doivent supporter les étoffes fournies par la manufacture de Lyon, pour cause de mauvaise teinture. Paris, 12 septembre 1808; signé, pour copie conforme, par l'administrateur du Mobilier Impérial, des Mazis. Manuscrit in-folio de 3 pages. L'expert constate que les ponceaux et les verts sont de mauvaise teinture, qu'ils se sont fanés après exposition au soleil pendant un mois. Il déclare que le teinturier qui a teint ces étoffes est extrêmement blâmable. Mais, séparant le fabricant du teinturier, il dit que le premier a parfaitement rempli sa tâche et a livré des étoffes d'une perfection de goût et de fabrication telle qu'on pouvait l'attendre de la première manufacture d'Europe; que le seul reproche à lui faire est d'avoir eu trop de confiance dans le teinturier qu'il a employé ; que toute la responsabilité du dommage incombe au teinturier, si le fabricant justifie qu'il n'a rien épargné pour avoir une teinture solide. L'expert croit devoir ajouter que, depuis la suppression des maîtrises, toute personne prenant une patente peut fabriquer sans avoir à justifier d'aucun apprentissage; qu'il s'est créé beaucoup d'ateliers dont les chefs manquent de capacité; mais que l'établissement des Conseils de prud'hommes permet d'espérer un meilleur ordre de choses. Les conclusions du rapport sont que la dépréciation résultant de la mauvaise teinture des étoffes soumises à l'expertise doit être estimée à 42.909 fr. 77 .

Comment l'affaire fut-elle réglée? Le rapport de l'expert ne nomme aucun fabricant; mais toutes les commandes citées sur le relevé des fournitures se trouvent sur les livres de Pernon. A supposer que le rabais ait été supporté par le teinturier auteur du dommage, le fabricant eut cependant la fin de sa carrière bien assombrie par cette disgrâce de la fortune, lui qui n'en avait connu jusque-là que les faveurs. Mais sa réputation commerciale n'eut pas à en souffrir. L'expert lui avait rendu justice et il garda quand même la clientèle du Mobilier National. Longtemps après la 
livraison de ces malheureuses étoffes du château de Saint-Cloud, en février 1807 , Pernon recevait une lettre datée de Varsovie; deux jours avant la bataille d'Eylau, du comte Daru, conseiller d'Etat, intendant général de la maison de l'Empereur et ancien collègue de Pernon au Tribunat, lui donnant des ordres de réassortiment pour les Tuileries, Saint-Cloud et Fontainebleau et une nouvelle commande pour le palais de Versailles ${ }^{i}$.

Camille Pernon reste donc une figure intéressante qui a marqué sa place, une grande place, dans l'histoire de la fabrique lyonnaise. De même que le nom d'un peintre célèbre est assuré de vivre aussi longtemps que ses œuvres seront exposées dans les musées, celui de Camille Pernon ne périra pas tant que les belles étoffes fabriquées par lui seront exposées, à Lyon, au Musée historique des tissus, en France et à l'étranger, dans les palais dont elles décorent les appartements.

1 Lettre autographe originale communiquée par M. Léon Galle.
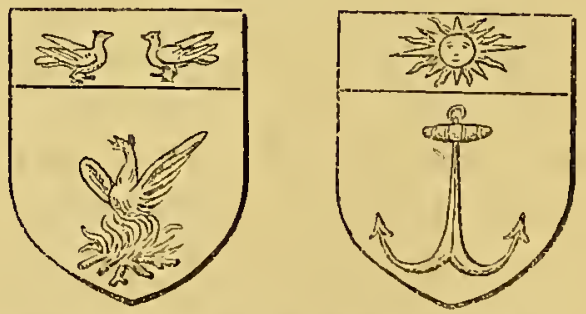

Blasons portés par deux branches de la ramille Pernon.

(V. page 4.) 
Pl. VII.

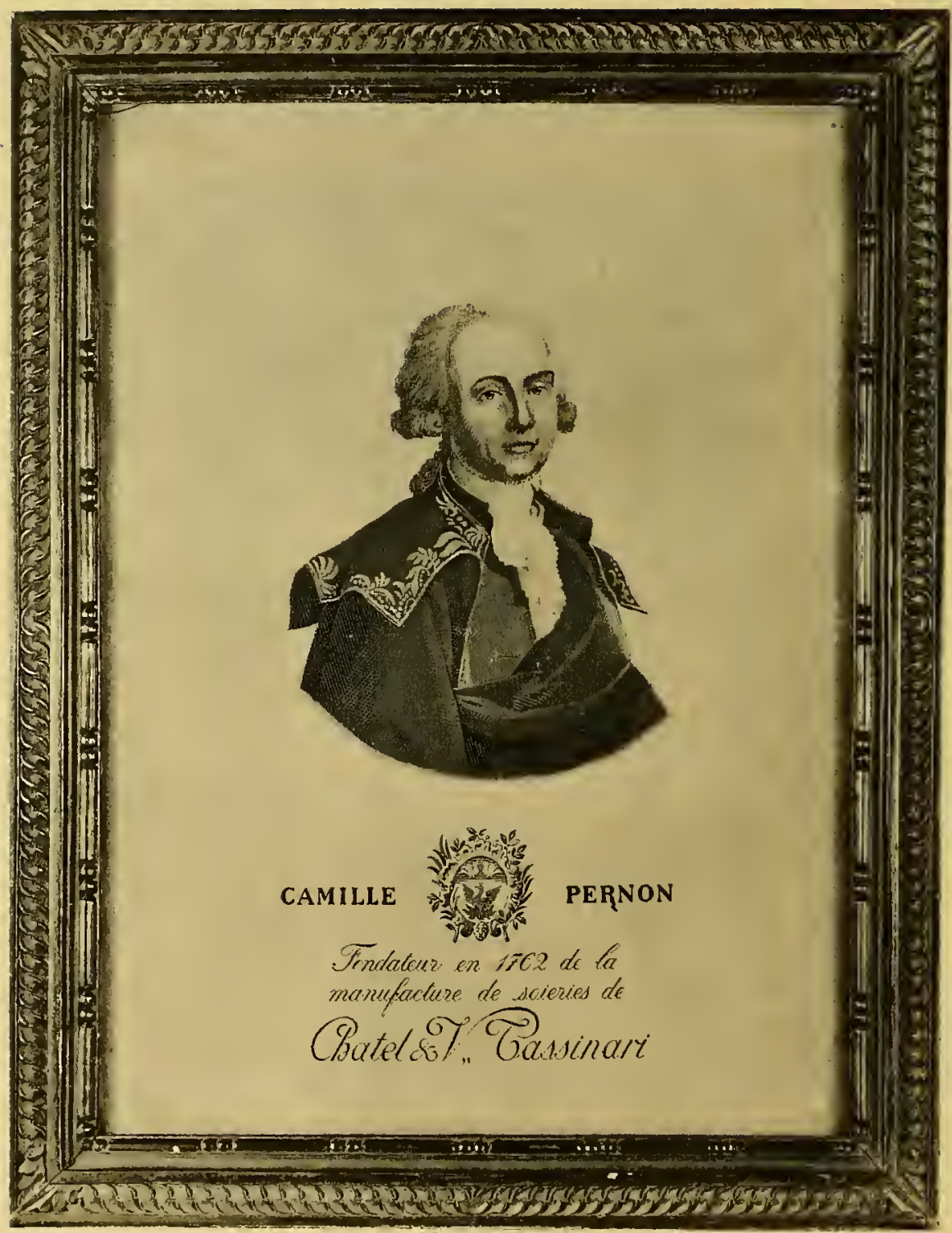

\section{PORTRAIT TISSE $\hat{\text { DE }} \mathrm{C}$. PERNON}

Reproduction de la lithographie de Naegelin, exécutée par la Maison Chatel et V. Tassinari, à l'occasion de l'Exposition de 1889. 


\section{II \\ L'CEUVRE}

I 'cuvre de Camille Pernon fut considérable, à en juger par les documents malheureusement trop rares qui nous en restent. Seul fournisseur du Mobilier de la Couronne sous Louis XVI et du Mobilier National sous l'Empire jusqu'en 1807 , il fit, pendant ces deux périodes qui remplirent toute sa vie, les plus belles étoffes sorties des ateliers lyonnais.

Il dut être très bien préparé à sa carrière au point de vue technique par l'exemple de son père, bon administrateur et chef habile d'une vieille fabrique de soieries, fondée à la fin du Xvile siècle et qui continua à progresser sous sa direction. La prospérité d'une semblable affaire ne pouvait être maintenue sans beaucoup de goût artistique, et le père de Pernon devait être homme de goût autant qu'habile technicien.

La célèbre statue de la Vierge, de Coysevox, lui aurait, paraitil, appartenu avant d'être placée dans la chapelle de Saint-Nizier où elle est encore, et après avoir orné l'angle de la maison qui faisait le coin de la rue Bât-d'Argent et de la rue du Plâtre-Saint-Pierre, dans laquelle avait demeuré Coysevox. M. Pernon la vendit, en 
I 77 1, au Chapitre de Saint-Nizier, 1.600 livres ${ }^{1}$. Le père de Camille, syndic de la confrérie des Pénitents de la Miséricorde, administrateur des mines de Chessy, etc., n'était-il pas, en même temps qu'homme pieux et charitable, amateur éclairé et bon commerçant?

Le registre de caisse de la manufacture de Sèvres porte recette d'une somme de 642 livres, payées par M. Pernon pour des porcelaines livrées le 15 janvier 1787 . Cette date nous ferait supposer qu'il s'agissait de Camille lui-même. Il s'adressait à bonne source pour sa vaisselle de table.

Ces petits faits nous prouvent qu'on avait la connaissance des belles choses dans la famille Pernon et que Camille avait été à bonne école.

Son père le fit voyager très jeune pour utiliser ses aptitudes; en Espagne d'abord, ensuite en Russie. 11 avait à peine vingt ans, et nous savons qu'il n'y perdit pas son temps.

De son retour de Russie datent le début de sa carrière commerciale et ses premières relations avec Philippe de Lasalle, le plus illustre des collaborateurs auxquels il a associé son nom².

1 J. Baud, Statistique des basiliques de Lyon, 1842, p. 56.

2 Après une courte association avec son beau-père Charrier (ce nom qu'on a écrit Charie et Charye est ainsi orthographié dans le décret du 8 brumaire an XII), Ph. de Lasalle s'établit à son compte dessinateur, et chef d'un atelier de tissage où il expérimentait ses inventions. 11 travailla spécialement pour Camille Pernon avec qui il entretint les meilleures relations jusqu'à la fin de sa vie.

Lorsque, déjà malade et ruiné par le siège de Lyon, il proposera à la Ville l'acquisition de ses métiers et de ses inventions, il écrira spécialement pour demander que M. Pernon, dont il connaît la compétence, soit de la commission « pour l'estimation de la valeur de ce que contient son atelier à fabriquer les étoffes $»$.

(Lettre du 28 frimaire an XI1, Arch. mun.)

Par décret du Préfet de Lyon, C. Pernon fut nommé de cette commission avec Dechazelle, comme lui membre du Conseil du commerce, et Defarge, conseiller de Préfecture.

(Bulletin de Lyon, du 3 nivôse an XII.)

Leur rapport décida l'achat de l'atelier de Lasalle qui fut installé au Conservatoire des Arts et Métiers. On sait que tout ce qui composait cet atelier fut malheureusement dispersé sans retour quelques années plus tard. 
PI. VIII.

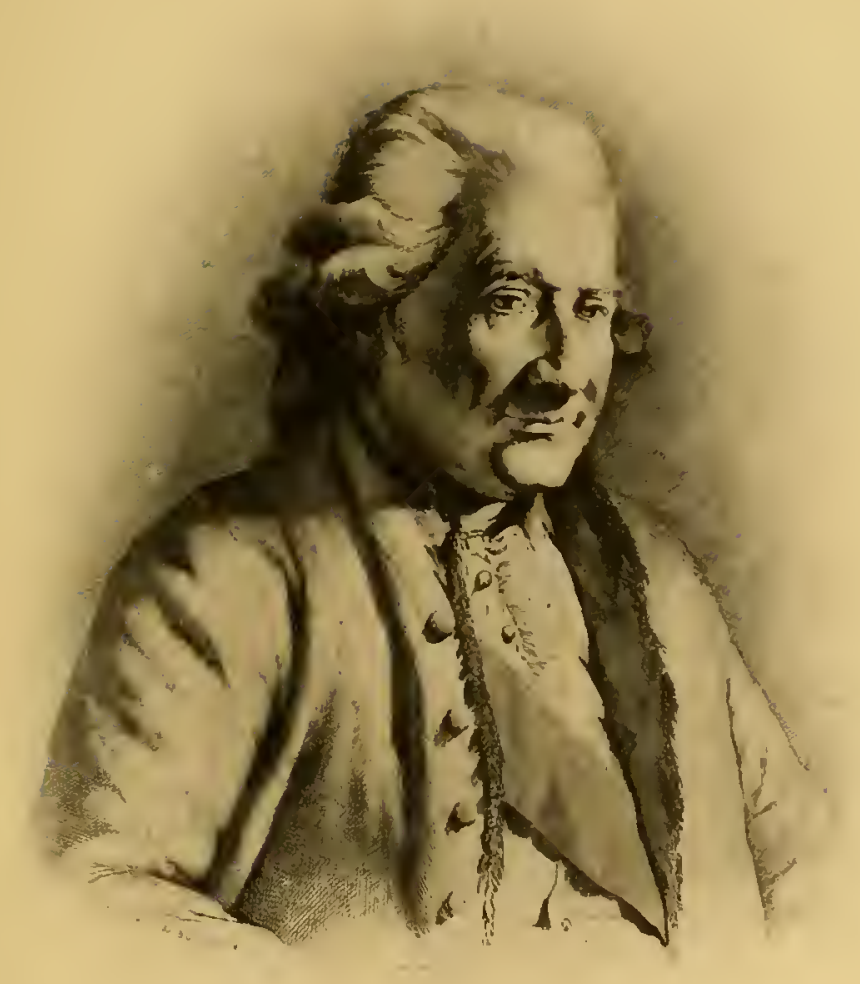

PHILIPPE DE LASALLE.

Gravure de Soumy, d'aprés le dessin original de De Boissieu. 


$$
\text { , }
$$


Pl. IX.
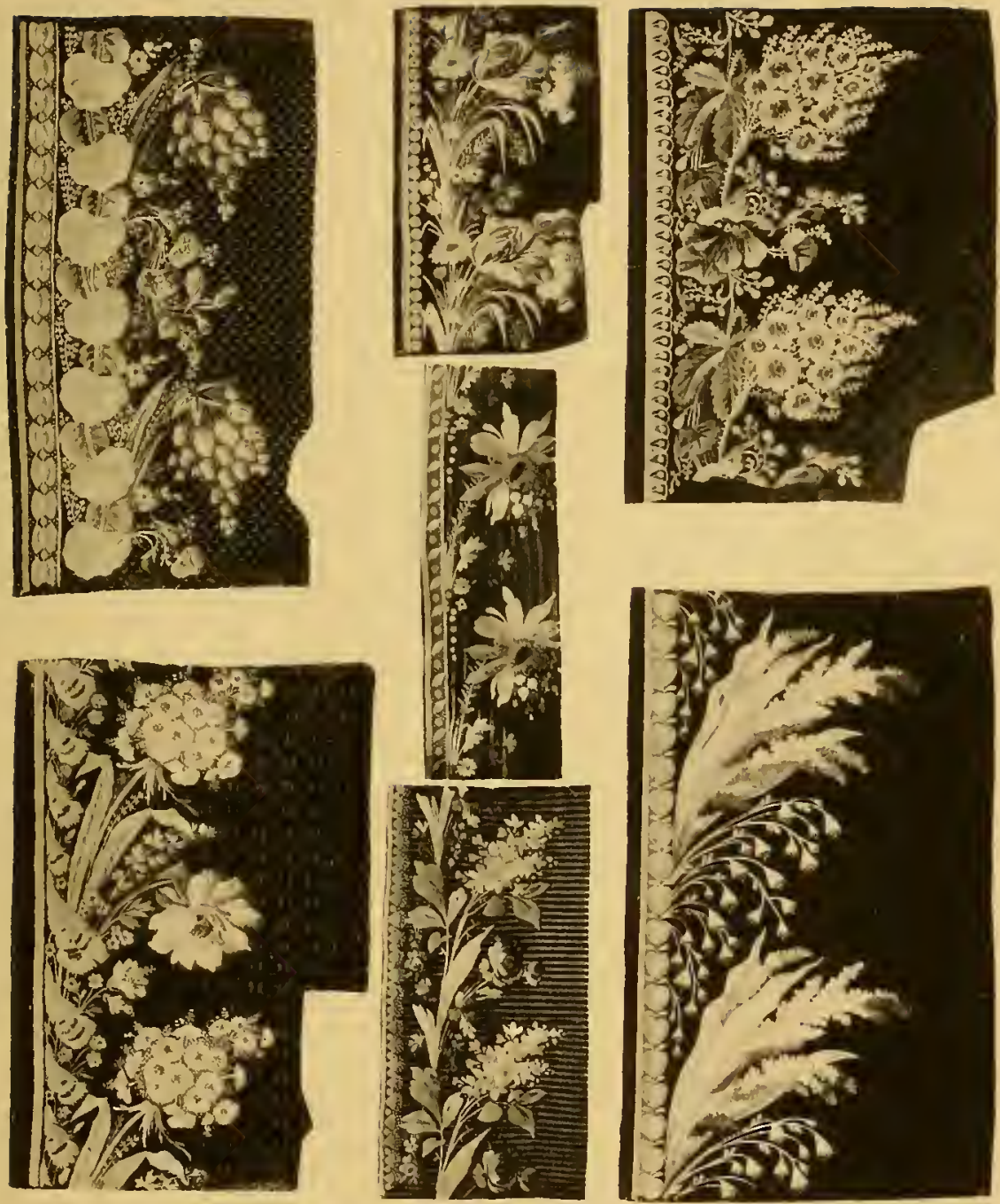

BRODERIES POUR BORDURES D*HABITS

Dessins de l'époque de Philippe de Lasalle, 

Celui-ci doit à la maison Pernon une grande part de sa gloire d'artiste dessinateur.

Sans Pernon, son talent n'aurait peut-être jamais trouvé l'occasion de se manifester autrement que sur de petits dessins d'étoffes et de broderies, admirables sans doute, mais qui, aujourd'hui encore, partagent avec tant d'autres un anonymat difficile à percer sans erreur.

Combien de ces broderies à l'aiguille, vrais bijoux d'ornementation, dont le dessin était fin comme une dentelle et modelé comme une peinture de maître, ont disparu avec la mode des vêtements dont ils étaient la parure.

Les étoffes pour habits d'hommes et de femmes, comme les étoffes pour meubles, étaient indistinctement fournies à cette époque par le même fabricant. N'utilisons-nous pas aujourd'hui, pour couvrir nos fauteuils, les soies dont nos grand'mères façonnaient leurs paniers et bouillonnaient leurs corsages? Les tissus vaporeux et souples dont on drape les robes d'aujourd'hui, demandent une organisation spéciale qui ne permet plus aux mêmes métiers de faire successivement de la robe et du meuble.

A l'époque de Pernon, une commande se composait souvent de deux ou trois habits pour Monsieur, avec vestes brodées (gilets) assorties, et de robes pour Madame, et de tentures et rideaux pour chambres et salons.

Dans leurs lettres, ses clients insistent souvent sur l'attention à donner aux mesures et aux patrons de leurs habits. Un fabricant tel que Pernon était, au xvine siècle, un véritable «couturier». II serait curieux d'étudier le rôle qu'a pu jouer, au point de vue de la mode à son époque, ce grand fabricant, en relations avec toutes les cours de son temps, avec la haute aristocratie, les duc de la Vauguyon, les marquis de Jranda, de Valdecarsane, etc., et avec des amateurs éclairés et des élégants raffinés : les Borelly (lettres de Grognard), les Grimod de la Reynière (coll. Chatel), et de le 
mettre en parallèle avec les créateurs actuels de la mode, grands artistes en leur genre, tels que les Doucet, les Worth, les Paquin. Nous retrouvons parfois, collées sur un vieux livre, ou enfoncées au fond d'un tiroir de chiffons, quelques-unes de ces broderies, frises d'habit d'homme ou bordures de robe, échappées à la destruction du temps. Il en est qui sont de véritables chefsd'œuvre du genre et dont on n'hésiterait pas à attribuer le dessin à Ph. de Lasalle lui-même.

Mais le génie commercial de Pernon donna à ce précieux talent, dont l'habileté se dispersait en œuvres secondaires, l'occasion de se déployer sans contrainte. Pernon, dont la séduction personnelle attira la bienveillance de hauts personnages tels que Catherine II de Russie et Napoléon ler , sut en faire profiter son industrie, et Philippe de Lasalle, élève de Boucher, dont la réputation d'excellent dessinateur était déjà connue à Lyon, se trouva à point nommé pour collaborer aux œuvres capitales que le cerveau d'artiste du fabricant avait conçues.

Parmi les plus belles œuvres produites par l'heureuse collaboration de $\mathrm{C}$. Pernon et de $\mathrm{Ph}$. de Lasalle, il faut citer, en première ligne, une tenture commandée par Catherine 11, probablement vers 177 l, et ce fut un des résultats heureux de ce voyage en Russie, où Pernon avait été reçu à la Cour, et remarqué, dit-on, d'une façon toute particulière par la Souveraine (pl. Io).

Le dessin de cette tenture, à fond satin or, est composé d'une tonnelle où courent des branches d'églantiers et dont les arceaux, reliés par des nœuds bleus, encadrent deux motifs principaux : un faisan et un cygne d'une part, un paon et des canards sauvages de l'autre. Leurs riches plumages donnent, au dessinateur, prétexte à étaler les couleurs les plus variées et les plus éclatantes. Cette étoffe est, peut-être, le chef-d'œuvre de Ph. de Lasalle et de Pernon. L'arabesque des lignes est d'une souplesse qui ne le cède en rien à l'harmonie des couleurs, et, malgré leur richesse et leur 


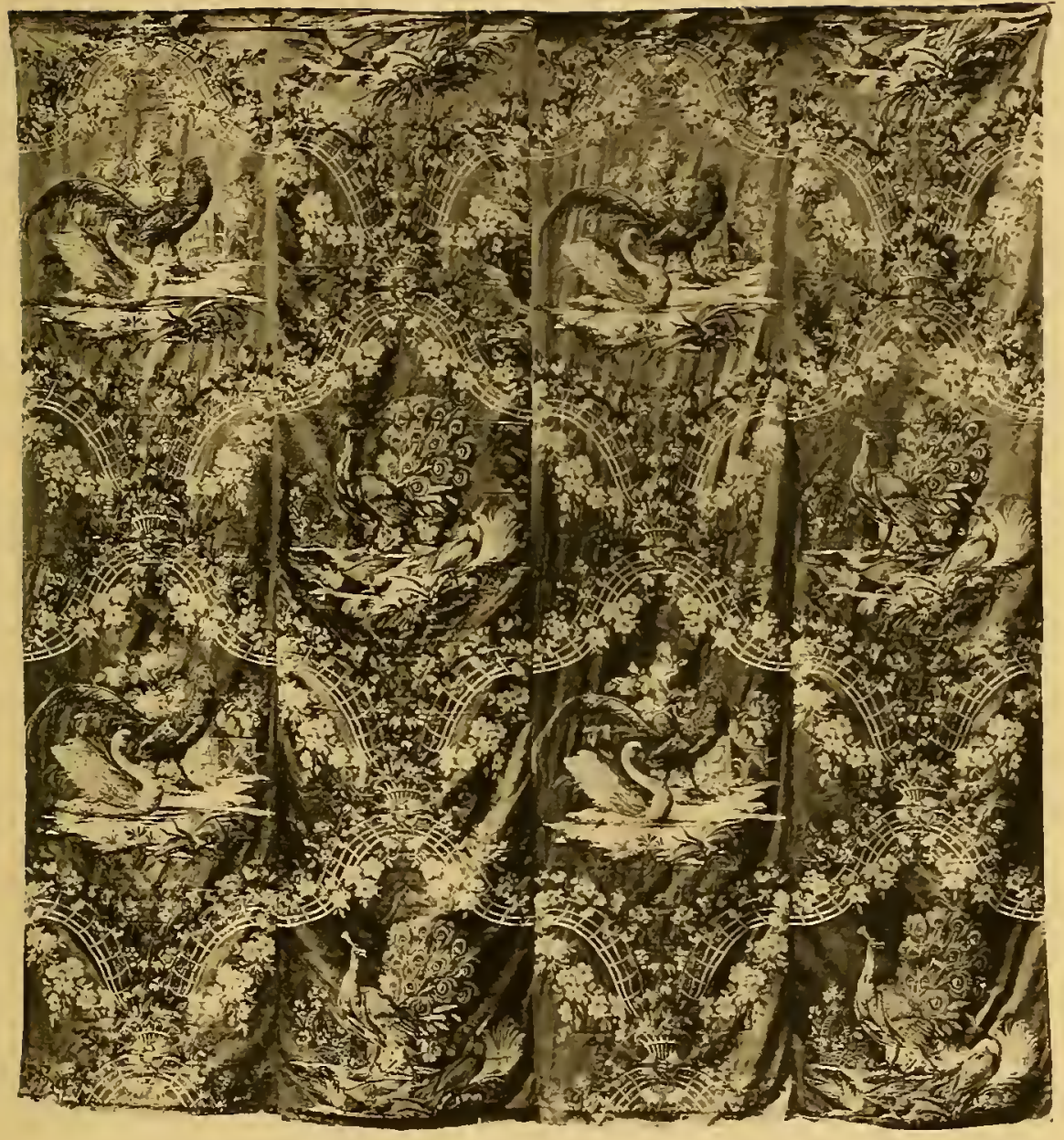

TENTURE DITE " AUX PAONS ET FAISANS "

Commandé à Pernon par la Grande Catherine. (Carlon de Philippe de Lasalle.) 



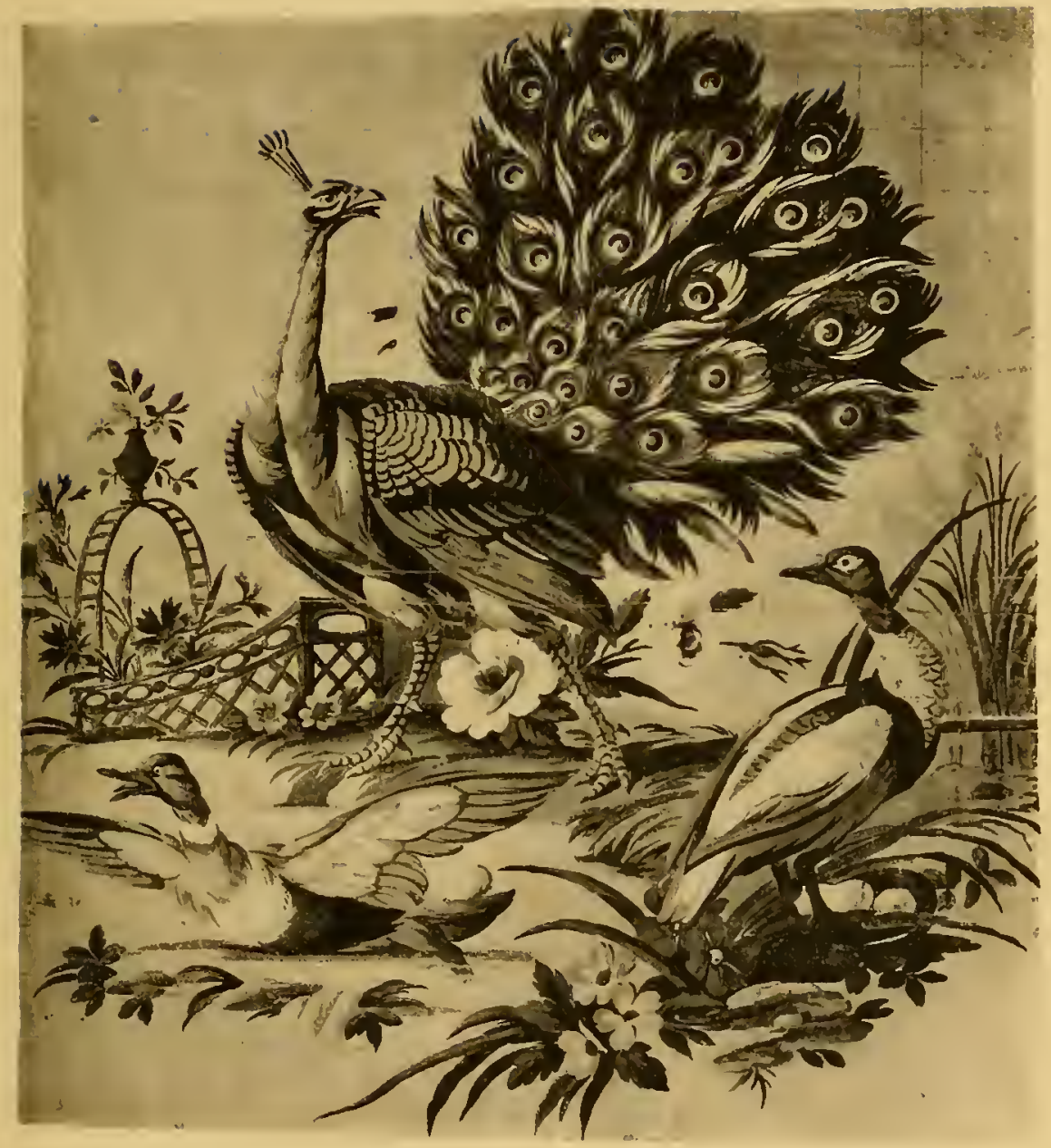

AQUARELLE DE PHILIPPE DE LASALLE

Maquette d'un des motifs de la tenture "Paons et Faisans ", passèe au carreau, pour ètre reportée sur le papier de mise en carte. 



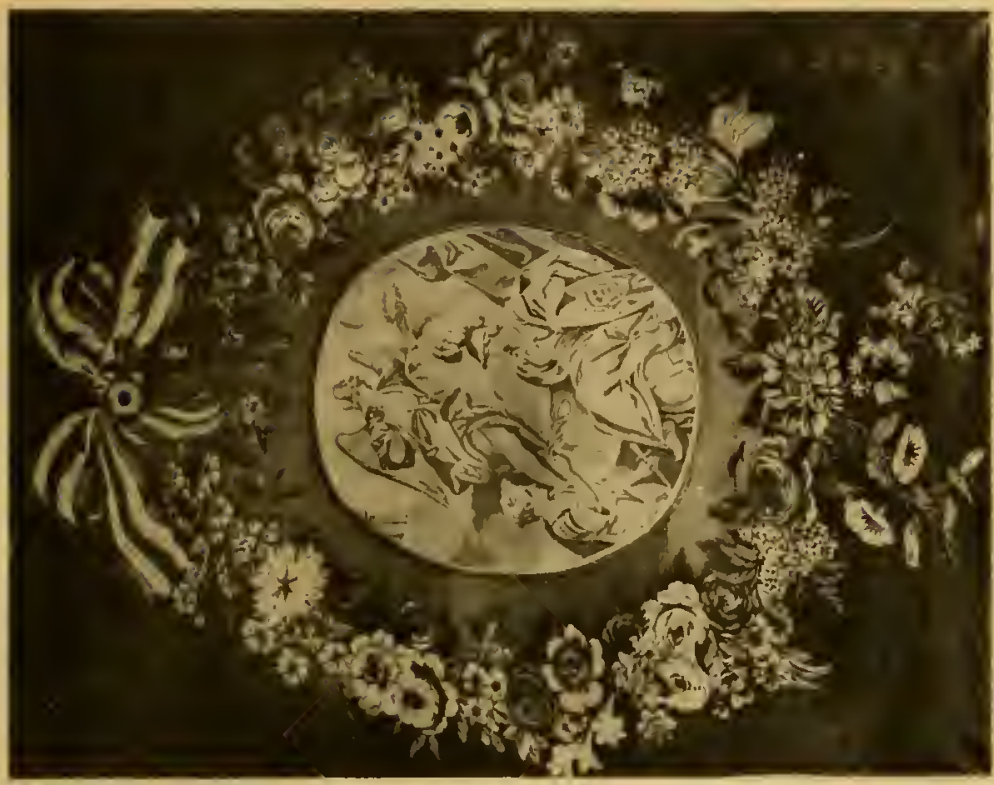

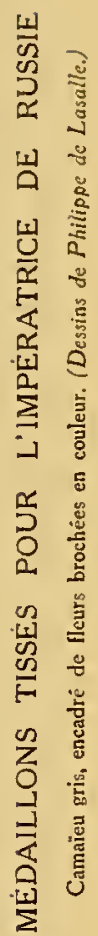

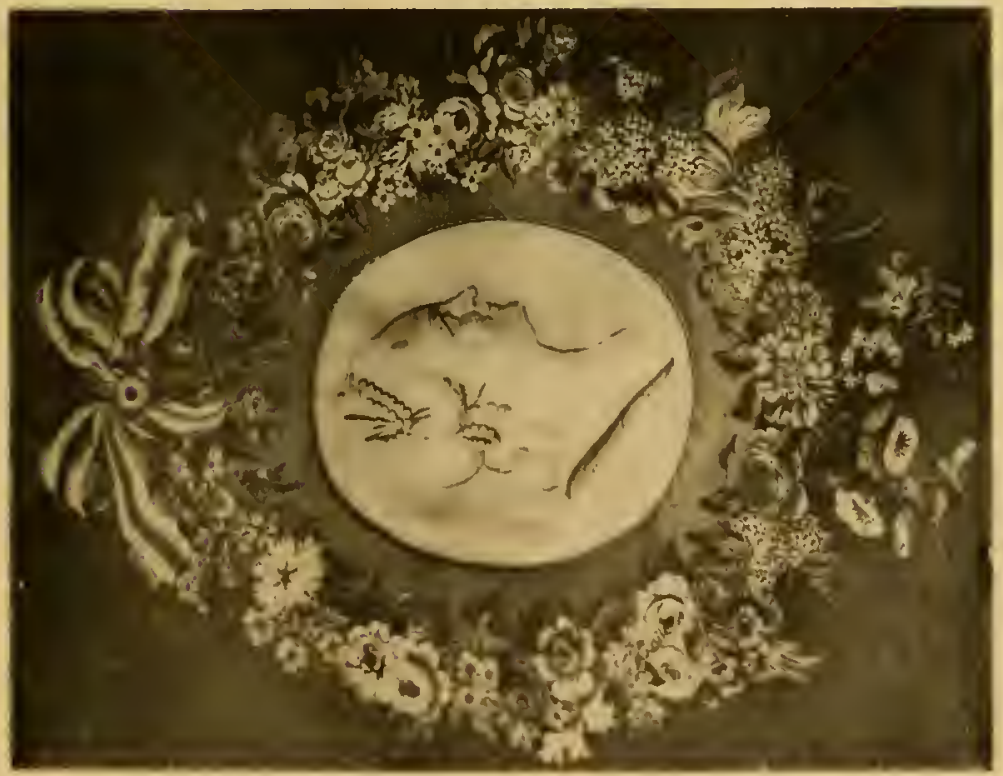



PI. XIII.
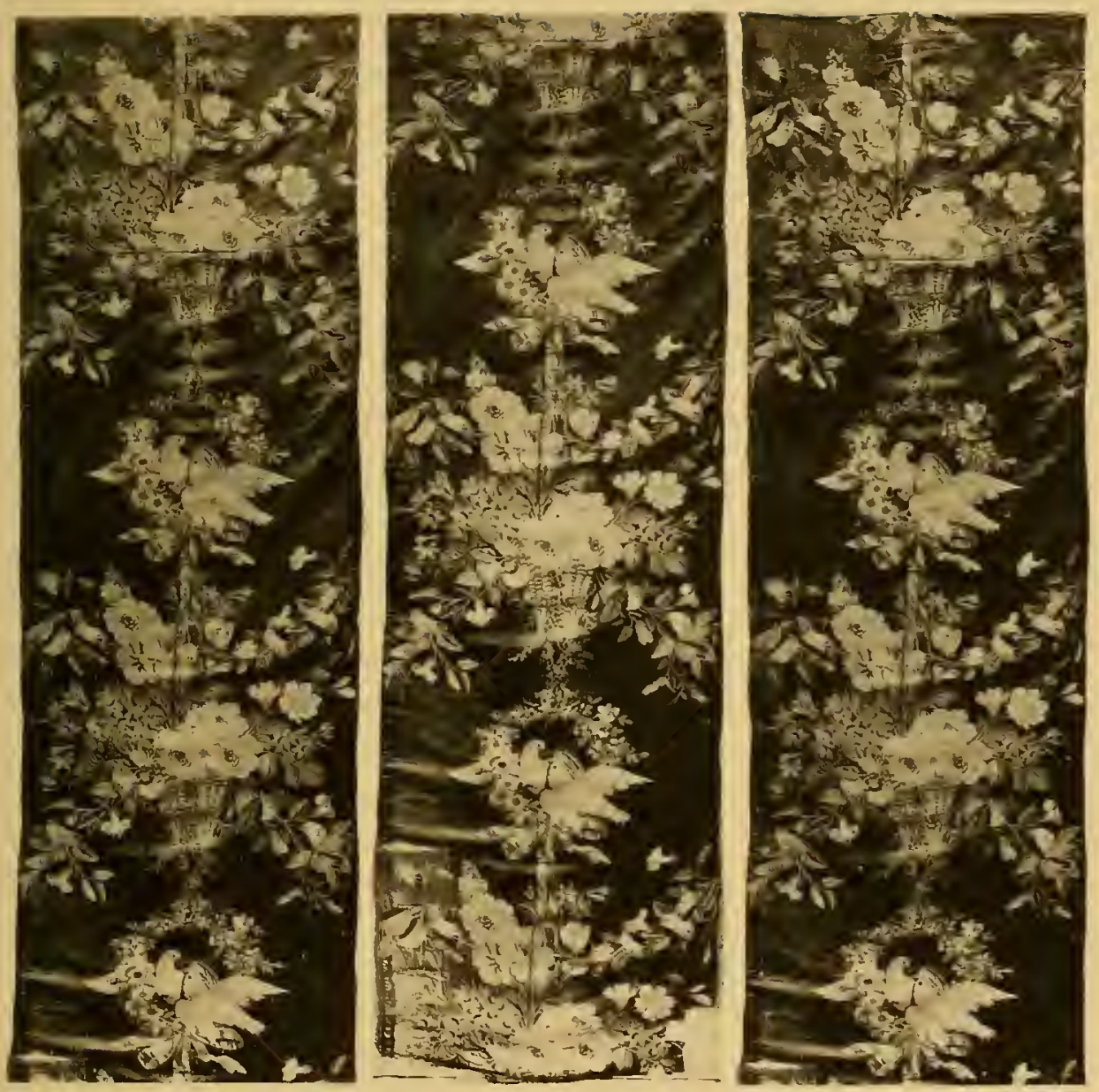

\section{ÉTOFFE BROCHÉE}

Motifs de colombes, paniers fleuris et guirlandes de lijerons bleu. sur fond satin cerise. Soierie fabriquée par Pernon pour la Russie. (Carlon de $P$. de Lasalle.) 
somptuosité, elles sont disposées avec une telle science des valeurs, que leur merveilleux effet ne dépasse pas les limites du goût le plus sûr. C'est une harmonie délicieuse faite pour les yeux, un concert de couleurs qui vaut les plus savantes symphonies.

On raconte que Voltaire, à qui Pernon, seul fournisseur attitré du Mobilier de la Couronne, ne pouvait être inconnu, n'aurait pas été étranger à l'introduction de celui-ci à la Cour de Russie. Le poète courtisan composa, d'ailleurs, des vers louangeurs qui devaient être brodés au-dessous d'un portrait de Catherine ll, tissé en forme de médaillon encadré de fleurs, et dont Ph. de Lasalle avait fait le dessin. Un autre médaillon, faisant pendant à celui-ci, représente Catherine en déesse de la guerre et des beaux-arts, donnant un ruban d'ordre à un de ses favoris ${ }^{1}$, couronné de lauriers et costumé en guerrier vainqueur. Une renommée, au-dessus du groupe, souffle dans une trompette et tient, sur la tête de la déesse, une couronne de victoire. Ces deux médaillons ${ }^{2}$, destinés à quelque cadeau, sont très rares, et durent être faits en très petit nombre (pl. 12).

Quelques années après, Ph. de Lasalle compose, pour Pernon, le dessin d'une tenture célèbre, qui peut se voir encore dans la pièce à laquelle elle était destinée, au château de Fontainebleau. C'est la fameuse étoffe connue sous le nom de «tenture des Perdrix», faite pour une chambre d'apparat de la Reine. Les rideaux du lit et les étoffes des sièges sont du même modèle, mais brodés en partie; et un couvre-lit tout brodé assorti fut donné en présent à la Reine par les dames notables de Lyon.

La reine Marie-Antoinette ne vit probablement jamais cette tenture. On mit plus de neuf ans à la tisser, et Napoléon, qui, heureusement, la trouva dans les armoires du Mobilier de la Couronne

1 Ce favori était le prince Alexis Orlof, vainqueur des Turcs à Tchesma en $177^{\circ}$.

¿L'un d'eux, exposé au Musée des tissus, a été classé comme objet ayant un intérêt artistique et historique. 
échappée aux pillages de la Révolution, la fit placer, pour l'Impératrice, dans la chambre où elle est encore (pl. 14).

Plus majestueux, dans son ensemble, que le dessin de la tenture des paons et des faisans, sans doute à cause de la grande élévation de plafond de la salle à laquelle il était destiné, le dessin de cette étoffe des "Perdrix 》 est cependant d'un effet de coloris plus discret et plus doux : c'était la tenture d'une chambre, et non celle d'une galerie de fêtes.

Sur un fond blanc, de larges guirlandes de feuillages vert d'eau s'entrecroisent en forme de losanges pour encadrer des attributs de musique, une cage et des chardonnerets aux riants plumages, une perdrix couvant ses petits, enfin trois fûts de colonnes corinthiennes supportant un reste de corniche, ruines de temple directement inspirées des fouilles du Forum ou d'Herculanum, alors si en honneur parmi les artistes. Des touffes de fleurs des champs égaient de leurs couleurs variées tous ces motifs. Tout ce qui caractérise le style Louis XVI est réuni dans cette splendide étoffe. L'ordonnance un peu raide, adoptée par Marie-Antoinette et inspirée par les styles antiques et la simplicité des goûts champêtres, a succédé ici à la fantaisie onduleuse des lignes de la tenture faite pour l'Impératrice de Russie. Mais Lasalle, dans les deux, fut égal à lui-même et marqua ces deux chefs-d'œuvre de l'empreinte de son génie. De son côté, Pernon n'épargna rien pour produire une cuvre d'art dont la qualité des matières précieuses fût digne de l'inspiration de l'artiste. Dans la tenture des Perdrix plus encore que dans celle des Faisans, la chenille de soie est employée à profusion et contribue à donner cet aspect velouté et chaud qu'on a recherché dans cette étoffe plutôt que l'éclat pompeux.

La maison Pernon avait fait, quelques années auparavant, pour le père de la reine Marie Leczinska, Stanislas, roi de Pologne, alors en résidence à Nancy, un tissu de même composition que 
Pl. XIV.

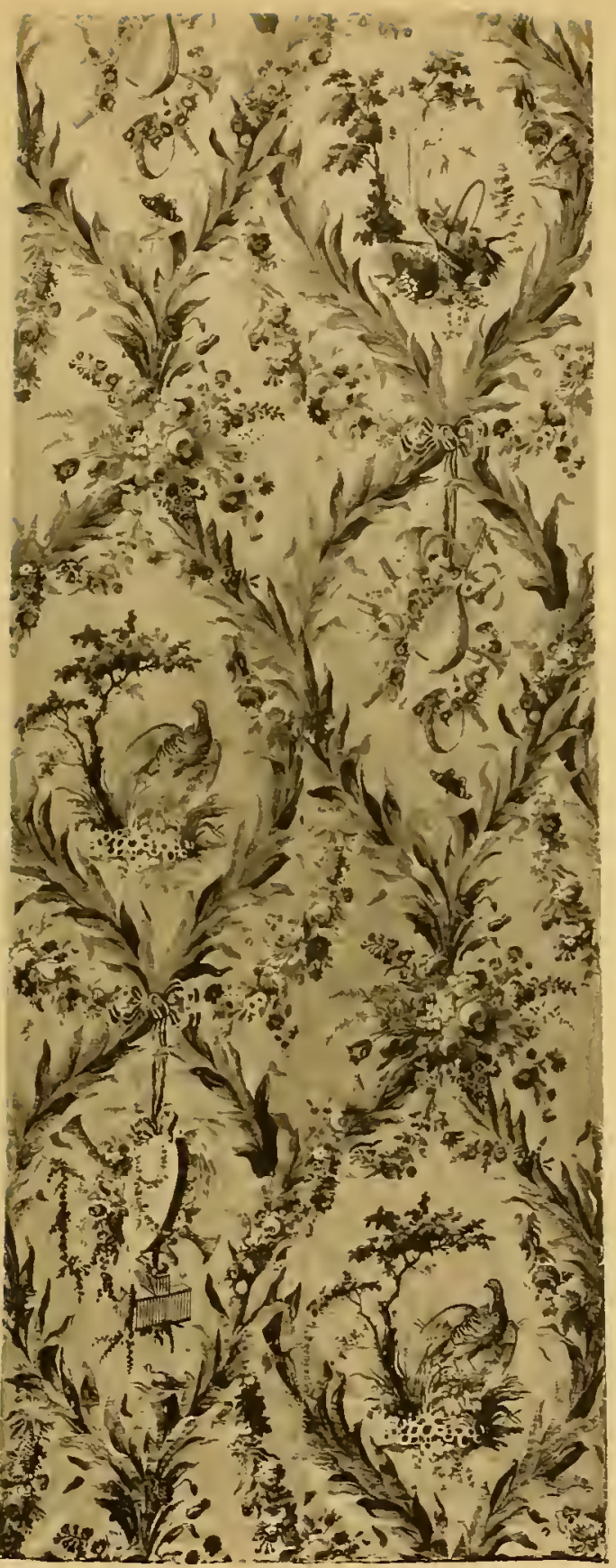

TENTURE DE LA “ PERDRIX "

Commandée à Pernon pour la Reine Marie-Antoinette.

(Carlan dc Philippe dc Lasalle.) 



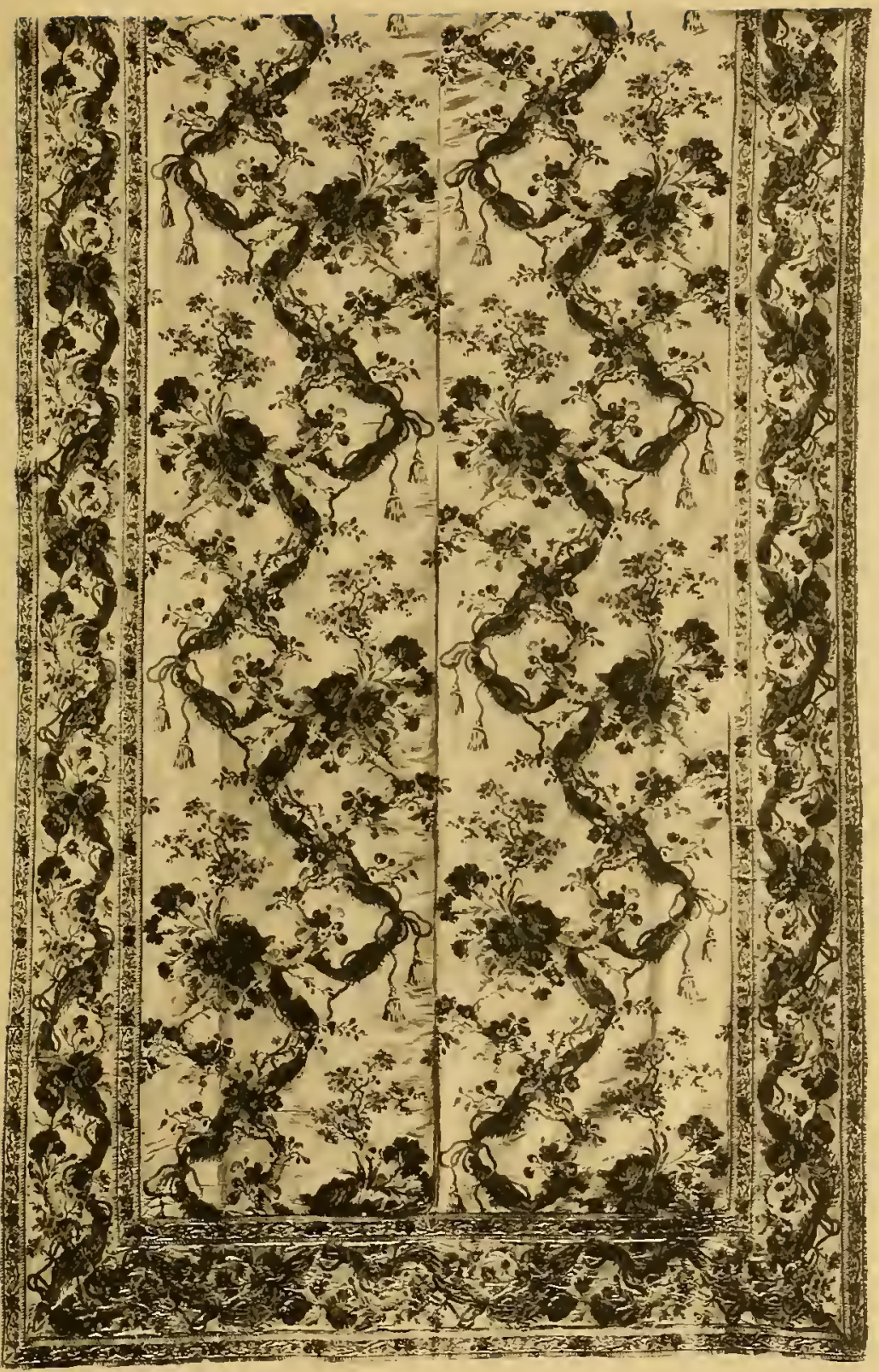

TENTURE BROCHEE CHENILLE ET SOIE

Commandée à Pernon pour le palais du Roi Stanislas Leckzinski, à Nancy. (Carlon de Philippe de Lasalle.) 

les deux précédents. Le dessin représentait une draperie bleue, aux plis savants, jetée autour de gerbes d'œillets et de roses rouges sur un fond clair ( $\mathrm{pl} .15)$.

Deux autres étoffes à motifs plus petits, destinées à couvrir des sièges, rappellent les victoires remportées sur les Turcs par l'Impératrice de Russie. Dans l'une, des trophées de drapeaux gisent sous les serres victorieuses de l'Aigle Impériale Russe dressée sur un char guerrier et dont les ailes déployées sont auréolées d'un soleil de gloire. Dans l'autre, l'Aigle lance ses foudres, sous forme d'éclairs en zigzags, sur un vaisseau turc battu par les flots d'une mer houleuse. L'écusson, sur lequel l'oiseau emblématique est représenté sous sa forme héraldique à deux têtes, est suspendu aux branches d'un immense laurier derrière lequel s'abrite le monde chrétien représenté par un globe surmonté d'une croix.

Outre ces chefs-d'œuvre, dont nous ne citons que les principaux, une foule de dessins de moindre importance, destinés à des damas ton sur ton, à des lampas à deux et à trois couleurs, tissés dans les ateliers de Pernon, peuvent être sans hésitation attribués à la main de Philippe de Lasalle. Plusieurs cartes, sur lesquelles l'illustre dessinateur jetait directement d'un premier jet, sans esquisse préalable, son dessin détaillé ensuite au pinceau par le travail de mise en carte ${ }^{1}$, servent encore aux ouvriers de la maison Tassinari et Chatel et portent au dos la signature de Pernon ou la marque de sa fabrique ${ }^{2}$ (pl. 17).

1 On appelle carte, en termes de fabrique, la peinture du dessin sur un papier quadrillé dont chaque petit carreau représente le croisement des fils de chaine et de trame. Cette carte servait directement à la traduction du dessin par le vieux métier à semples ou à la tire. Elle sert aujourd'hui à lire ou percer de trous dans un certain ordre, les cartons qui dirigent l'action de la mécanique Jacquarả.

$2 \mathrm{Ph}$, de Lasalle faisait tisser lui-même sur ses métiers, munis de perfectionnements de son invention, les dessins qu'il composait pour Pernon. Dans une lettre du 22 ventôse an XII, il se plaint qu'on veut dèménager en vingt jours, des deux chambres du Pensionnat du Grand Collège où $M$. Verninac l'avait provisoirement installé, ses métiers couverts d'étoffes pour M. Pernon (Arch. mun.). 
D'une façon générale, jusqu'au temps d'arrêt marqué dans l'industrie lyonnaise par les années désastreuses de la Terreur, les dessins sortis à cette époque de la maison Pernon sont de l'école de Philippe de Lasalle, empreints de la manière large et si décorative dont il fut le novateur.

Cette influence se fait encore sentir dans un très beau dessin fait pour le Palais Royal, à Madrid, et qui, attribué jusqu'à ce jour à Bony, de Givors, présente cependant la plupart des caractères de l'art et du talent de Dugourc. Ce dessin, composé sans doute sur les indications de Grognard, fut créé vers 1790 et porte sur les livres de Pernon la dénomination de Verdures du Vatican. ll est, en effet, directement inspiré des fameuses fresques de Raphaël, et, quoique franchement Louis XVl encore par une certaine souplesse de lignes, il annonce déjà, par la recherche minutieuse des détails, la mesquinerie dont le style Empire cherchera à atténuer sa lourdeur (pl. 18).

Lorsque, quelques années plus tard, sous le Consulat, Bony reprendra le même thème, toujours sur ordre de la maison Pernon, et pour le projet de décoration d'un salon du château de SaintCloud, l'influence du xv111 ${ }^{\circ}$ siècle aura disparu; et, malgré la similitude d'inspiration, le dessin de ces panneaux très curieux de détails n'aura plus rien de commun avec la manière de Philippe de Lasalle (pl. 19).

La maison Tassinari et Chatel possède des maquettes de ces dessins et quelques-uns des petits médaillons ronds, d'un si curieux travail, encastrés dans ces panneaux et rappelant les principales gloires de l'Empire. Sur un fond de satin et de velours ils sont brodés de points lancés et de chenille, et rehaussés de peinture, alliant tous ces procédés de profondeur de coloris, de brillant et de fondu, pour rendre les effets de la nature: miniatures excessivement curieuses, mais, à vrai dire, bien compliquées pour un simple morceau de décoration. Ces médaillons représentent les pays éloignés où l'Empire français étendait sa puissance : Anvers et son port; 


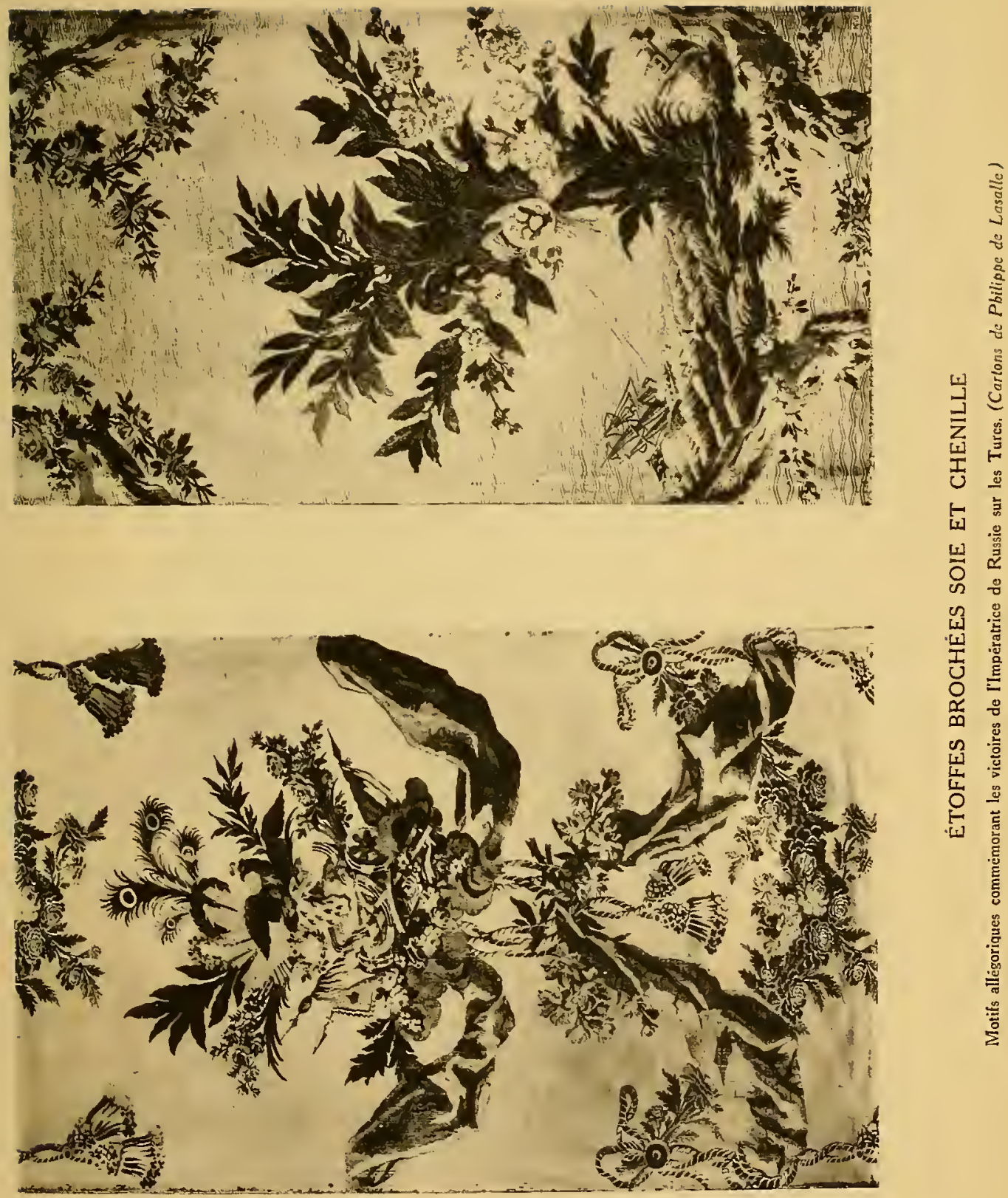




$$
-
$$


Pl. XVII.

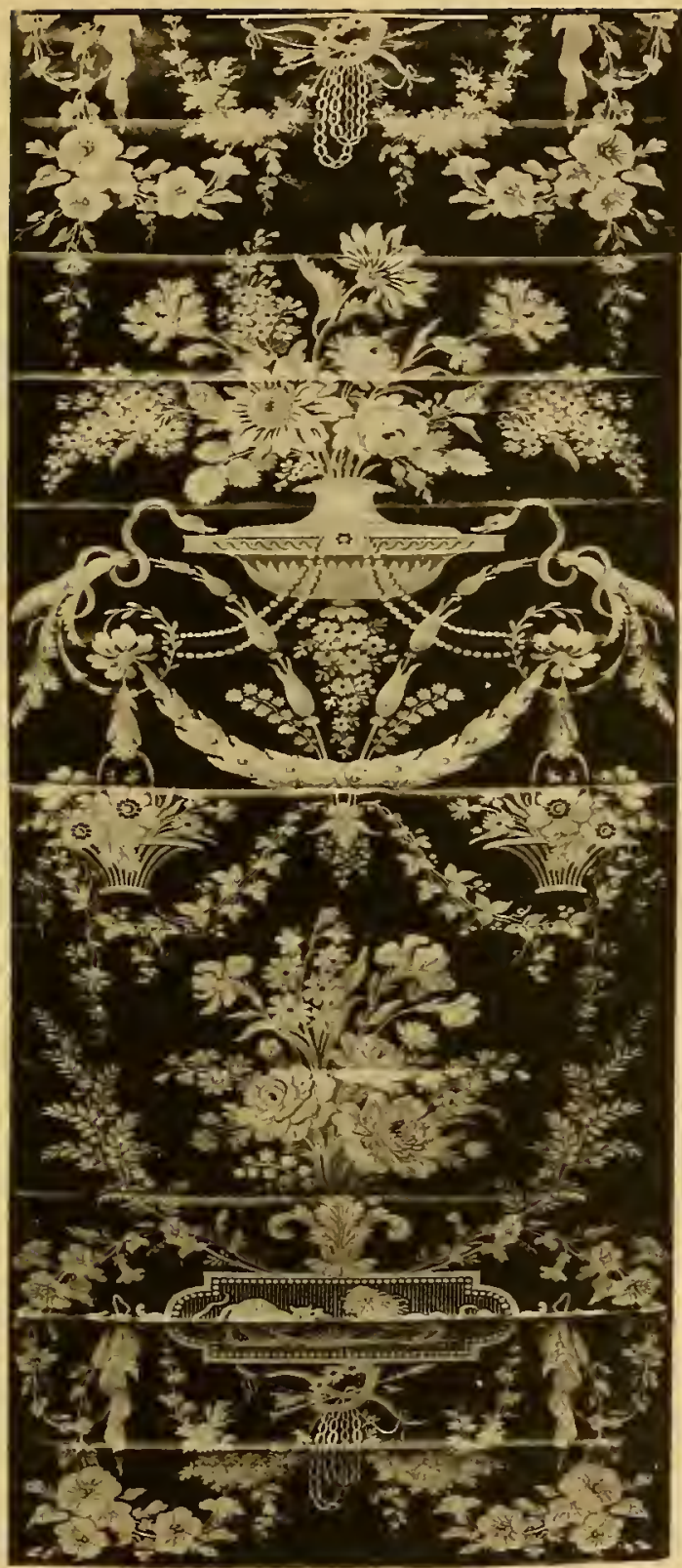

LAMPAS TROIS COULEURS

Dont la carte, dessinèe et peinte par Philjppe de Lasalle, porte au dos la signature de Pernon. 


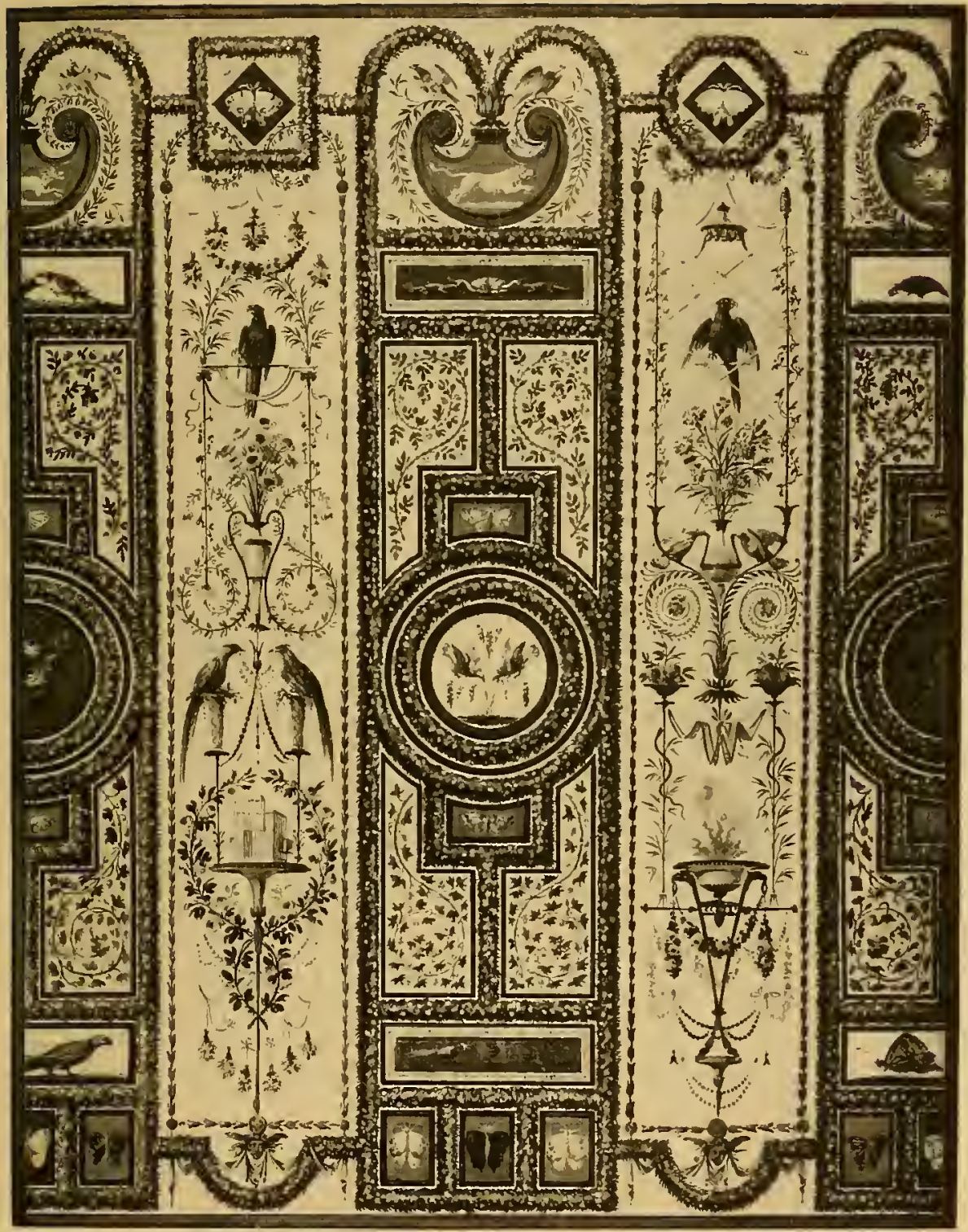

DESSIN DE J.-D. DUGOURC

Maquette d'un projet de tenture brochée pour le Palais Royal a Madrid. 


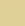


Pl. XIX.

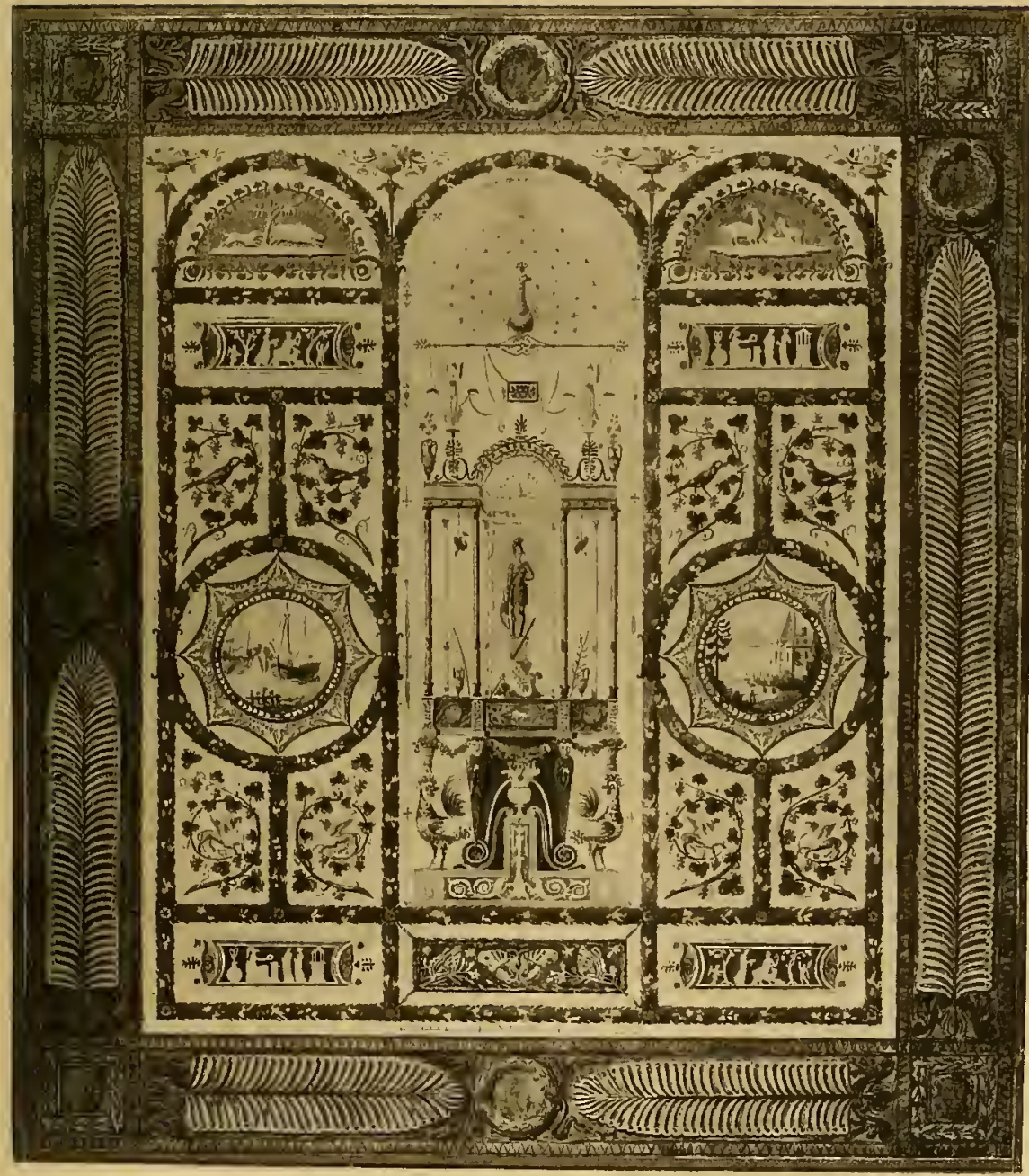

DESSIN ATTRIBUÉ A BONY

Maquette d'un projet de Tenture brochẻe et brodée pour le palais de Saint-Cloud. 

Naples et son volcan; et la Malmaison qui en était le cœur. Ces trois médaillons et un fragment de panneau sont tout ce qui nous reste, inestimables reliques, de cette série de tentures décoratives, irrémédiablement détruites par l'incendie, en 1871 , avec tous les trésors dont le château de Saint-Cloud était rempli.

Nous notons, entre autres, deux étoffes dont il est question dans deux lettres adressées le 12 septembre 1787 et le 9 juin de la même année, par $M$. Thierry de Villedavray (sic), directeur du Garde-Meuble de la Couronne, à M. Pernon, négociant à Lyon. L'une, destinée aux meubles du salon du Jeu de la Reine, à SiintCloud, est désignée sous le nom de «Roses blanches». L'autre, appelée «Bosquet de Roses », devait orner le lit et les meubles de la chambre à coucher de la Reine. Malgré de minutieuses recherches, nous n'avons pas encore pu identifier ces deux étoffes faites spécialement par Pernon pour la reine Marie-Antoinette, et dont la dénomination suggestive marque la prédilection de la souveraine pour la Reine des Fleurs.

Une belle esquisse gouachée en blanc sur fond bleu (pl. 20), et qui ne fut probablement jamais reproduite en étoffe, porte une note intéressante écrite au verso ainsi libellée : $n^{\circ} 27, M$. C. Pernon, Palais de Versailles. Dessin des quatre éléments en damas trois couleurs fond bleu pour tenture. Ce numéro 27 laisserait supposer qu'il y en eut toute une série aujourd'hui disparue.

A côté de Philippe de Lasalle et des autres artistes plus ou moins connus dont les noms sont parvenus jusqu'à nous et qui purent occasionnellement travailler pour la maison Pernon, tels que Bony, Pillement, Bourne, Dechazelle, etc., nous ne pouvons oublier celui d'un homme qui fut certainement en rapports suivis avec Pernon et dont l'œuvre créatrice, pour être restée au second plan, n'en fut pas moins considérable et d'une influence prépondérante sur le style de son époque. C'était le dessinateur Jean-Démosthène Dugourc. Fils de François Dugourc, contrôleur 
de bouche du duc d'Orléans, il naquit à Versailles le 24 septembre 1749. Emmené tout jeune à Rome par le comte Cani, il rapporta de la vue des monuments gréco-romains une impression qui eut sur toute son œuvre une influence capitale. Par nécessité ingénieur militaire, en 1777, à Valenciennes, avec Vaquette de Gribauval, il obtint, en 1780 , la fonction, plus conforme à ses goûts, de Dessinateur du Cabinet de Monsieur. Comme tel, il collabore aux fêtes de Brunoy, à la restauration de Maisons et de Bagatelle. réforme les costumes et décors de théâtre, dessine des maquettes pour les opéras de Stockholm et de Pétersbourg. En 1783 , Dugourc est nommé Directeur des Décorations de l'Opéra de Paris. Il fournit des dessins à Gouthière, à Godon, à Thomire, à Camille Pernon, crée les modèles d'ameublements du duc d'Aumont, de la duchesse de Mazarin, du banquier Laborde, etc. Après des essais industriels malheureux, il est obligé, en 1799, de s'expatrier à Madrid, d'où il ne revient qu'à la Restauration pour obtenir de ses anciens protecteurs l'emploi de Dessinateur du Mobilier de la Couronne, ou Dessinateur des Menns Plaisirs du Roi, qu'il occupe de 1817 à 1823 . 11 meurt en 1825 , à soixante-quinze ans ${ }^{1}$.

Artiste consommé, peintre et graveur à ses heures, organisateur de fêtes, comme l'exigèrent ses fonctions, il excellait à crayonner, d'une main experte et toujours originale, un projet de décor, une perspective de jardin, et surtout l'ensemble et les détails de tout ce qui composait la décoration des palais : boiseries, meubles, bronzes et même le dessin des étoffes qui devaient accompagner cette décoration d'un style nouveau pour l'époque.

La maison Tassinari et Chatel a hérité de Pernon une merveilleuse collection de ses dessins dont nous nous proposions de parler un jour plus en détail. On assiste en les parcourant à la naissance et à

1 Dumonthier, Recueil de dessins de Tapis et Tabisseries du Mobilier de la Couronne, Ch. Massin, édit., Paris, lolı. 
PI. XX.
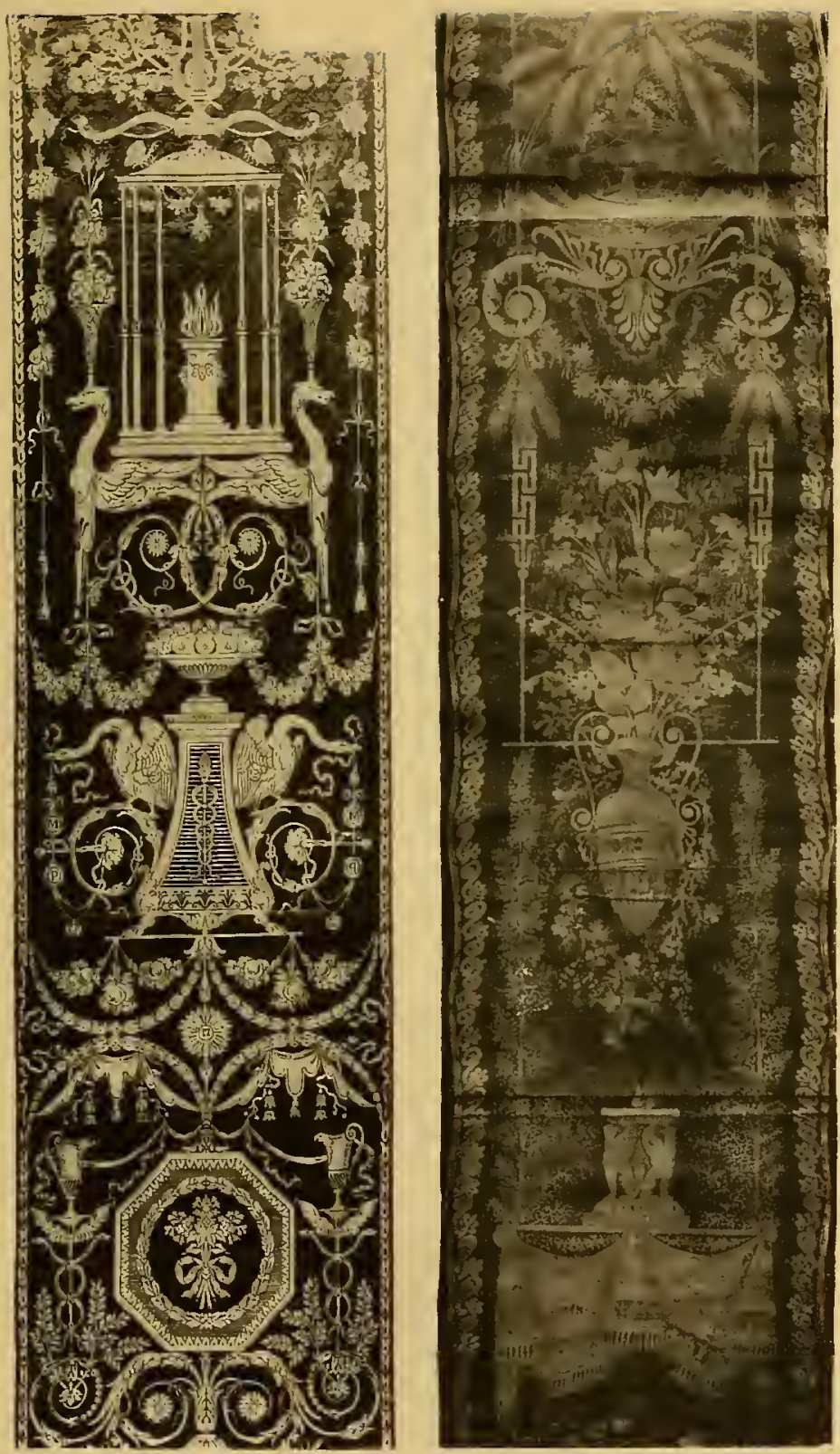

1. DAMAS BLANC SUR FOND JAUNE

Oú se lisent sur de petits médaillons les lettres M. P. C. (Manufacture Pernon et $C^{\prime}$ ). (Certon de Dugourc.)

2. DESSIN BLANC SUR FOND BLEU

Maquette proposée par Pernon pour le palais de Versailles. 

Pl. XXI.

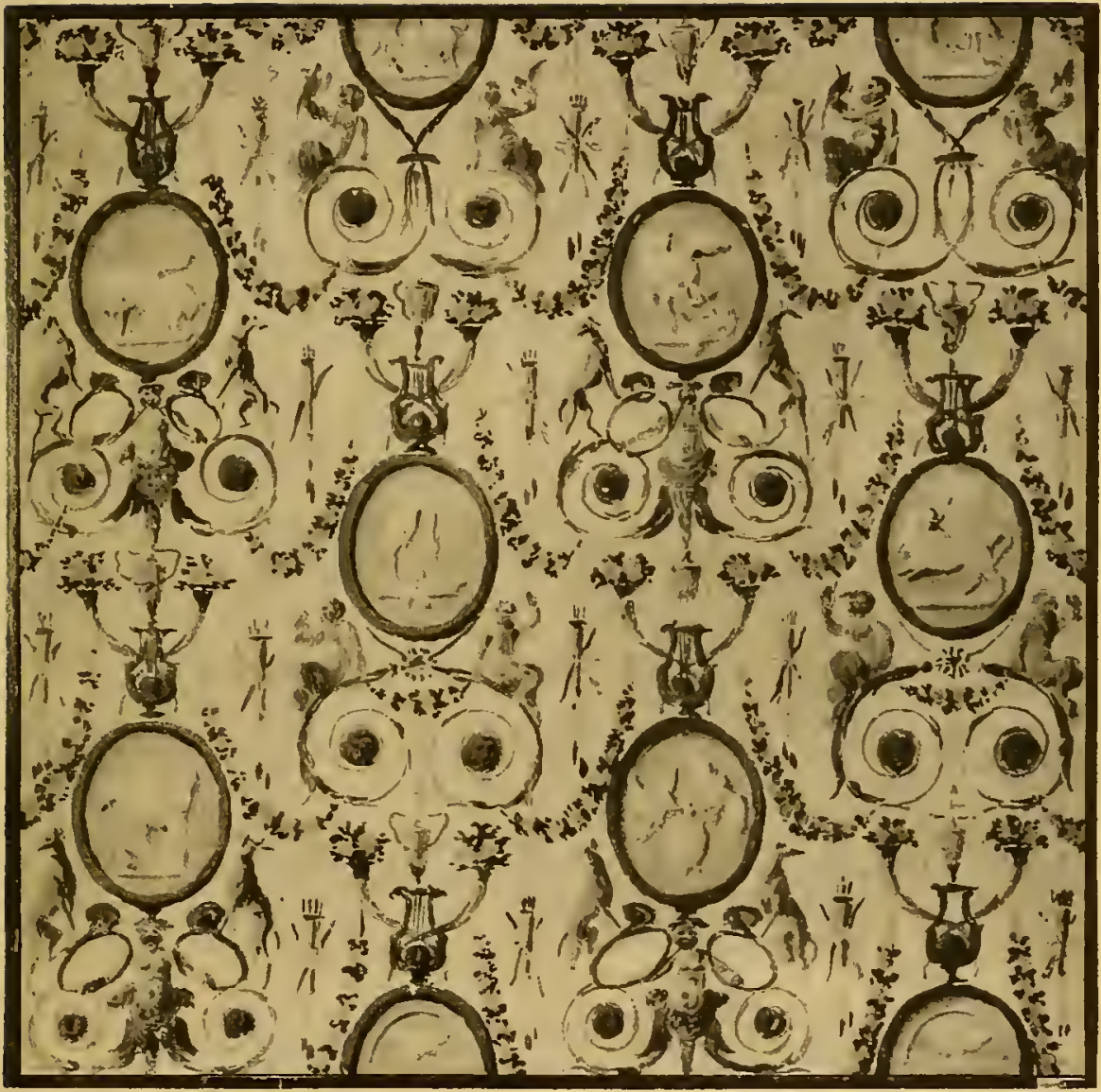

IDEEE DE TENTURE

Esquisse à laquarelle camposée par J.-D. Dugaure pour C. Pernon. Motifs inspirés des Fables de La Fanlaine. 



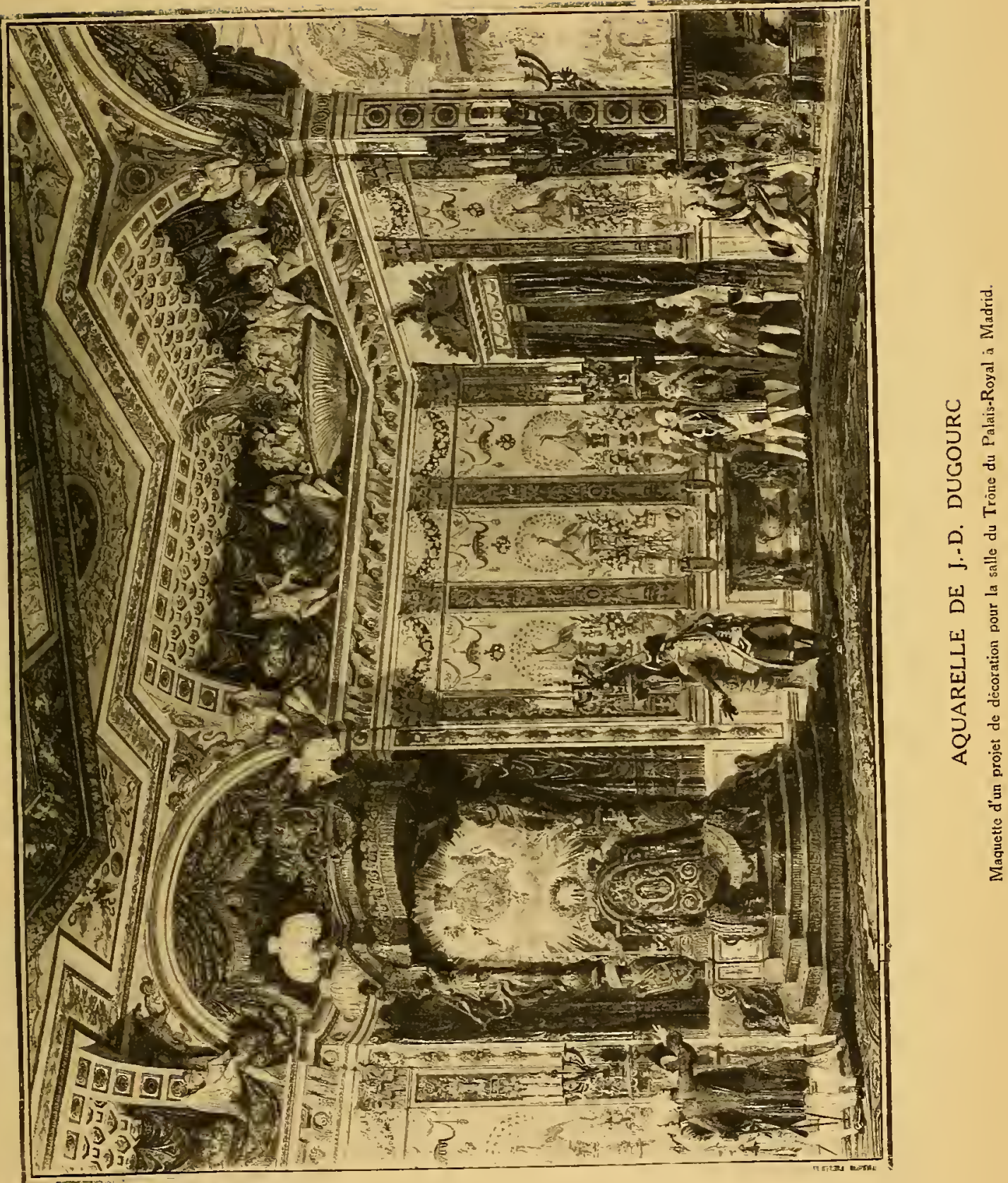



Pl. XXIII,

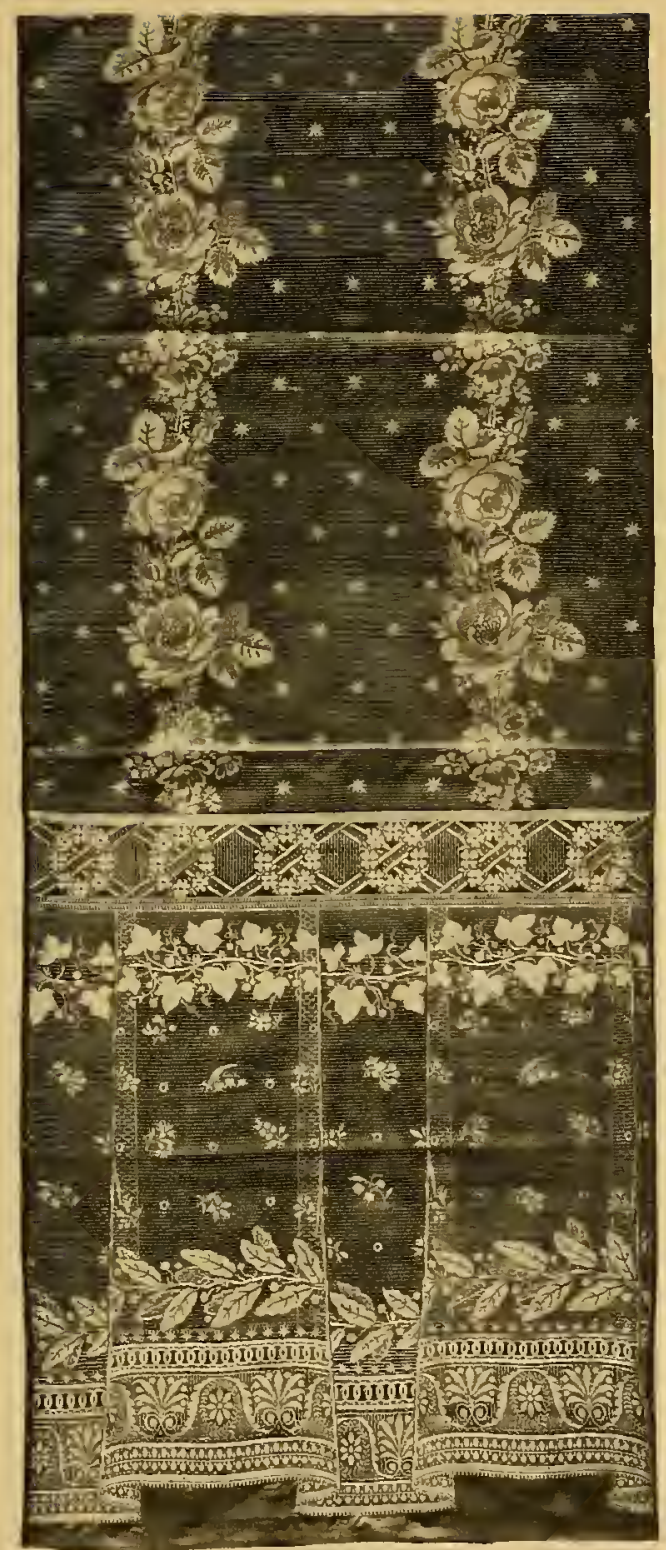

TENTURE ROSE ET CREME

Cabinet de toilette de la Reine d'Espagne. 

$N$
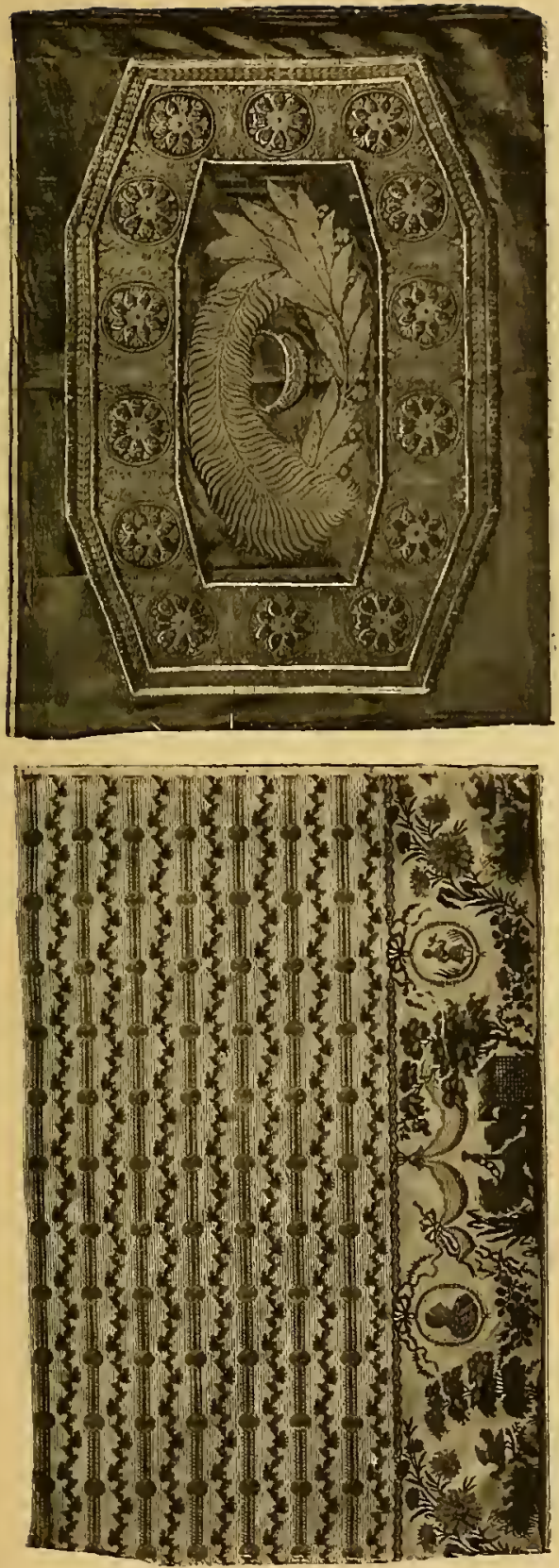
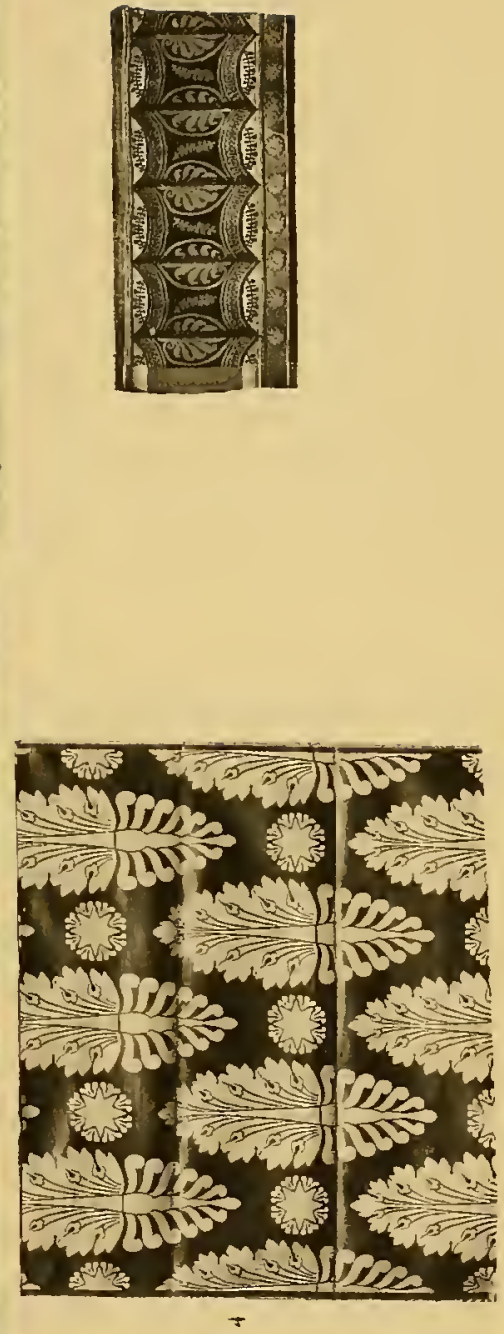

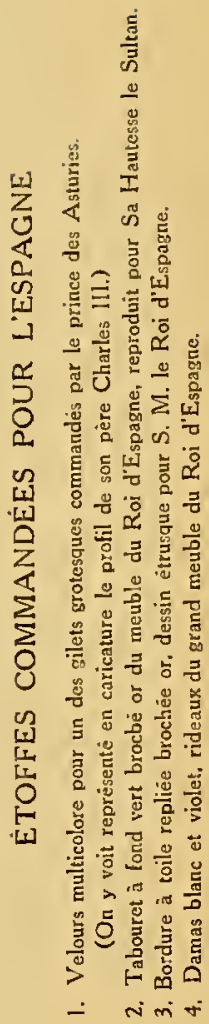





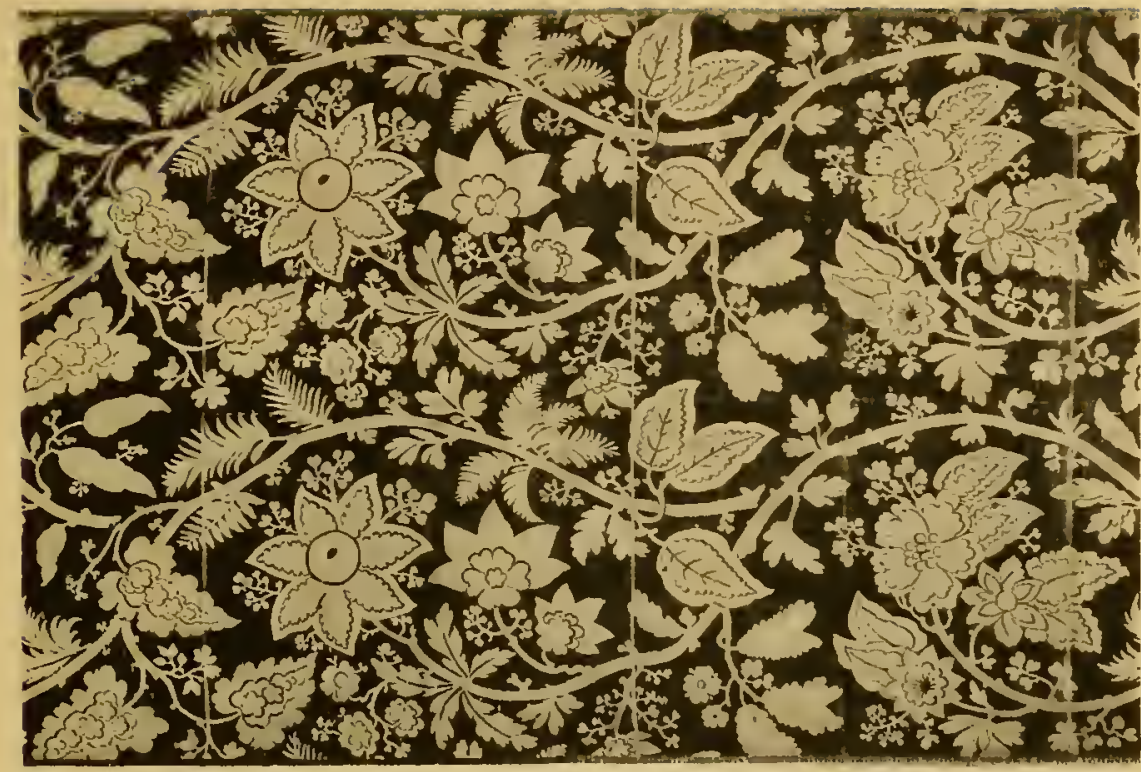

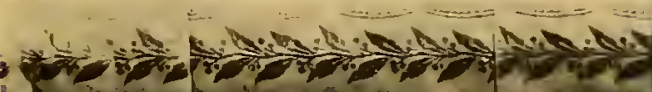
1)

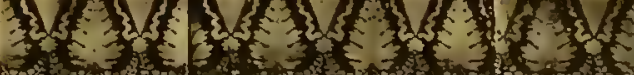

\section{$\overrightarrow{\mathrm{DI}^{2}}$}

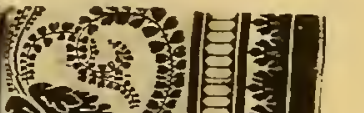

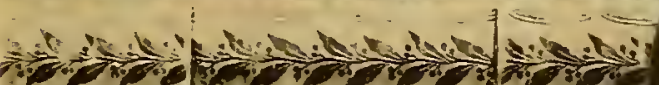
-

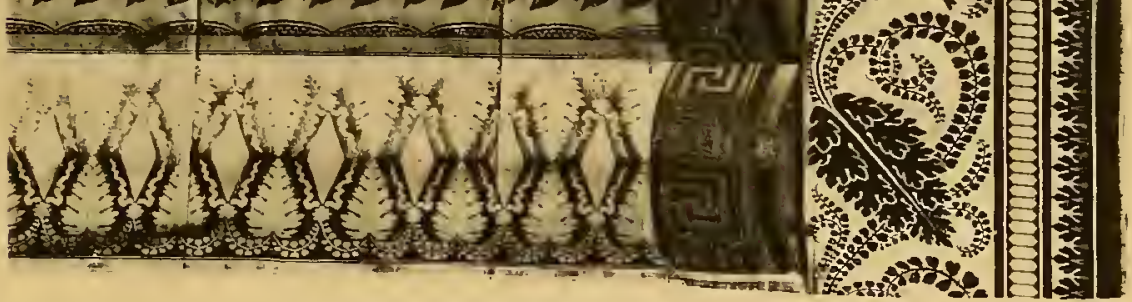


PI. XXVI.

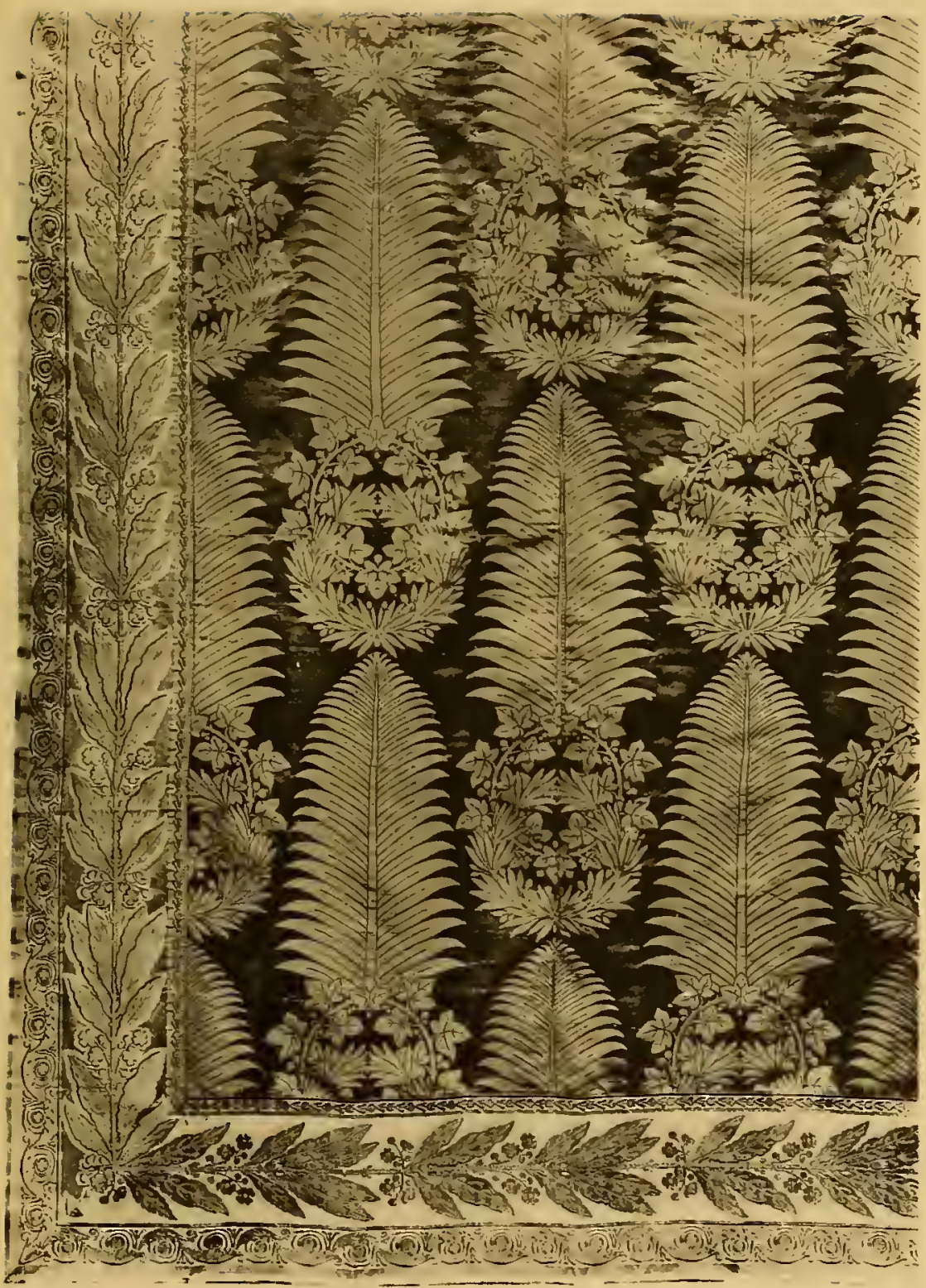

TENTURE POUR LE PALAIS DE SAINT-CLOUD

Cabinet du Premier Consul.

Damas vert bordé de brocart or sur fond ponceau. 

l'éclosion du style de la fin du règne de Louis XVI, inspiré des études gréco-romaines que les artistes d'alors rapportaient d'ltalie, et que nous sommes convenus aujourd'hui d'appeler style Directoire ou Consulat.

On ne saurait donner un meilleur échantillon du talent complet de Dugourc que la remarquable aquarelle reproduite dans ces pages et représentant la salle du Trône du Palais Royal, à Madrid. Ce dessin, si parfaitement fini et si minutieusement détaillé, fut sans doute remis à Pernon pour lui indiquer le rôle que devaient jouer les étoffes dans cet ensemble. L'œuvre commerciale de Grognard eût trouvé là son apogée si la Révolution n'était pas venue arrêter l'exécution de ces beaux projets, car rien n'existe aujourd'hui de ce que nous voyons si admirablement détaillé dans cet intéressant dessin où tout est créé par le cerveau de Dugourc. Remarquons avec quel souci de vérité et quelle justesse de proportion il anime son tableau, pour en indiquer la véritable échelle, par quelques groupes de courtisans et de visiteurs dont les élégants costumes de soie multicolore complètent la décoration d'ensemble. Mais ces riches panneaux brochés de fleurs encadrant un paon majestueux et ces chaudes portières de velours bleu bordées de bandes rouge et or ne furent jamais exécutés. Nous n'en trouvons pas trace aujourd'hui (pl. 22).

Les relations entre Pernon et l'Espagne ne furent cependant que momentanément interrompues, car nous retrouvons, sur les livres de patrons, le dessin d'une étoffe, fabriquée après 1793 , pour le cabinet de toilette de la Reine d'Espagne. Elle nous rappelle une lettre où Grognard insistait sur le goût de cette princesse, alors encore Infante, pour les dentelles. C'est l'imitation d'un rideau de dentelles à guirlande de roses avec frises de lauriers formant volant, et légèrement drapé sur un dessous de satin rose. Cette idée sera reprise, plus tard, avec plus de richesse mais avec moins de sobriété et de goût, dans le somptueux rideau fait, dit-on, pour l'Impéra- 
trice, et dont on peut voir un spécimen au Musée historique des Tissus.

Notons, en passant, un de ces curieux gilets de velours dont le goût offusqué de Pernon se refusait à accepter la commande, mais que Grognard, surtout désireux de satisfaire la fantaisie de son royal client, réclamait avec insistance. Le portrait du Roi lui-même, avec son profil caractéristique, est semé en petits médaillons sur l'étoffe, ainsi que l'image d'une petite paysanne tenant un oiseau. On peut lire leurs noms sur les médaillons de la bordure : Liména Hermosa et Carlos Tercero. Que signifient ces deux lions enchaînés se montrant les dents devant une cage exiguë? L'allusion nous échappe, mais le dessin est en effet d'une recherche bizarre (pl. 24,1).

Pernon fit encore quelques étoffes pour le roi d'Espagne Charles IV, avant sa chute et l'occupation de son trône par Joseph Bonaparte. Nous notons, entre autres, une bordure de style dit Etrusque (pl. 24,3) qui marque bien la transition entre ce qu'était l'influence antique dans le style du xvi11 e siècle et l'importance exclusive qu'elle va prendre dans le style Empire.

Un joli damas ( $\mathrm{pl} .25, \mathrm{r}$ ) or et bleu, pour tenture murale, avec ses bordures, fait pour la Préfecture de Lyon, nous intéresse tout particulièrement. Ce même dessin, encore empreint de la grâce de la fin du règne de Louis XVl et qui caractérise bien ce que nous appelons le style Consulat, sera utilisé dans d'autres couleurs au château de Fontainebleau et au palais des Tuileries, où il décorera le petit salon de l'Impératrice Joséphine.

Pendant le Consulat, Bonaparte, à qui notre industrie lyonnaise doit une si grande reconnaissance, commence à remplir de belles étoffes les palais où il réside entre deux campagnes, et qu'il fait réparer à son usage : la Malmaison, Saint-Cloud, les Tuileries. Déjà il se traite en Empereur, en maître incontesté de la place, comme il le fit bien sentir un jour à l'architecte Fontaine, l'associé de Percier. Celui-ci, devant un devis un peu chargé, faisait naïve- 
PI. XXV11.
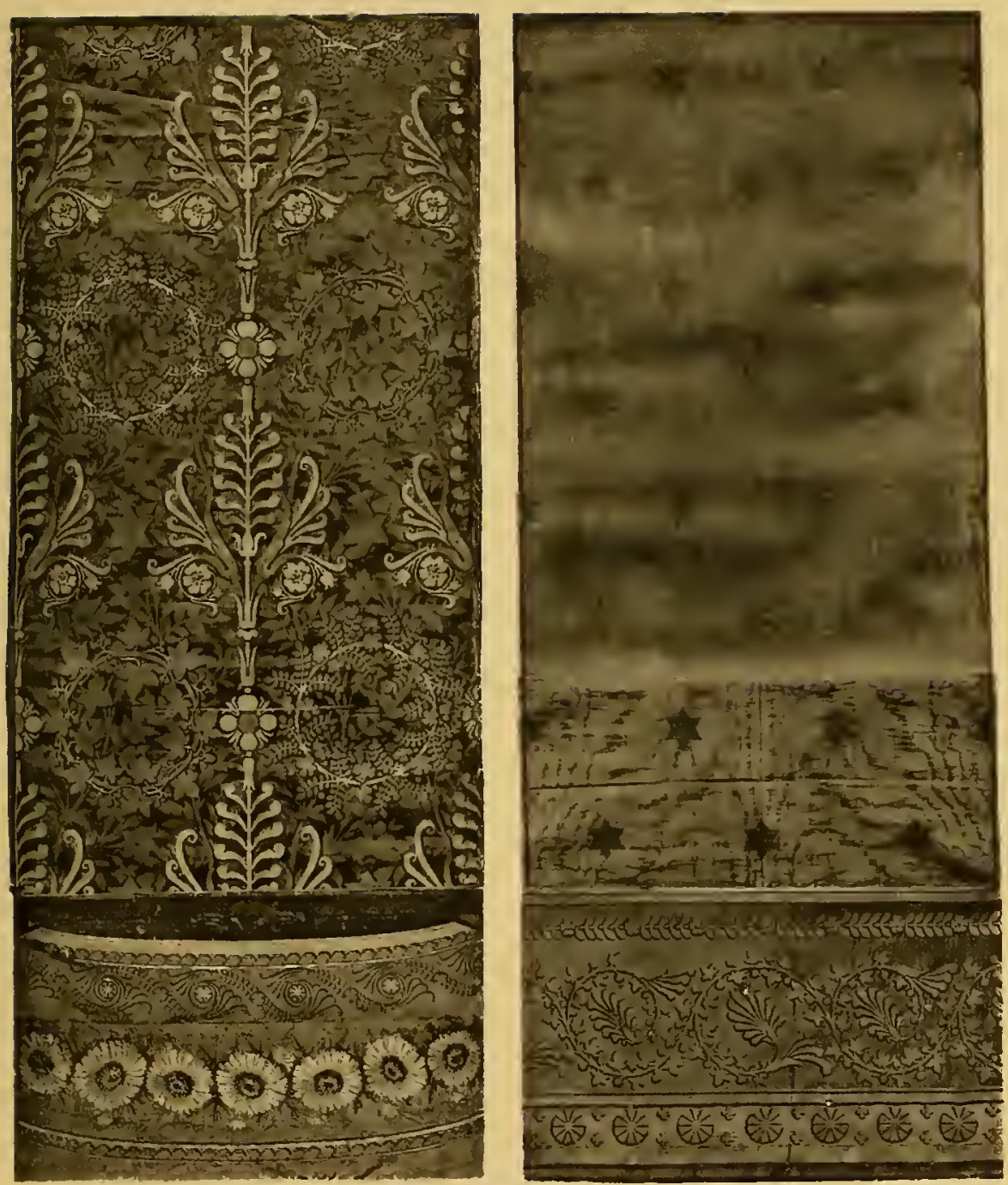

\section{TENTURES DES APPARTEMENTS DE L'IMPERATRICE}

1. Brocart argent sur fond bleu commandè par $\mathrm{M}^{\text {ute }}$ Bonaparte pour son salon des Tuileries. Cette étoffe fut employée au palais de Saint-Cloud par Josẻphine, devenue Impératrice.

2. Brocart argent sur lond citron fabriqué pour le Salon de musique de llmpératrice. 

ment observer au Premier Consul que la majeure partie des frais incombait à l'Etat dont il n'était pour ainsi dire que le « locataire »: Le locataire ! s'écria Bonaparte, en regardant fixement son interlocuteur, qui jugea au moins indiscret d'insister ${ }^{1}$.

Les dessins d'étoffes que nous retrouvons sur les livres de la maison Pernon, composés dès ce moment pour les palais de SaintCloud et des Tuileries, sont bien déjà du style que nous dénommons Empire. Les couronnes de pampres, les lauriers, les étoiles, les palmes de victoire y sont semés à profusion.

Le cabinet du Premier Consul, à Saint-Cloud, sera tapissé d'un superbe damas vert ( $\mathrm{pl}$. 26) où ces emblèmes sont réunis en un style imposant et où d'énormes palmes plantées droit rappellent au général celles qu'il vient de cueillir au pied des Pyramides. La bordure ( $\mathrm{pl}$. 26) de lauriers d'or sur fond ponceau est remarquable.

$M^{\text {me }}$ Bonaparte, dont $F$. Masson nous a décrit en détail le luxe de garde-robe, suit sans peine l'impulsion donnée par son mari pour les belles étoffes de mobilier. Elle commande à Pernon, pour son meuble particulier au palais des Tuileries, une tenture (pl. 27,1) à fond bleu de ciel, brochée de couronnes de myrtes, d'étoiles et de palmettes d'argent. La bordure (pl. 27, I), faite de guirlandes de reines-marguerites d'argent au cœur d'or, sur le même fond bleu, est une merveille qui sera bien digne de l'Impératrice. L'étoffe du salon de musique est à fond uni citron semé d'étoiles d'argent avec une bordure de même couleur (pl. 27,2).

En même temps se fabriquent, dans les ateliers Pernon, d'autres tentures et bordures d'égale richesse, pour la salle du Conseil d'Etat, à Saint-Cloud (pl. 28,5); pour le salon du Grand Trianon : gros bleu broché or ( $\mathrm{pl} .28,3)$; pour le grand cabinet du palais de Saint-Cloud : couronnes de myrtes et de pavots et palmes

1 Journal de Fontaine (Revue de Paris, mars 1911). 
de lauriers sur fond blanc (pl. 28, 2); le salon de Compiègne : gros bleu broché d'or $(\mathrm{pl} .28,4)$.

Un damas blanc pour tenture de salon et un tapis à fond vert broché d'un croissant d'or encadré de palmes et de lauriers pour tabourets, qui fut reproduit en fond gris pour Sa Hautesse le Sultan, sont les deux dernières commandes de S. M. le Roi d'Espagne avant son abdication en 1808 (pl. 24).

Nous ne saurions oublier un beau lampas à dessin blanc sur fond jaune (pl. 25, 2), fabriqué pour l'archevêque de Lyon, le fastueux oncle de l'Empereur. Mais ce dessin n'a rien du style à la mode; il faut se reporter à cinquante ans en arrière pour en trouver de semblables, lorsque les chinoiseries florissaient à la Cour de Louis XV. Le cardinal Fesch avait conservé les goûts du xvı" siècle.

Les palmes, qui, tout à l'heure, sur la tenture du cabinet du Premier Consul, à Saint-Cloud, nous rappelaient la campagne d'Egypte, reparaissent, entremêlées d'étoiles, toutes brochées d'or, sur une bordure à fond cramoisi (pl. 28, I). Ce sont les palmes du Suprême Triomphe. Elles orneront le trône où Napoléon sera coulronné Empereur à Notre-Dame.

La bordure de la salle du Trône, aux Tuileries, ne sera pas moins riche, également brochée d'or fin sur fond cramoisi. L'N, initiale du nom de l'Empereur, y figure encadrée des inévitables lauriers.

C. Pernon, malgré l'amère déception que lui causèrent les étoffes du château de Saint-Cloud, continue à tapisser les palais impériaux. Ses livres donnent de nombreux dessins que nous ne saurions tous citer, faits pour Compiègne, Trianon, Versailles, etc. Il faut cependant nous arrêter encore au velours de la chambre de l'Empereur, à Fontainebleau ( $\mathrm{pl} .29)$. C'est une œuvre d'une technique compliquée qui rappelle à première vue ces velours de Grégoire, petites miniatures si recherchées aujourd'hui des amateurs. Ce velours, dit " chiné à la corde 》 ou «à la branche ", était décoré par un principe analogue à celui du velours Grégoire, 
PI. XXVIII.
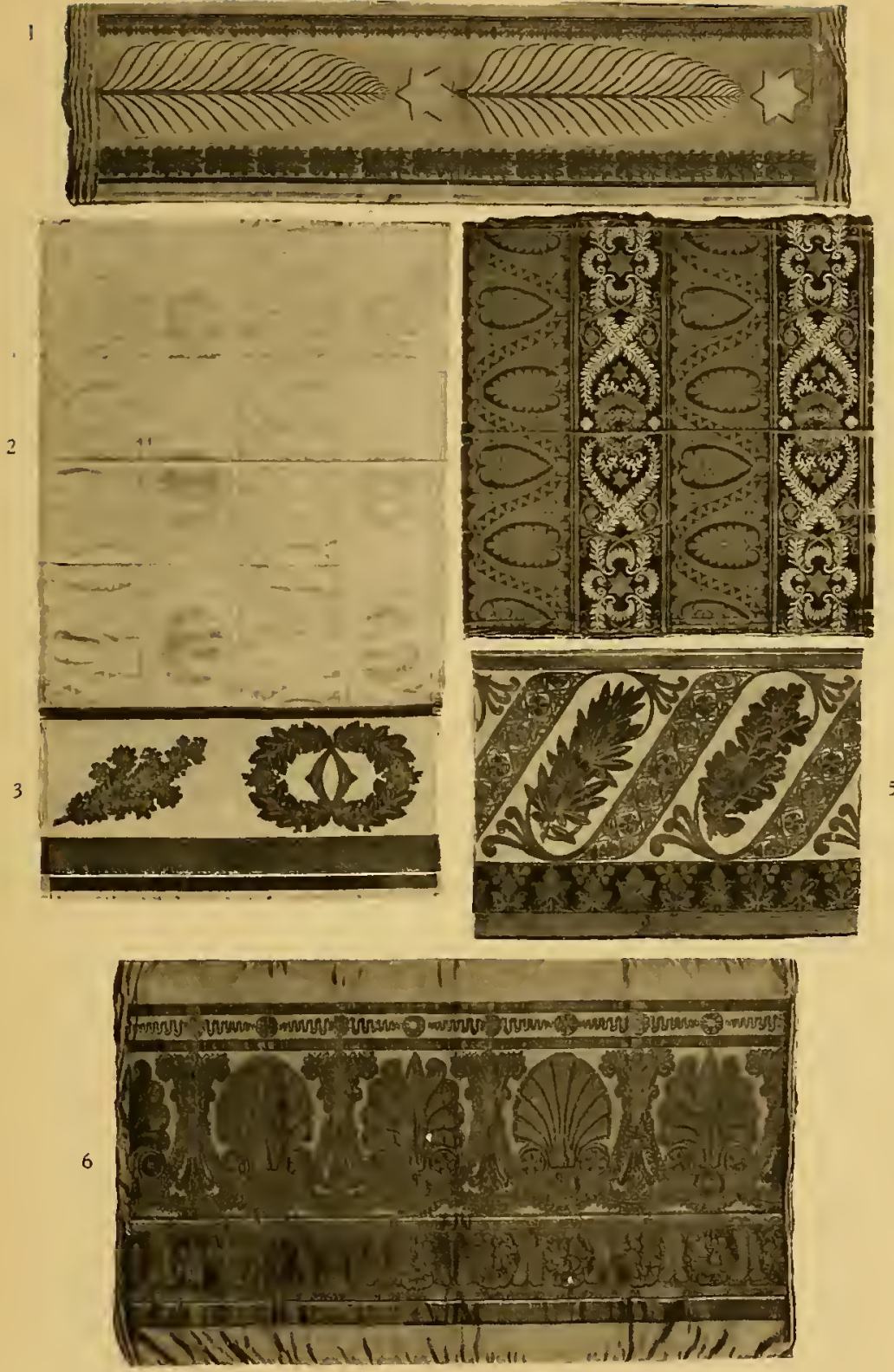

\section{COMMANDES DU MOBILIER IMPERIAL}

1. Bordure du trône de Notre-Dame, fond cramoisi brocbé or.

2 et 3. Rideau de fenètre et bordure du cabinet de travail de S. M. l'lmpératrice à Saint-Cloud.

4. Tenture rayée fond jonquille et gros bleu pour le Grand Trianon.

5. Bordure fond bleu brocbee or pour la salle des Ministres au palais de Compiègne.

6. Bordure fond cramoisi brocbee or pour la salle du Conseil d'État au palais de Saint-Cloud. 

PI. XXIX.

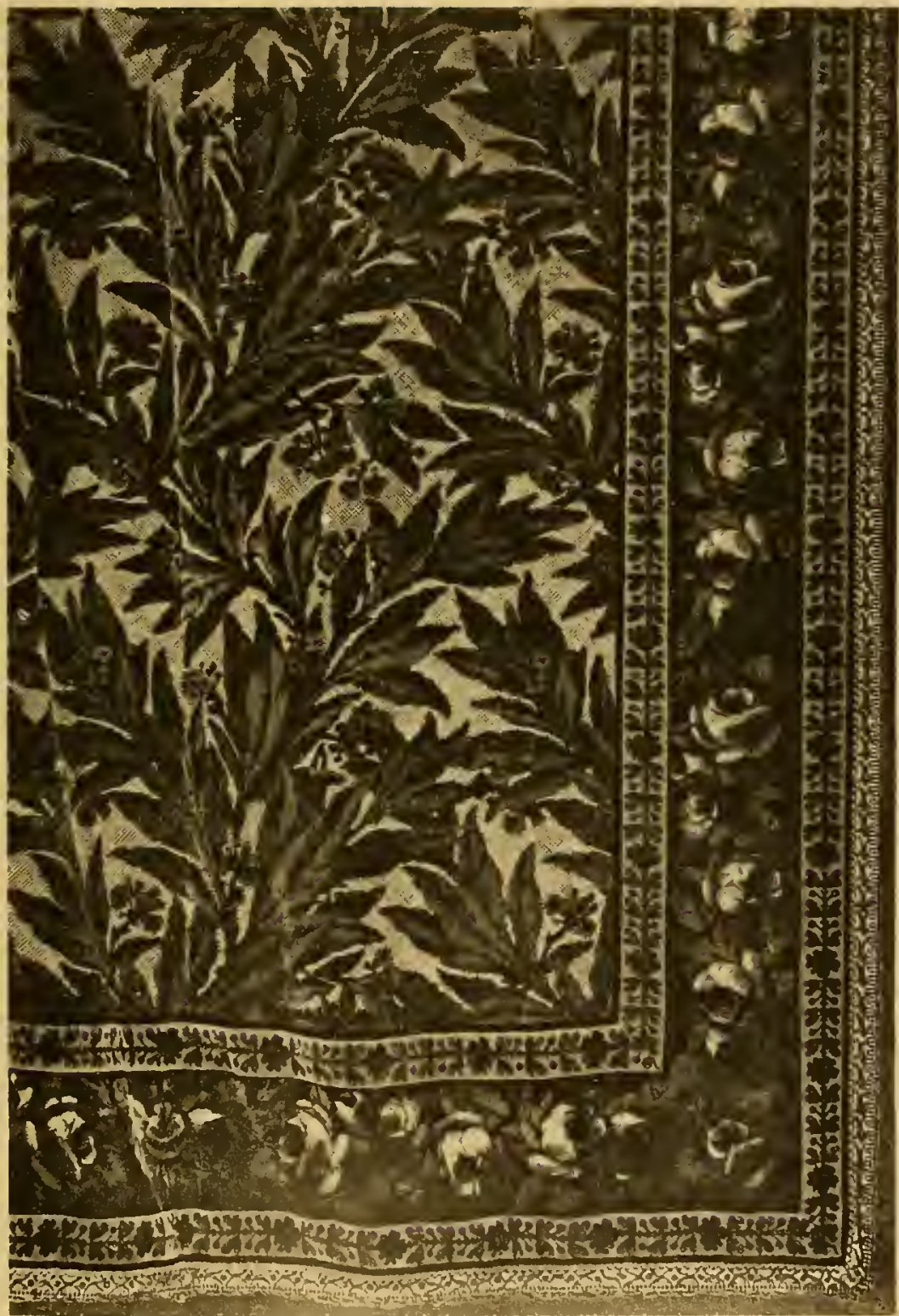

TENTURE DE VELOURS " CHINE"

Commandèe à Pernon pour la chambre de Napolèon $\mathrm{I}^{\circ \mathrm{r}}$, à Fontainebleau. 

mais, au lieu d'être peint à la main, le dessin était produit par un minutieux procédé de teinture qu'il serait trop long de décrire ici en détail. Contentons-nous de dire que les parties de soie, que ne devait pas toucher le liquide colorant étaient protégées par de petites bandes de parchemin enroulées autour d'un certain nombre de fils, et liées à chaque extrémité, de façon à former une enveloppe imperméable. Cette opération était naturellement répétée de place en place, pour chaque couleur, les unes après les autres. Nous obtenons aujourd'hui à peu près le même résultat par des procédés d'impression. Mais cela ne donne pas le même fondu, la même douceur, le même «chiné ». Nous n'aurions plus le temps d'employer l'ancien procédé.

L'étoffe était tissée comme un velours uni et le dessin se montrait automatiquement à la surface dans les proportions définitives. On peut toujours admirer le velouté et le fondu si doux à l'œil de ces lauriers, encadrés de guirlandes de roses, qui décorent encore, à Fontainebleau, la chambre de l'Empereur. Le fond du dessin était de couleur prune; sur la demande de l'Empereur qui en trouvait l'aspect trop triste, il fut recouvert d'un réseau brodé de chenille crème qui éclaircissait sensiblement l'ensemble du dessin.

Une des dernières choses marquantes que fit encore Pernon fut un superbe brocart d'or sur fond cramoisi pour écran et paravent, destiné au palais de Versailles, et dont le dessin pompeux exalte toute la gloire de Napoléon. Un aigle impérial, au front étoilé et aux ailes déployées, supporte, dans une couronne de lauriers, une croix de la Légion d'Honneur; et deux palmes qui se croisent dans le fond dressent leur feuillage vers un $\mathrm{N}$ impérial couronnant le tout (pl. 30).

Une curieuse remarque est notée sur le livre de Patrons de Pernon (Arcb. Tassinari et Cbatel) en marge de l'article concernant un Damas trois couleurs fond lapis, liseré jaune et gros de 
Tours blanc, fait pour le palais de Trianon en 1806 , et qui est indiqué comme ayant été mis sur la première mécanique à la Jacard (sic).

Voici textuellement cette note:

An 1806 , au mois de février, ce dessin monté chez Imbert, quai de Retz, avec une mécanique à la Jacard qui ne peut marcher, on leva la piéce pour la donner à Pitiot sur un métier à semples.

La mécanique Jacquard n'avait pas encore obtenu gain de cause. En 1806 , elle n'était employée qu'à titre d'essai, et sans succès, comme l'indique cette note.

Toutes ces riches étoffes aux dessins compliqués furent donc tissées sur le vieux métier à semples ou à la tire. Cela ne peut qu'augmenter notre admiration pour l'habileté avec laquelle Pernon sut diriger l'exécution de ces belles choses.

Quel parti eut-il su tirer de la découverte de Jacquard, lui qui avait été le principal protecteur des inventions de Philippe de Lassalle? Peut-être, sous sa direction, les dessinateurs lyonnais, auraient-ils évité de donner à leurs compositions, encouragés qu'ils étaient par les admirables ressources de la nouvelle invention, cette excessive minutie qui fut tròp souvent le défaut des dessins de fabrique pendant le cours du xix siècle. Tant il est vrai que plus la main de l'homme a de moyens mécaniques à sa disposition pour réaliser son œuvre, plus l'œuvre risque de perdre en beauté décorative ce qu’elle gagne en précision scientifique.

Mais Camille Pernon n'eut pas le temps d'appliquer sa belle intelligence à l'utilisation pratique de la mécanique Jacquard. Sa santé déjà ébranlée par le profond découragement que lui causèr ent les teintures du palais de Saint-Cloud, revint définitivement ruinée d'un pénible et dernier voyage d'affaires à la Cour d'Espagne. 11 fut terrassé par la mort en plein travail, à 55 ans.

Après Terret, l'ami fidèle qui fit son éloge sur sa tombe, nous 


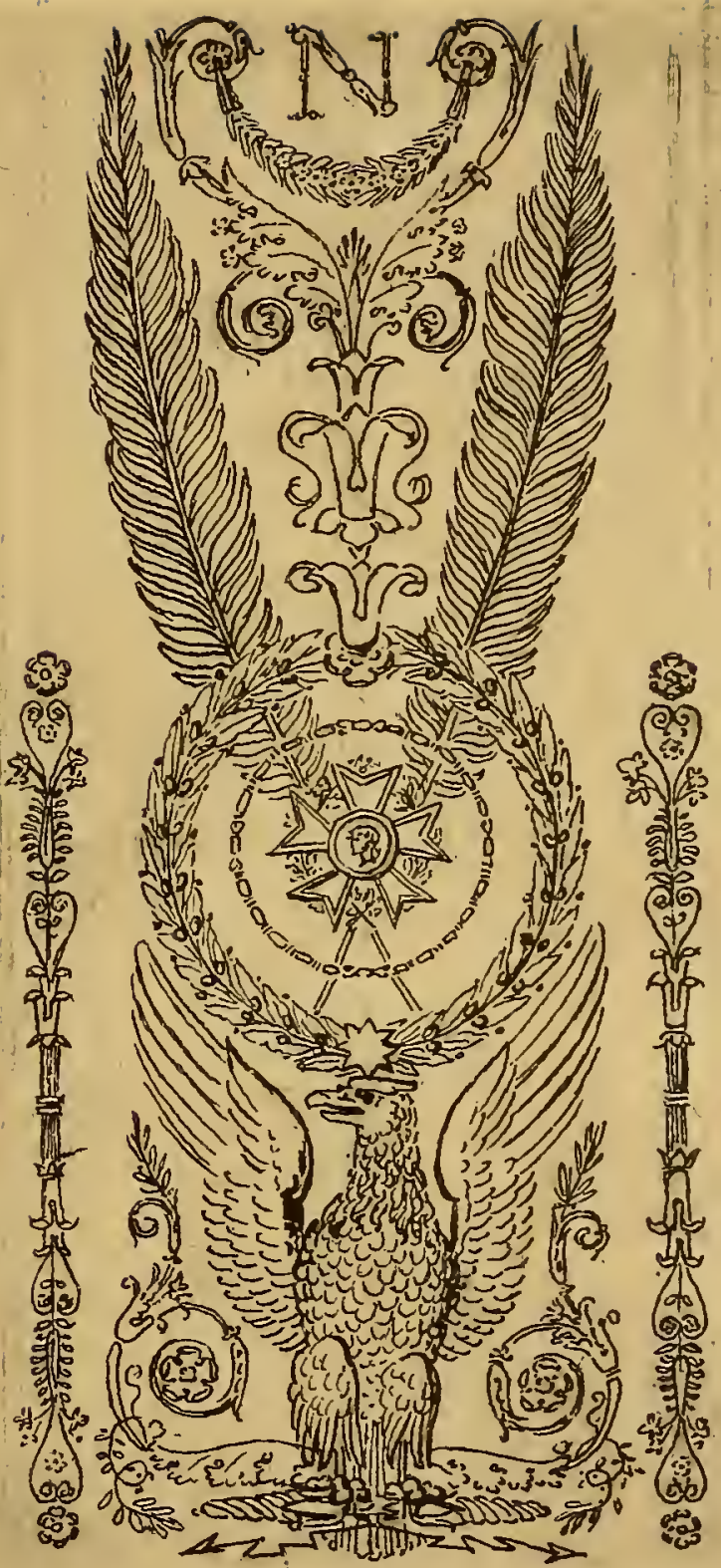

\section{DESSIN D'UN BROCART}

Croquis du dessin d'une étoffe pour paravent et écran

à fond cannetillé broché or, pour le palais de Versailles.

(Commande de 1805. Livre de Pernon.) 

avons pensé qu'il était « nécessaire d'offrir le modèle de cet homme justeet bon pour l'exemple des générations futures. "

Pendant les dernières années de sa vie, Camille Pernon avait préparé à lui succéder son employé Zacharie Grand et ses deux frères. Tous trois surent continuer avec goût et activité l'élan qui leur avait été donné par leur ancien chef, et ils l'ont transmis heureusement à leurs successeurs actuels avec toutes ses excellentes traditions.

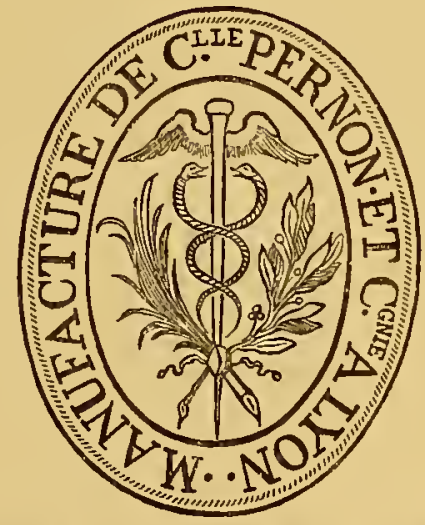

Marque de fabrique imprimée sur les échantillons de la maison Pernon. 

Lyon. - Imprimerie A. REצ, 4, rue Gentil. - 1,1518 











Bound with the
DeTullio Process 起 $\mathrm{Pal}$ App. For

1) UeKa!t Ave., Brooklyв, E. Y. 
